LA WRENCE LIVEAMOAE NATIONAL LABOAATOAY
Technical Review Report for the Model 9975-96 Package Safety Analysis Report for Packaging (S-SARP-G-00003, Revision 0, January 2008)

M. West

June 2008 
This document was prepared as an account of work sponsored by an agency of the United States government. Neither the United States government nor Lawrence Livermore National Security, LLC, nor any of their employees makes any warranty, expressed or implied, or assumes any legal liability or responsibility for the accuracy, completeness, or usefulness of any information, apparatus, product, or process disclosed, or represents that its use would not infringe privately owned rights. Reference herein to any specific commercial product, process, or service by trade name, trademark, manufacturer, or otherwise does not necessarily constitute or imply its endorsement, recommendation, or favoring by the United States government or Lawrence Livermore National Security, LLC. The views and opinions of authors expressed herein do not necessarily state or reflect those of the United States government or Lawrence Livermore National Security, LLC, and shall not be used for advertising or product endorsement purposes. 


\section{Technical Review Report for the Model 9975-96 \\ Package Safety Analysis Report for Packaging (S-SARP-G-00003, \\ Revision 0, January 2008)}

June 2008

LLNL-TR-415462

Prepared by

Packaging and Transportation Group

Lawrence Livermore National Laboratory

7000 East Avenue

Livermore, CA 94550

Prepared for

U.S. Department of Energy 
This Page Intentionally Blank. 


\section{CONTENTS}

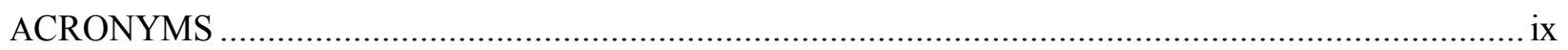

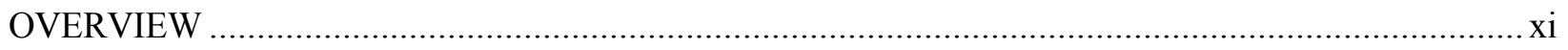

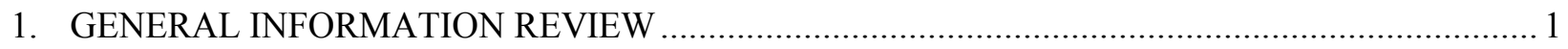

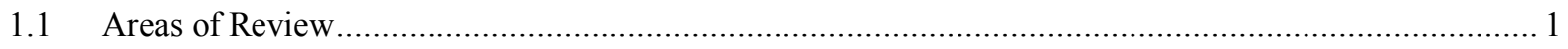

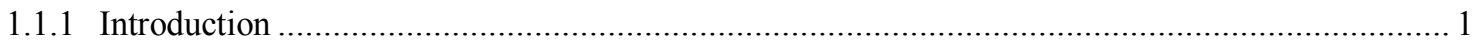

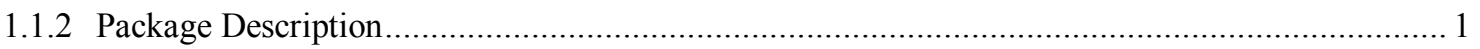

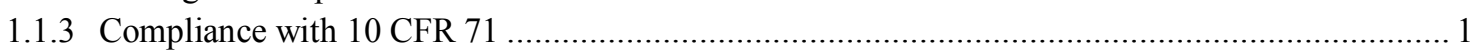

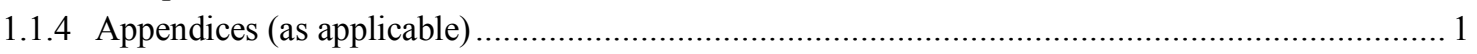

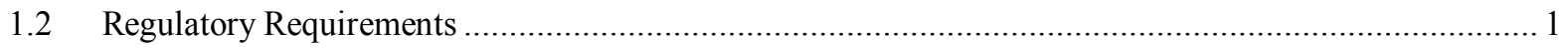

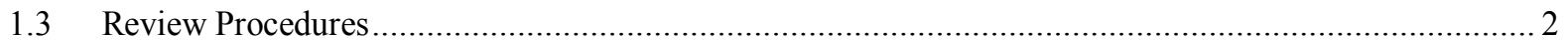

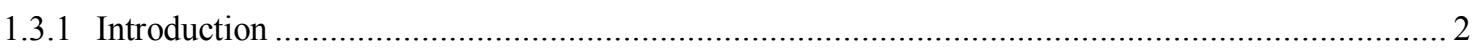

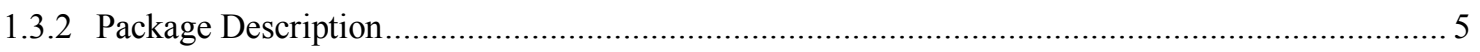

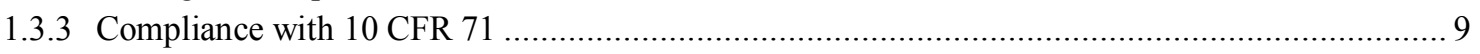

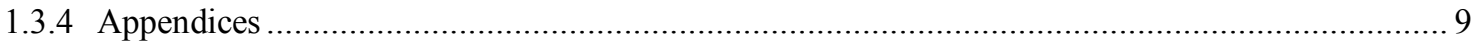

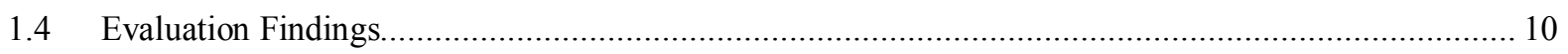

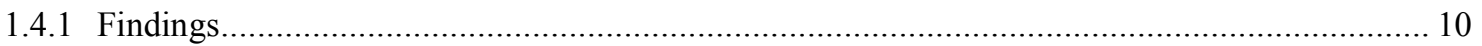

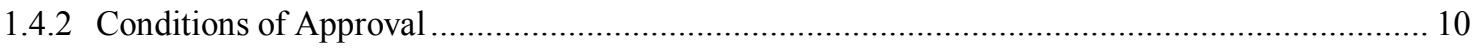

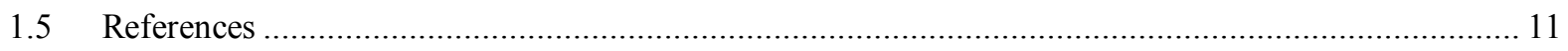

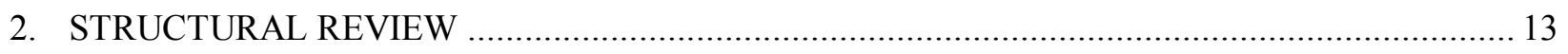

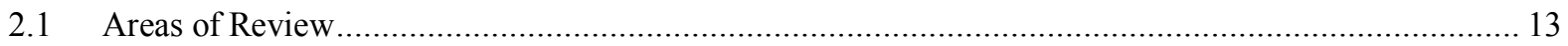

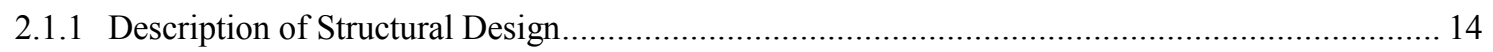

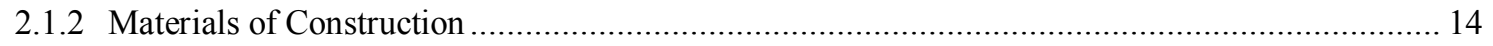

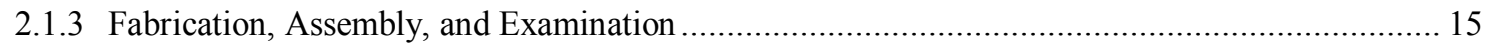

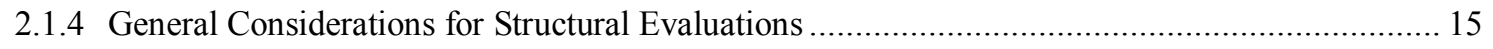

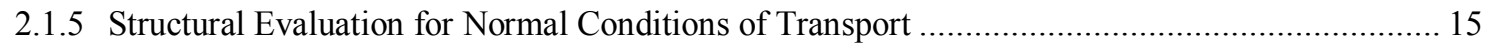

2.1.6 Structural Evaluation for Hypothetical Accident Conditions..................................................... 15

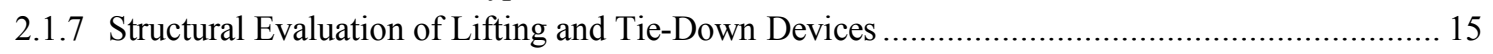

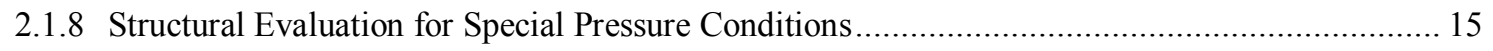

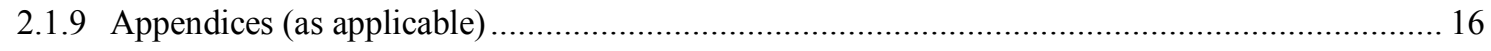

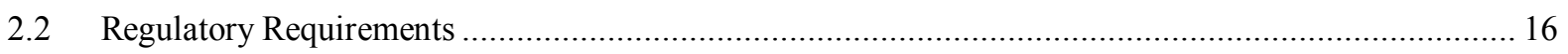

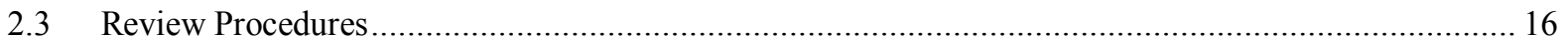

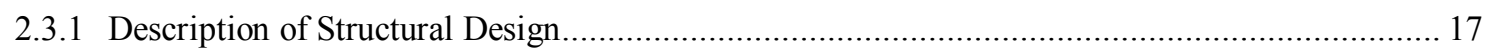

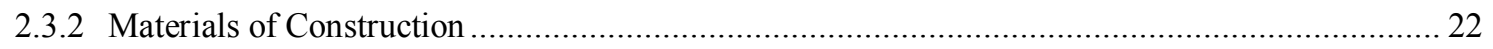

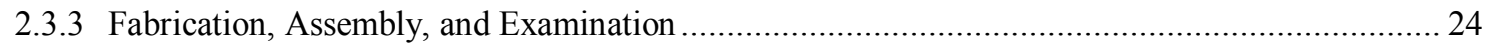

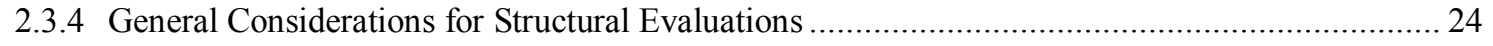

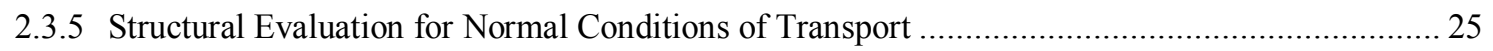

2.3.6 Structural Evaluation for Hypothetical Accident Conditions..................................................... 28

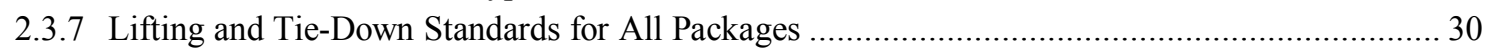

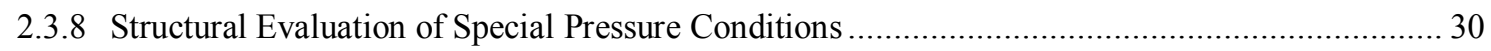

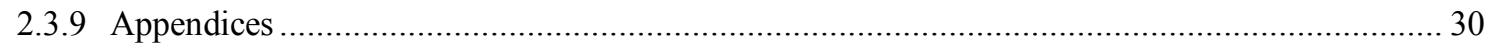




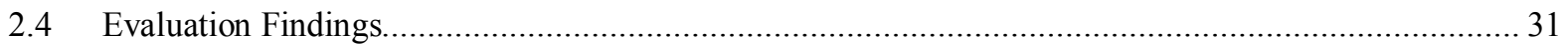

2.4 .1 Findings

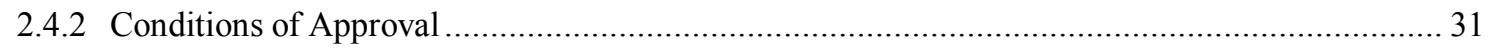

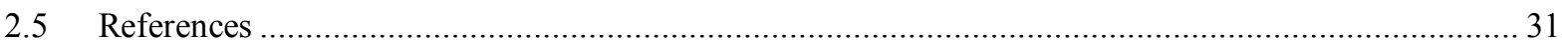

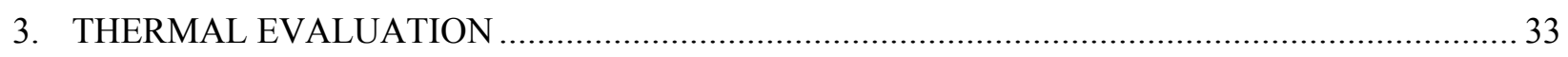

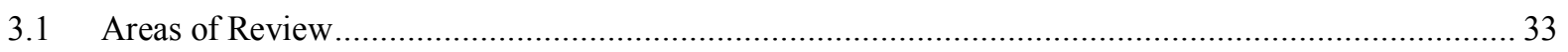

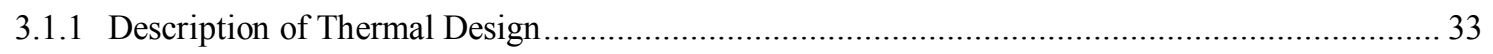

3.1.2 Material Properties, Thermal Limits, and Component Specifications ........................................ 33

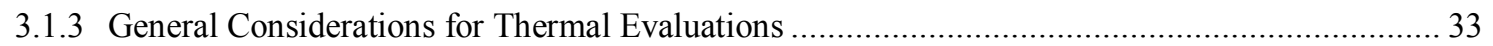

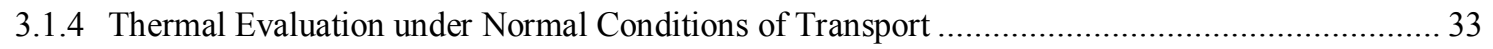

3.1.5 Thermal Evaluation under Hypothetical Accident Conditions...................................................... 33

3.1.6 Thermal Evaluation of Maximum Accessible Surface Temperature............................................. 34

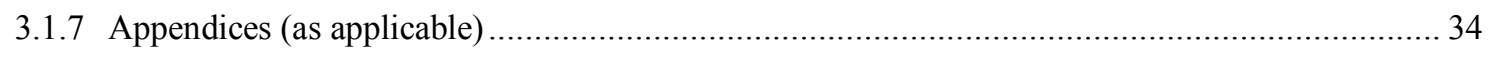

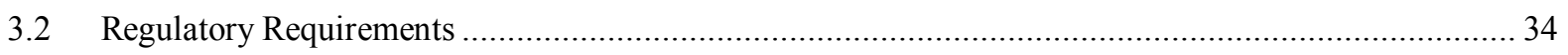

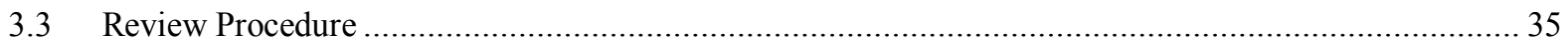

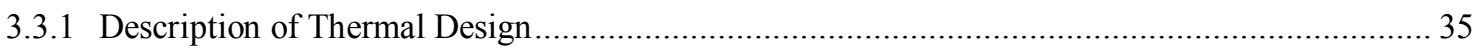

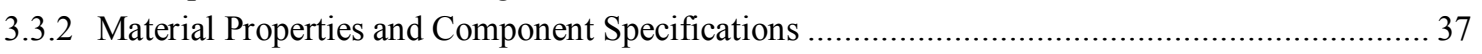

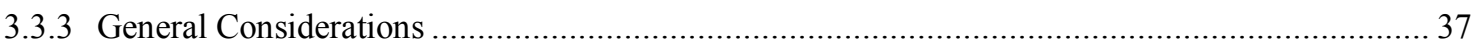

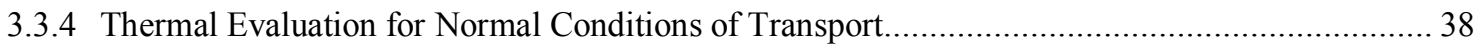

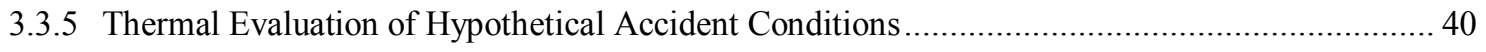

3.3.6 Thermal Evaluation of Maximum Accessible Surface Temperature............................................ 42

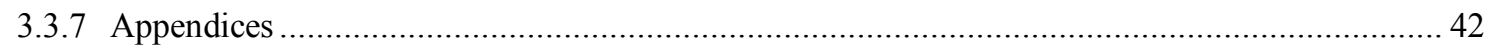

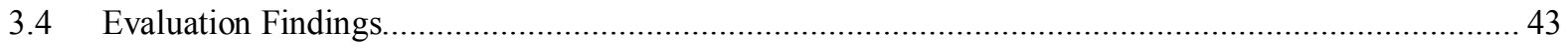

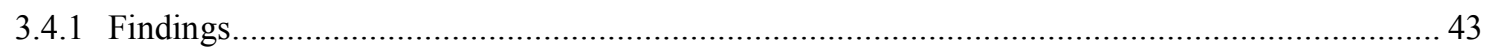

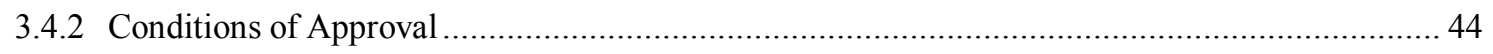

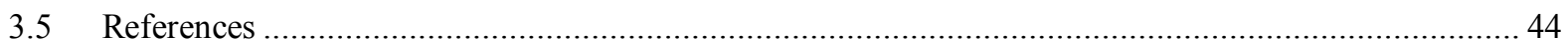

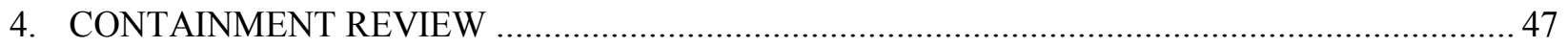

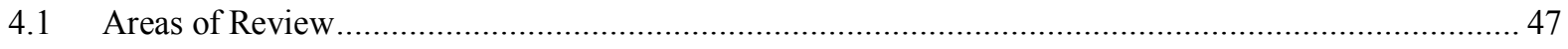

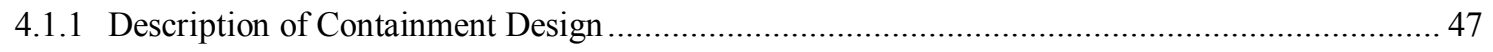

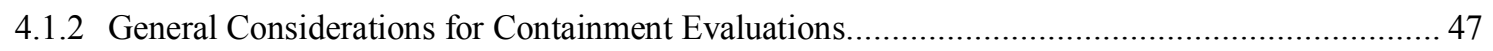

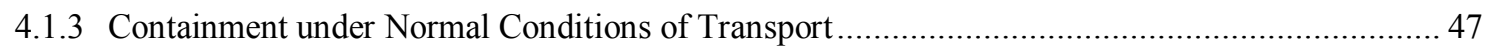

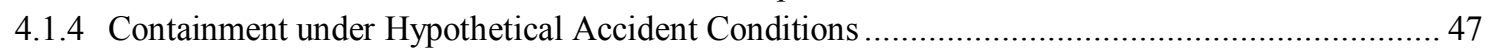

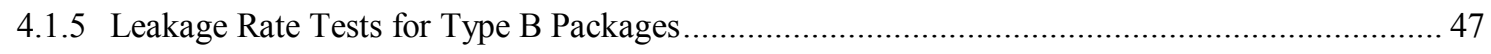

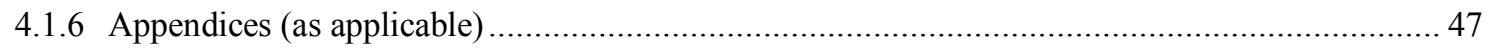

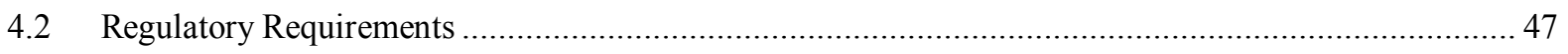

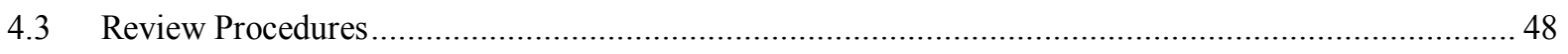

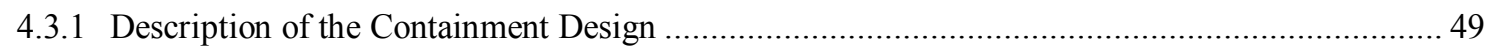

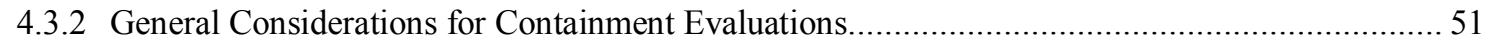

4.3.3 Containment under Normal Conditions of Transport (Type B Packages) ……........................... 53

4.3.4 Containment under Hypothetical Accident Conditions (Type B Packages) ................................ 53

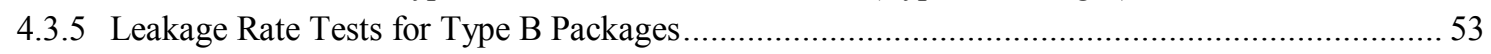

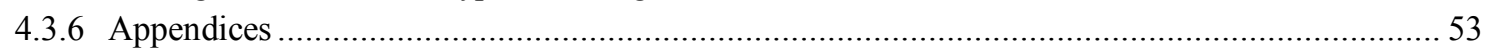

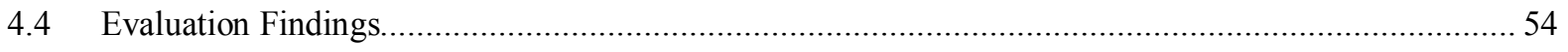

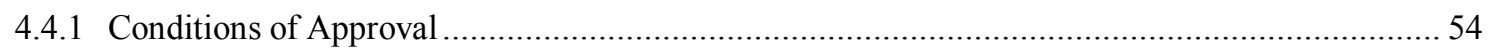




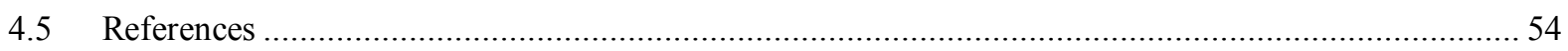

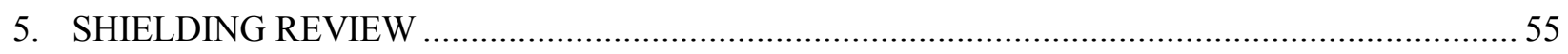

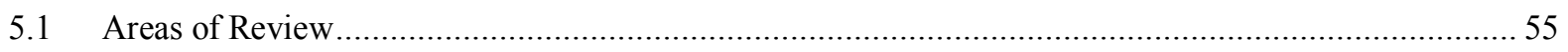

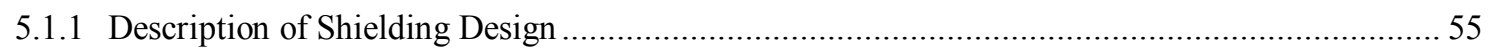

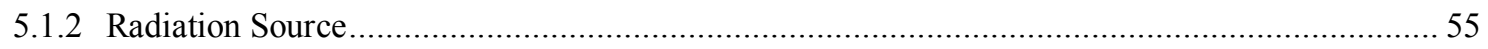

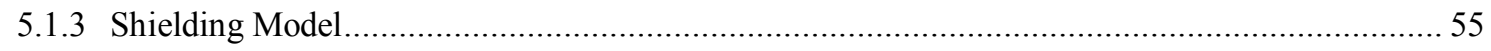

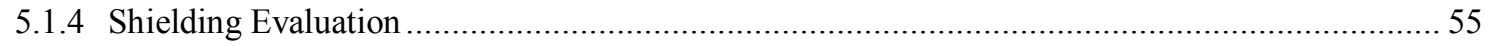

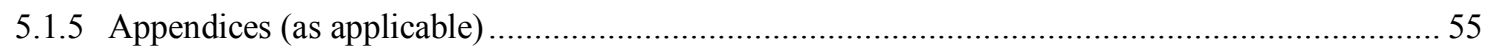

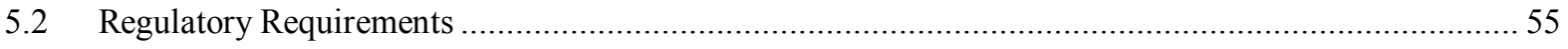

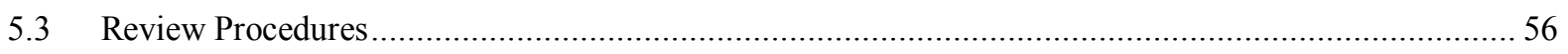

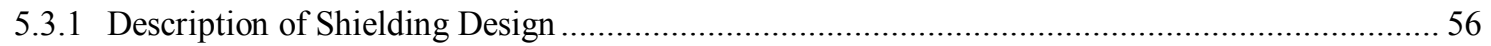

5.3.2 Radiation Source

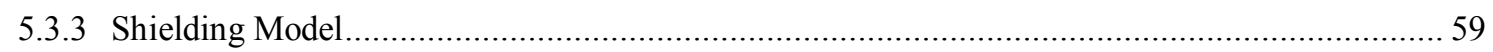

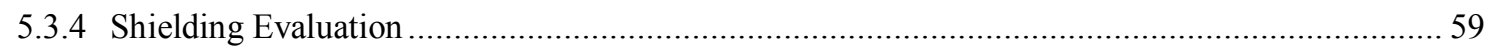

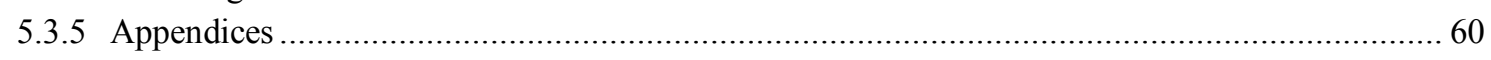

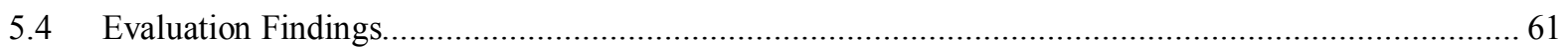

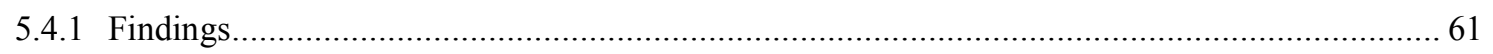

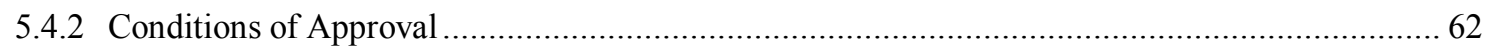

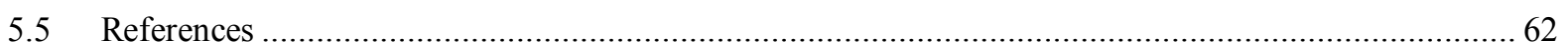

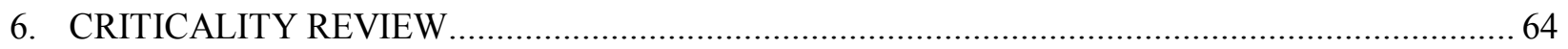

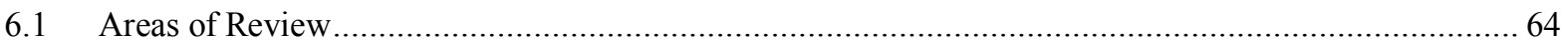

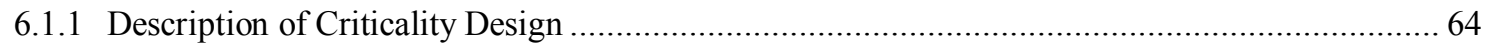

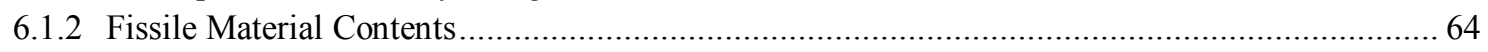

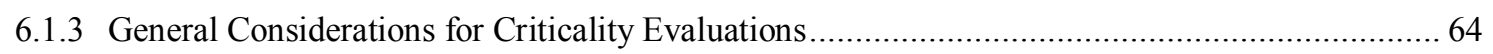

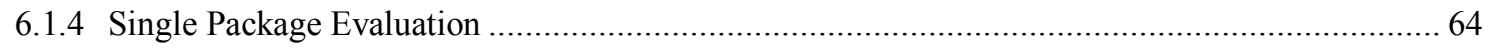

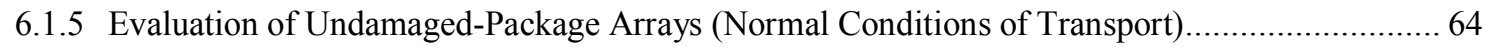

6.1.6 Evaluation of Damaged-Package Arrays (Hypothetical Accident Conditions).............................. 64

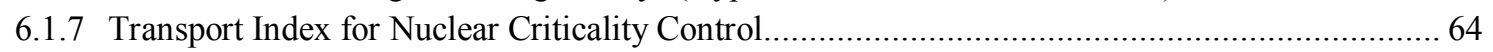

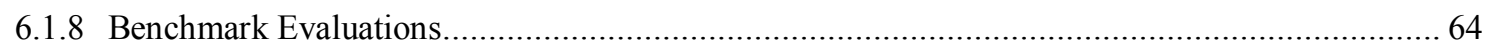

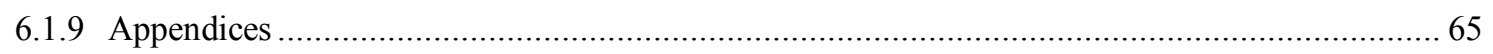

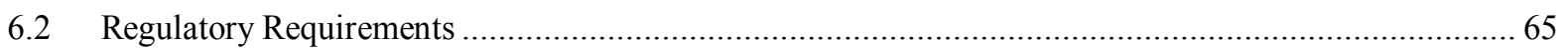

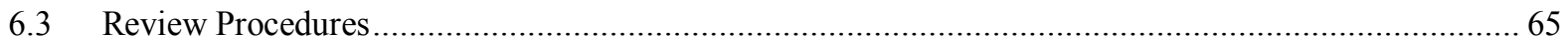

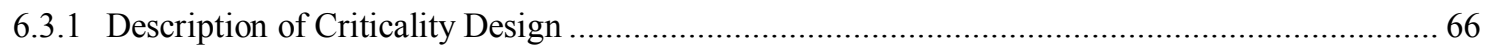

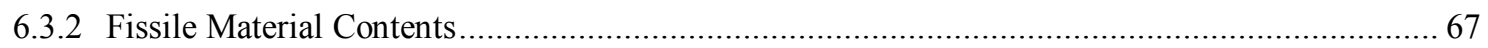

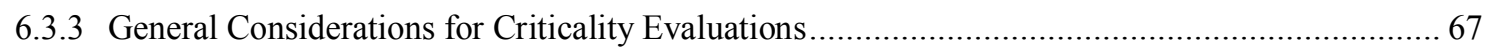

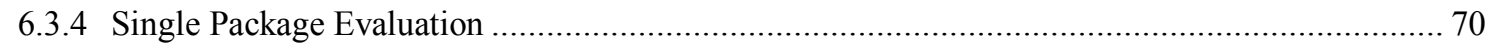

6.3.5 Evaluation of Undamaged-Package Arrays (Normal Conditions of Transport)........................... 71

6.3.6 Evaluation of Damaged-Package Arrays (Hypothetical Accident Conditions)............................. 72

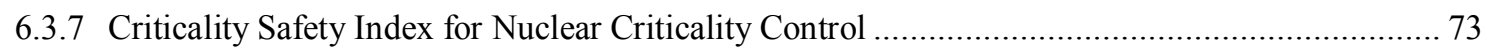

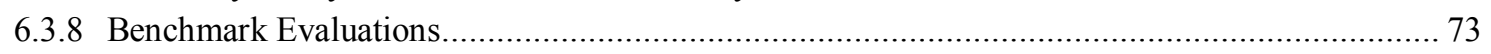

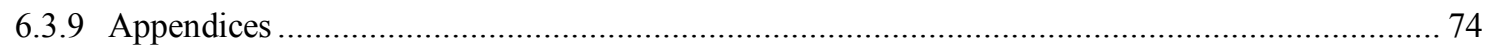

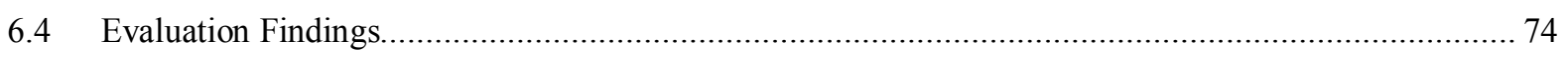

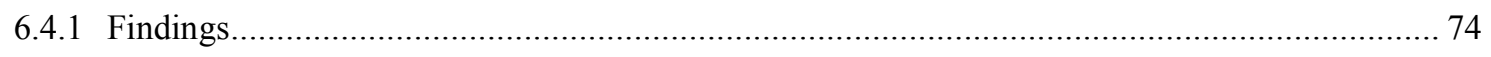

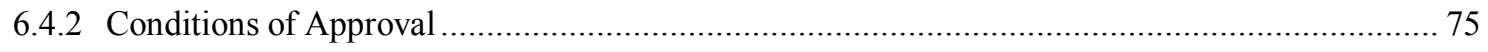




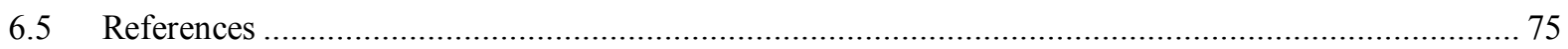

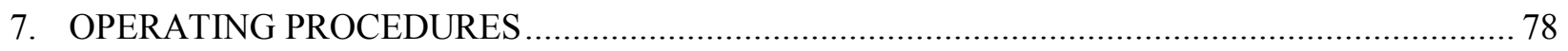

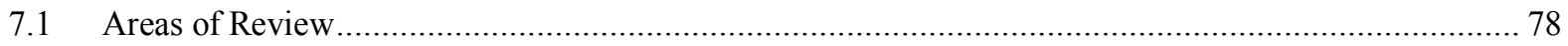

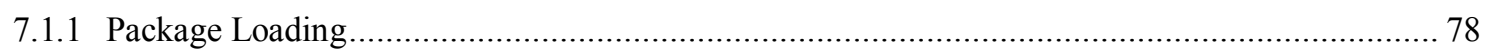

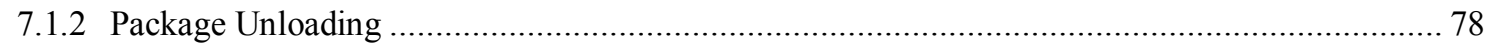

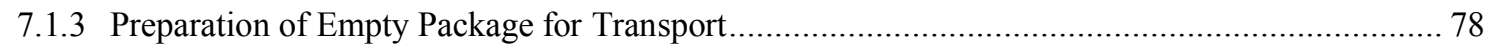

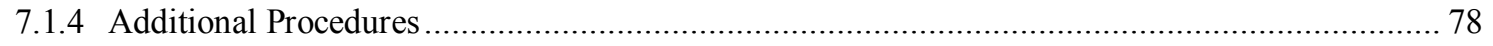

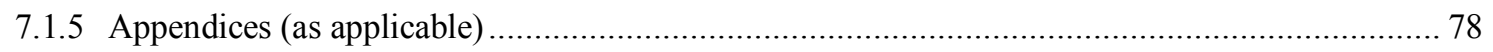

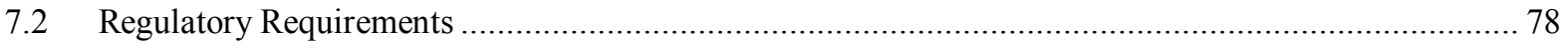

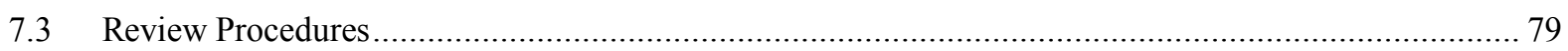

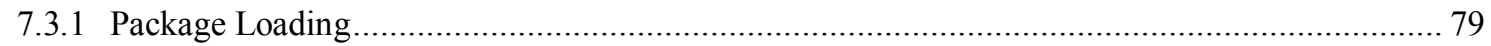

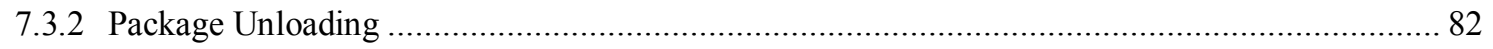

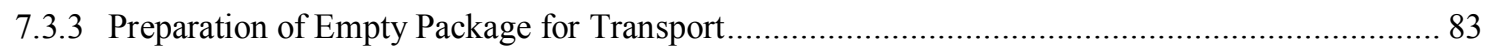

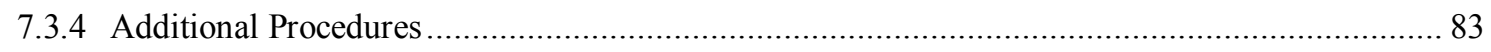

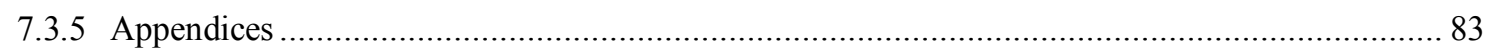

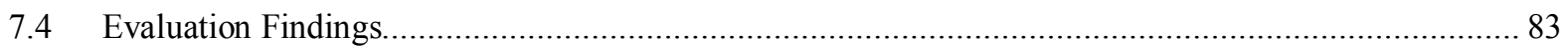

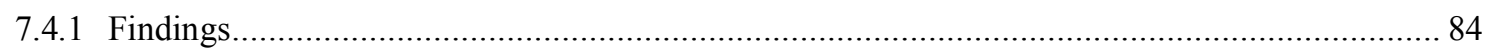

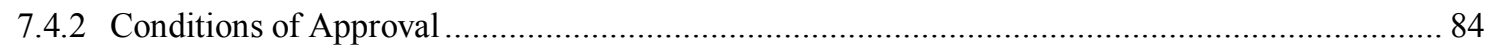

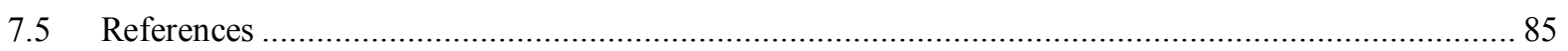

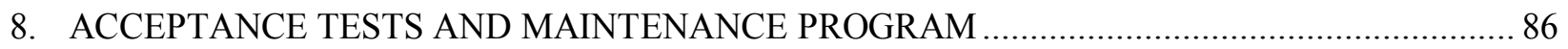

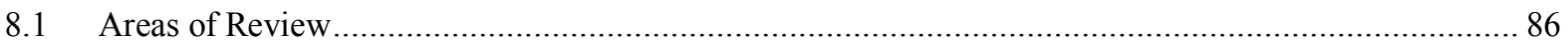

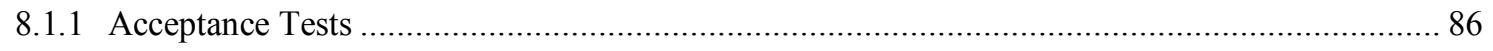

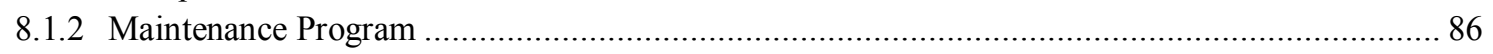

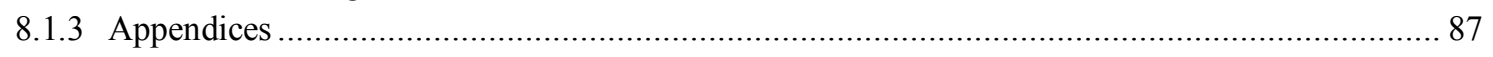

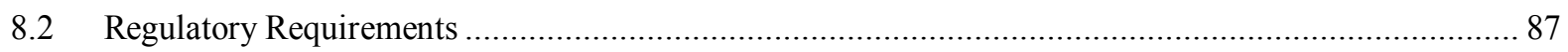

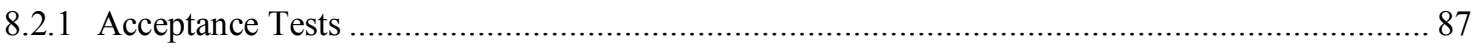

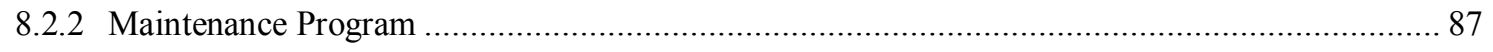

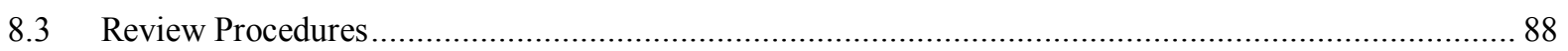

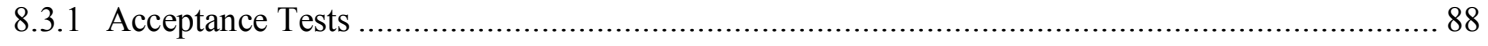

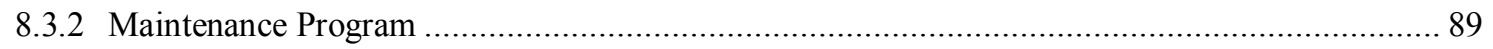

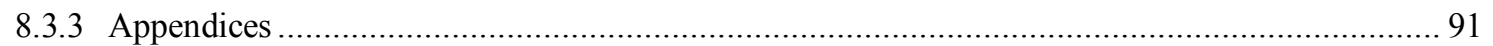

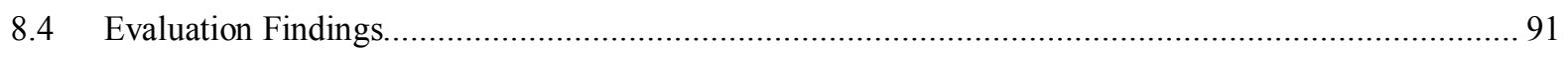

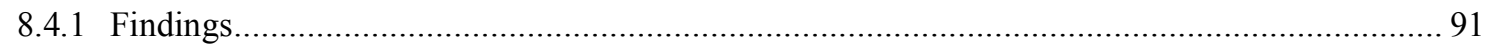

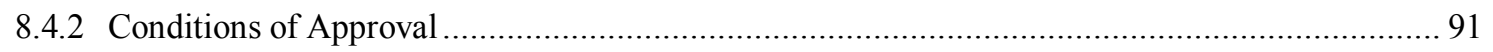

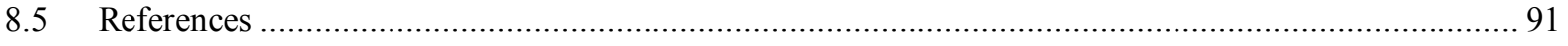

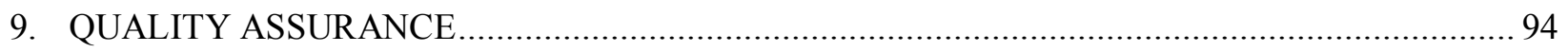

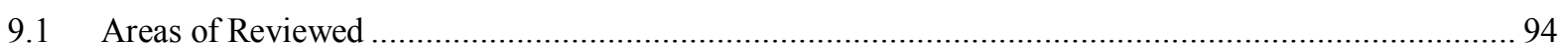

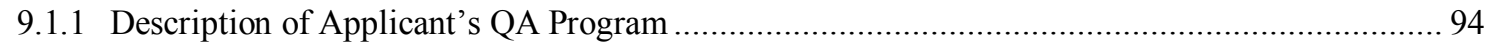

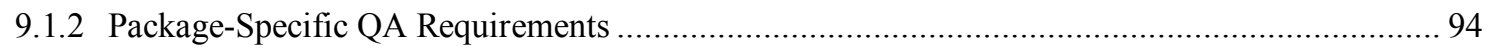

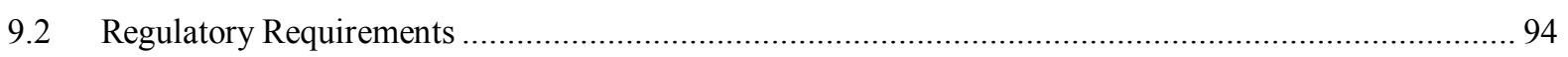

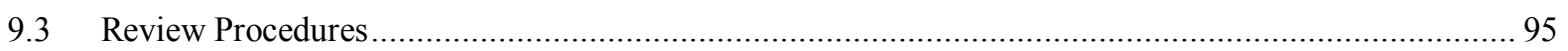

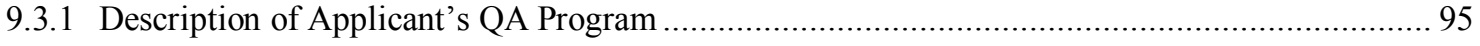

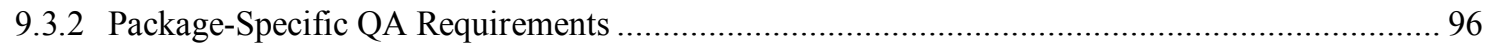




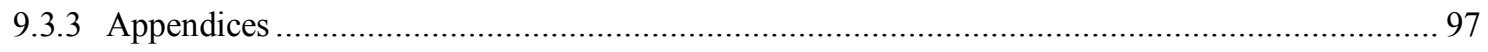

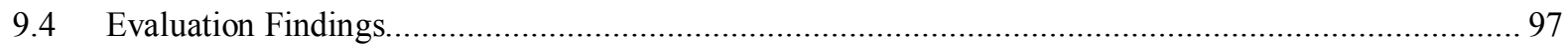

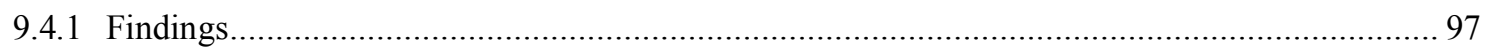

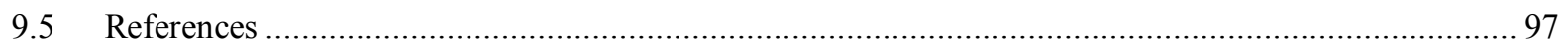

\section{TABLES}

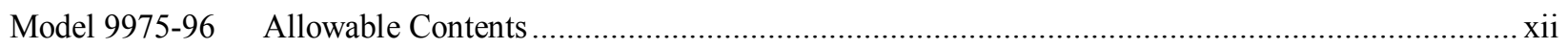

Table 2.3.1 Data Summary of Components of the Model 9975-96 Package................................................ 18

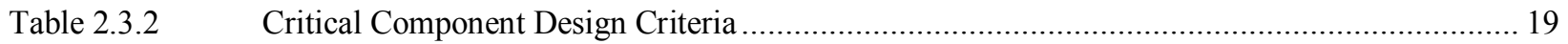

Table 2.3.3 Model 9975-96 Package Component Weights ........................................................................ 21

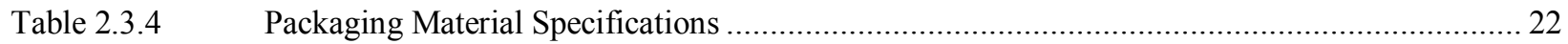


This Page Intentionally Blank. 


\section{ACRONYMS}

$\begin{array}{ll}\text { ANSI } & \text { American National Standards Institute } \\ \text { ASME } & \text { American Society for Mechanical Engineers } \\ \text { ASTM } & \text { American Society for Testing and Materials } \\ \text { B\&PV } & \text { (ASME) Boiler and Pressure Vessel Code } \\ \text { CoC } & \text { Certificate of Compliance } \\ \text { CSI } & \text { Criticality Safety Index } \\ \text { DDT } & \text { Deflagration to Detonation } \\ \text { DOE } & \text { U.S. Department of Energy } \\ \text { DOT } & \text { Department of Transportation } \\ \text { FEA } & \text { Finite Element Analysis } \\ \text { HAC } & \text { Hypothetical Accident Conditions } \\ \text { IAEA } & \text { International Atomic Energy Agency } \\ \text { ID } & \text { Inner diameter } \\ \text { LDPE } & \text { Low-density Polyethylene } \\ \text { LLNL } & \text { Lawrence Livermore National Laboratory } \\ \text { MCNP } & \text { Monte Carlo Nuclear Particle } \\ \text { MNOP } & \text { Maximum Normal Operating Pressure } \\ \text { NCT } & \text { Normal Conditions of Transport } \\ \text { NRC } & \text { Nuclear Regulatory Commission } \\ \text { OD } & \text { Outer diameter } \\ \text { OST } & \text { Office of Safeguards Transportation } \\ \text { PCV } & \text { Primary Containment Vessel } \\ \text { QA } & \text { Quality Assurance } \\ \text { RSICC } & \text { Radiation Safety Information Computational Center } \\ \text { SAR } & \text { Safety Analysis Report } \\ \text { SARP } & \text { Safety Analysis Report for Packagings } \\ \text { SCV } & \text { Secondary Containment Vessel } \\ \text { SGT } & \text { SafeGuards Transporter } \\ \text { SI } & \text { System of Units } \\ \text { SNM } & \text { Special Nuclear Materials } \\ \text { SRNL } & \text { Savannah River National Laboratory } \\ \text { SS } & \text { Stainless Steel } \\ \text { SSCs } & \text { Structures, Systems, Components } \\ \text { SGT } & \text { Safeguards Transporter } \\ \text { SST } & \text { Safe Secure Trailer } \\ \text { TI } & \text { Transport index } \\ \text { TID } & \text { Tamper-indicating device } \\ \text { TRR } & \text { Technical Review Report } \\ \text { vol\% } & \text { Percent composition by volume } \\ \text { WSRC } & \text { Washington Savannah River Company } \\ & \end{array}$


This Page Intentionally Blank. 


\section{OVERVIEW}

This Technical Review Report (TRR) documents the review, performed by the Lawrence Livermore National Laboratory (LLNL) Staff, at the request of the U.S. Department of Energy (DOE), on the Safety Analysis Report for Packaging, Model 9975, Revision 0, dated January 2008 (S-SARP-G-00003, the SARP). ${ }^{[1]}$ The review includes an evaluation of the SARP, with respect to the requirements specified in $10 \mathrm{CFR} 71,{ }^{[2]}$ and in International Atomic Energy Agency (IAEA) Safety Standards Series No. TS-R-1. ${ }^{[3]}$

\section{Background}

The Model 9975-96 Package is a 35-gallon drum package design that has evolved from a family of packages designed by DOE contractors at the Savannah River Site. Earlier package designs, i.e., the Model 9965, the Model 9966, the Model 9967, and the Model 9968 Packagings, were originally designed and certified in the early 1980s. In the 1990s, updated package designs that incorporated design features consistent with the then newer safety requirements were proposed. The updated package designs at the time were the Model 9972, the Model 9973, the Model 9974, and the Model 9975 Packagings, respectively. The Model 9975 Package was certified by the Packaging Certification Program, under the Office of Safety Management and Operations.

The safety analysis of the Model 9975-85 Packaging is documented in the Safety Analysis Report for Packaging, Model 9975, B(M)F-85, Revision 0, dated December 2003. ${ }^{[4]}$ The Model 9975-85 Package is certified by DOE Certificate of Compliance (CoC) package identification number, USA/9975/B(M)F-85, ${ }^{[5]}$ for the transportation of Type B quantities of uranium metal/oxide, ${ }^{238} \mathrm{Pu}$ heat sources, plutonium/uranium metals, plutonium/uranium oxides, plutonium composites, plutonium/tantalum composites, ${ }^{238} \mathrm{Pu}$ oxide/beryllium metal.

\section{Design Changes}

The basic Model 9975-96 Package design remains largely unchanged from its Model 9975-85 counterpart, with the following exceptions:

- An outer liner of 20 gauge stainless steel (SS) has been added to supplement the 20 -gauge inner SS liner and encapsulate the lead shielding. This change will potentially reduce, or eliminate, the potential for lead carbonate corrosion;

- Increased torque values for the Cone Seal Plug, Cone Seal Nut, and fasteners are included to improve operability;

- Equivalent materials for the Primary and Secondary containment vessel O-rings are allowed, i.e., Viton ${ }^{\circledR}$ GLT/Viton ${ }^{\circledR}$ GLT-S;

- Softwood-based and cane-based Celotex ${ }^{\mathrm{TM}}$ are both considered for the purpose of impact limiters and thermal insulation;

- Additional text is included in the SARP to allow for:

$>$ The addition of plutonium oxide densities that are greater than $19.4 \mathrm{~g} / \mathrm{cm}^{3}$ and/or less than $2.0 \mathrm{~g} / \mathrm{cm}^{3}$;

$>$ An increase in the ${ }^{241} \mathrm{Am}$ plus ${ }^{241} \mathrm{Pu}$ content from $11 \mathrm{wt} \%$ to $15 \mathrm{wt} \%$; and

$>$ The addition of increased thorium content to Content Envelopes C.3 and C.4; 
(Note: The inclusion of these changes to the allowable Content Envelopes had already been approved, and documented, in a letter amendment to the Model 9975-85 CoC. $) ;{ }^{[6]}$ and

- Improvements and clarifications identified since the previous edition of the SARP for the Model 9975-85 Package $^{[4]}$ was issued.

All other packaging features, as described in the Model 9975-85 SARP, remain unchanged, to, and including, the allowable contents, i.e.,

Model 9975-96 Allowable Contents

\begin{tabular}{|c|l|}
\hline $\begin{array}{c}\text { Content } \\
\text { Envelope }\end{array}$ & Allowable Contents \\
\hline C. 1 & Uranium Metal \\
\hline C. 2 & ${ }^{238}$ Plutonium Oxide Heat Sources \\
\hline C. 3 & Plutonium and/or Uranium Metal \\
\hline C. 4 & Plutonium and Uranium Oxides \\
\hline C. 5 & Plutonium Composites \\
\hline C. 6 & Plutonium/Tantalum Composites \\
\hline C. 7 & ${ }^{238}$ Plutonium Oxide/Be Metal \\
\hline C. 8 & Neptunium Oxide \\
\hline
\end{tabular}

\section{Regulatory Changes}

On April 30, 2002, a series of Proposed Rule Changes to 10 CFR 71 was issued by the Nuclear Regulatory Commission (NRC). ${ }^{[7]}$ A total of nineteen (19) issues were presented. Eleven (11) of the issues originated from TS-R-1 (IAEA) compatibility concerns; the remaining eight (8) were initiated by the NRC.

In the 2002 Proposed Rule, the eleven IAEA compatibility issues were noted as:

- Issue 1: Changing Part 71 to the international system of units (SI) only;

- Issue 2: Radionuclide exemption values;

- Issue 3: Revision of $A_{1}$ and $A_{2}$ values;

- Issue 4: Uranium hexafluoride package requirements;

- Issue 5: Introduction of the Criticality Safety Index (CSI) requirements;

- Issue 6: Type $\mathrm{C}$ packages and low dispersible material;

- Issue 7: Deep Immersion Test;

- Issue 8: Grandfathering previously approved packages;

- Issue 9: Changes to various definitions;

- Issue 10: Crush test for fissile material package design; and 
- Issue 11: Fissile material package design for transport by aircraft.

The additional eight NRC-initiated issues were noted as:

- Issue 12: Special package authorizations;

- Issue 13: Expansion of Part 71 Quality Assurance (QA) requirements to CoC holders;

- Issue 14: Adoption of the American Society of Mechanical Engineers (ASME) Code;

- Issue 15: Change authority for dual-purpose package certificate holders;

- Issue 16: Fissile material exemptions and general license provisions;

- Issue 17: Decision on petition for rulemaking on double containment of plutonium;

- Issue 18: Contamination limits as applied to spent fuel and high-level waste packages; and

- Issue 19: Modifications of event reporting requirements.

The Final Rule was published on January 26, 2004. ${ }^{[2]}$ As was noted in the Final Rule, Issues 1,6 14,15 , and 18 were not adopted by the NRC, and, therefore, no longer need to be considered for purposes of this TRR. Although Issues 2, 3, 4, 11, and 12 were adopted by the NRC, the changes and the requirements added by the adoption of these issues are not relevant to this submittal. The remaining Issues adopted by the NRC, i.e., Issues 5, 7, 8, 9, 10, 13, 16, 17, and 19, were addressed in the submittal, as appropriate:

- This submittal reports the CSI, as required by Issue 5; CSI-related issues are discussed in Chapters 1 and 6;

- The deep water immersion test pressure, as required by Issue 7, is addressed in Chapter 2 and Appendix 2.2;

- Grandfathering of the Model 9975-85 Package, as required by Issue 8, is addressed in Chapter 1;

- Changes to various definitions, as defined in Issue 9 have been addressed throughout the submittal, i.e., existing definitions for fissile material and Transport Index have been modified, while new definitions for $\mathrm{A}_{2}$, Certificate of Compliance, consignment, CSI, and United States Department of Transportation have been added;

- The Crush test for fissile material package designs, as required by Issue 10, is discussed in Chapters 1 and 2, but was not required for this submittal because the package density exceeds $62.4 \mathrm{lb} / \mathrm{ft}^{3}$;

- Changes to the requirements for certificate holders and applicants for a $\mathrm{CoC}$, as required under Issue 13, are discussed in Chapter 9;

- Changes to the requirements for Fissile material exemptions and general license provisions, as required under Issue 16, are discussed throughout the submittal;

- In spite of the fact that the Double-Containment requirement for plutonium had now been eliminated, as discussed under Issue 17, the applicant has chosen to retain the double- 
containment requirement for the Model 9975-96 Packaging, in order to minimize the design changes relative to the Model 9975-85 Packaging.

- Under Issue 19, a licensee has 60 days to provide a written event report to the NRC.

As was noted with the publication of the Final Rule for 10 CFR 71 on January 26, 2004, all of the changes went into effect on October 1, 2004. ${ }^{[2]}$ The changes were in the submittal, or in the WSRC supplement to the submittal, NRC Final Rule Change and Impact to the 9975 SARP for -96 Certification. ${ }^{[8]}$

Because the TRR for this package was prepared for a newly consolidated application, the review presented in this TRR was performed using the methods outlined in the Packaging Review Guide for Reviewing Safety Analysis Reports for Packagings. ${ }^{[9]}$

\section{References}

[1] Washington Savannah River Company, Safety Analysis Report for Packaging, Model 9975, S-SARP-G-00003, Revision 0, Savannah River Packaging Technology, Savannah River National Laboratory (January 2008).

[2] Nuclear Regulatory Commission, 10 CFR Part 71, Compatibility with IAEA Transportation Standards (TS-R-1) and Other Transportation Safety Amendments; Final Rule, 69 F.R. 3698, pp. 3698-3814, January 26, 2004, as amended.

[3] Regulations for the Safe Transport of Radioactive Material, Safety Requirements, IAEA Safety Standards Series No. TS-R-1, 1996 Edition (As Amended 2003) International Atomic Energy Agency, Vienna, Austria (July 2004).

[4] Safety Analysis Report for Packaging, Model 9975, B(M)F-85, Revision 0, WSCR-SA-2002-0008, Radioactive Materials Packaging Technology, Savannah River Technology Center, Westinghouse Savannah River Company, December 2003.

[5] Department of Energy Certificate of Compliance, USA/9975/B(M)F-85 (DOE), Rev. 18, October 3, 2007.

[6] U.S. Department of Energy, Safety Evaluation Report for Addendum 1 to the Safety Analysis Report for Packaging for the 9975 Package, Docket No. 05-7-9975, July 5, 2005.

[7] Nuclear Regulatory Commission, 10 CFR Part 71, Compatibility with IAEA Transportation Standards (TS-R-1) and Other Transportation Safety Amendments, 67 F.R. 21390, pp. 21390-21484, April 30, 2002.

[8] NRC Final Rule Change and Impact to the 9975 SARP for -96 Certification, J.L. Murphy and D.S Hoang, Savannah River National Laboratory, SRNL-IES-2007-00090 (November 2007).

[9] Packaging Review Guide for Reviewing Safety Analysis Reports for Packagings, A.A. DiSabatino, et al., UCID-21218, Rev. 3, Lawrence Livermore National Laboratory (February 2008). 


\section{GENERAL INFORMATION REVIEW}

\subsection{Areas of Review}

This review includes an evaluation of the SARP with respect to the requirements specified in 10 CFR $71,{ }^{[1-1]}$ and in International Atomic Energy Agency (IAEA) Safety Standards Series No. TS-R-1.1 $1^{1-2]}$ The description and engineering drawings in Chapter 1, General Information Review of the Safety Analysis Report for Packaging (the SARP), Model 9975-96 Package, $\mathrm{B}(\mathrm{M}) \mathrm{F}-96,{ }^{[1-3]}$ were reviewed. The review also addresses Content Envelopes C.1 through C.8, as described in Table 1.2 of the SARP.

Included in the General Information Review were the following:

\subsubsection{Introduction}

- Purpose of Application

- Summary Information

\subsubsection{Package Description}

- Packaging

- Contents

\subsubsection{Compliance with 10 CFR 71}

- Statement of Compliance

- Summary of Evaluation

\subsubsection{Appendices (as applicable)}

- Drawings

- Other Information

\subsection{Regulatory Requirements}

The requirements of 10 CFR 71 applicable to the General Information review of the Model 9975-96 Package include:

- An application for package approval must be submitted in accordance with Subpart D of 10 CFR 71. [\$71.0(d)(2)]

- An application for modification of a previously approved package is subject to the provisions of $\S 71.19$ and $\S 71.31(\mathrm{~b})$. All changes in the conditions of package approval must be approved. [\$71.19, §71.31(b), §71.107(c)]

- The application must include a description of the packaging design in sufficient detail to provide an adequate basis for its evaluation. [\$71.31(a)(1), §71.33(a)]

- The application must include a description of the contents in sufficient detail to provide an adequate basis for evaluation of the packaging design. [\$71.31(a)(1), §71.33(b)] 
- The application must reference or describe the quality assurance program applicable to the package. [\$71.31(a)(3), §71.37]

- The application must identify the established codes and standards used for the package design, fabrication, assembly, testing, maintenance, and use. In the absence of such codes, the application must describe the basis and rationale used to formulate the quality assurance program. [\$71.31]

- An application for renewal of a previously approved package must be submitted no later than 30 days prior to the expiration date of the approval to assure continued use. [ $\$ 71.38]$

- The smallest overall dimension of the package must not be less than $10 \mathrm{~cm}$ (4 in.). [\$71.43(a)]

- The outside of the package must incorporate a feature that, while intact, would be evidence that the package has not been opened by unauthorized persons. [\$71.43(b)]

- A package with a transport index greater than 10, a Criticality Safety Index greater than 50 , or an accessible external surface temperature greater than $50^{\circ} \mathrm{C}\left(122^{\circ} \mathrm{F}\right)$ must be transported by exclusive-use shipment. [\$71.43(g), §71.47(a), §71.47(b), §71.59(c)]

- The maximum activity of radionuclides in a Type A package must not exceed the $\mathrm{A}_{1}$ or $\mathrm{A}_{2}$ values listed in 10 CFR 71, Appendix A, Table A-1. For a mixture of radionuclides, the provisions of Appendix A, paragraph IV apply, except that for krypton-85, an effective $A_{2}$ equal to $10 \mathrm{~A}_{2}$ may be used. [Appendix $\mathrm{A}, \S 71.51(\mathrm{~b})$ ]

- A fissile material packaging design to be transported by air must meet the requirements of $\S 71.55(\mathrm{f})$.

- A fissile material package must be assigned a Criticality Safety Index for nuclear criticality control to limit the number of packages in a single shipment. [ $\$ 71.59$, $\S 71.35(\mathrm{~b})]$

- Plutonium in excess of $0.74 \mathrm{TBq}(20 \mathrm{Ci})$ must be shipped as a solid. [§71.63]

- The package must be conspicuously and durably marked with its model number, serial number, gross weight, and package identification number. [\$71.19, $§ 71.85(\mathrm{c})]$

\subsection{Review Procedures}

The following subsections describe the review methods for the Areas of Review applicable to the General Information chapter of the SARP for the Model 9975-96 Package.

\subsubsection{Introduction}

\subsubsection{Purpose of Application}

Regulatory Changes: This section of the TRR covers the review of the General Information provided in Chapter 1 of the SARP. The SARP documents the analysis and testing performed on and for the Model 9975-96 Package. The performance evaluation presented in the SARP documents the compliance of the Model 9975-96 Package with the regulatory safety requirements for Type B packages. 
The primary purpose for this application was to bring the Model 9975-96 Package into compliance with respect to current regulatory requirements, both within the United States, and on an international basis. Under its initial certification, the Model 9975 Package was certified under the version of 10 CFR 71 that went into effect on April 1, 1996. ${ }^{[1-4]}$ At the time, this version of 10 CFR 71 was also deemed to be in full compliance with the requirements specified in the International Atomic Energy Agency's, Regulations for the Safe Transport of Radioactive Materials, Safety Series No. 6, 1985 Revised Edition (As Amended). ${ }^{[1-5]}$ The cross-linkage to the 1985 IAEA regulations is what gave the Model 9975 Package its "-85" designation.

On April 30, 2002, a series of Proposed Rule Changes to 10 CFR 71 was published by the Nuclear Regulatory Commission (NRC). ${ }^{[1-6]}$ A total of 19 issues was presented. Eleven (11) of the issues originated from TS-R-1 (IAEA) compatibility concerns; the remaining eight (8) were initiated by the NRC. (Note: For a more detailed description of the 19 Issues, see the Overview section, above.)

The Final Rule for this set of changes to 10 CFR 71 was published on January 26, 2004. ${ }^{[1-1]}$ As was noted in the Final Rule, Issues 1, 614 , 15, and 18 were not adopted by the NRC, and, therefore, no longer need to be considered for purposes of this TRR. Although Issues 2, 3, 4, 11, and 12 were adopted, the changes, and the requirements added by the adoption of the newer requirements are not relevant to this submittal. The remaining Issues adopted by the NRC, i.e., Issues 5, 7, 8, 9, 10, 13, 16, 17, and 19, were addressed in the submittal, as appropriate:

- This submittal reports the CSI, as required by Issue 5; CSI-related issues are discussed in Chapters 1 and 6;

- The deep water immersion test pressure, as required by Issue 7, is addressed in Chapter 2 and Appendix 2.2;

- Grandfathering of the Model 9975-85 Package, as required by Issue 8, is addressed in Chapter 1;

- Changes to various definitions, as defined in Issue 9 have been addressed throughout the submittal, i.e., existing definitions for fissile material and Transport Index have been modified, while new definitions for $\mathrm{A}_{2}$, Certificate of Compliance, consignment, CSI, and United States Department of Transportation have been added;

- The Crush test for fissile material package designs, as required by Issue 10, is discussed in Chapters 1 and 2, but was not required for this submittal because the package density exceeds $62.4 \mathrm{lb} / \mathrm{ft}^{3}$;

- Changes to the requirements for certificate holders and applicants for a $\mathrm{CoC}$, as required under Issue 13, are discussed in Chapter 9;

- Changes to the requirements for Fissile material exemptions and general license provisions, as required under Issue 16, are discussed throughout the submittal;

- The applicant has chosen to retain the double-containment design for the Model 9975-96 Packaging, though double containment is no longer required; and

- Under Issue 19, a licensee has 60 days to provide a written event report to the NRC. 
As was noted with the publication of the Final Rule for 10 CFR 71 on January 26, 2004, all of the changes went into effect on October 1, 2004. ${ }^{[1-1]}$ While all of the changes may not have been addressed specifically in the submittal, they were addressed directly in the WSRC supplement to the submittal, NRC Final Rule Change and Impact to the 9975 SARP for-96 Certification. ${ }^{[1-7]}$

The incorporation of these changes, along with the design changes discussed below, bring the Model 9975-96 Package into compliance with the newer requirements specified in the current version of 10 CRF 71. The incorporation of these changes also brings the Model 9975-96 Package into compliance with the requirements specified in the IAEA Regulations, specified in Safety Standards Series No. TS-R-1, 1996 Edition (As Amended 2003). ${ }^{[1-2]}$

Design Changes: The basic Model 9975-96 Package design is unchanged from its Model 9975-85 counterpart, with the following exceptions:

- An outer liner of 20 gauge stainless steel (SS) has been added to supplement the 20 -gauge inner SS liner and encapsulate the lead shielding. This change will potentially reduce, or eliminate, the potential for lead carbonate corrosion;

- Increased torque values for the Cone Seal Plug, Cone Seal Nut, and fasteners are included to improve operability;

- Equivalent materials for the Primary and Secondary containment vessel O-rings are allowed, i.e., Viton ${ }^{\circledR}$ GLT/Viton ${ }^{\circledR}$ GLT-S;

- Softwood-based and cane-based Celotex ${ }^{\mathrm{TM}}$ are both considered for the purpose of impact limiters and thermal insulation;

- Additional text is included in the SARP to allow for:

$>$ The addition of plutonium oxide densities that are greater than $19.4 \mathrm{~g} / \mathrm{cm}^{3}$ and/or less than $2.0 \mathrm{~g} / \mathrm{cm}^{3}$;

$>$ An increase in the ${ }^{241}$ Am plus ${ }^{241} \mathrm{Pu}$ content from $11 \mathrm{wt} \%$ to $15 \mathrm{wt} \%$; and

$>$ The addition of increased thorium content to Content Envelopes C.3 and C.4; (Note: The inclusion of these changes to the allowable Content Envelopes had already been approved, and documented, in a letter amendment to the Model 9975-85 CoC.),$^{[1-8]}$ and

- Improvements and clarifications identified since the previous edition of the SARP for the Model 9975-85 Package ${ }^{[1-9]}$ was issued.

All other packaging features, as described in the Model 9975-85 SARP, ${ }^{[1-9]}$ remain unchanged.

\subsubsection{Summary Information}

The Model 9975-96 Package is designed to transport fissile actinide metals and oxides in excess of Type A quantities. The Package is designed for an internal pressure of $63 \mathrm{MPa}(900 \mathrm{psi})$. The package type and Model Number, $9975 \mathrm{~B}(\mathrm{M}) \mathrm{F}-96$ is provided on Drawing R-R2-F-0025, Sheet 1 of 2, Rev. 4. The Package is shipped by non-exclusive use, using a Safe Secure Trailer (SST), Safeguards Transporter (SGT), or by commercial carrier as determined by the contents per DOE Order 470.4A. ${ }^{[1-10]}$ Package users may also ship by exclusive use dose-rate limits in SSTs or SGTs provided approval is granted by the DOE Office of Safeguards Transportation. 
The SARP does not demonstrate that the package meets the requirements for shipment of plutonium by air. Section 2.1.2 states that the package is designed as Category I, per NUREG/CR-3854. ${ }^{[1-11]}$

Section 1.2 of the SARP includes a summary of the design criteria for the package. The American Society for Mechanical Engineers (ASME) Boiler and Pressure Vessel Code (B\&PVC), Division 1, Section III, Subsection NB, 2004 Edition will be used to determine package containment system design, fabrication, and inspection requirements. Stainless steel drum bodies are fabricated in accordance with 49 CFR 178, Subpart L. ${ }^{[1-12]}$ Softwood-based or cane fiberboard-based Celotex ${ }^{\text {TM }}$ insulating and impact-absorbing material must meet ASTM Specification C 208-95. ${ }^{[1-13]}$ Additional discussion of applicable codes and standards is included in Chapters 2-9 of the TRR.

The applicant's QA program is identified in Chapter 9 of the SARP.

The Package has a calculated Criticality Safety Index of 2.0. The Transport Index (TI), based on package surface dose rate, will be determined from measurements made at the time of shipment. Calculations, presented in Section 5, and procedures discussed in Section 7 of the SARP, limit the maximum dose rate on the surface of the package to $<200 \mathrm{mrem} /$ hour for all shipments.

\subsubsection{Package Description}

\subsubsection{Packaging}

The Model 9975-96 Package assembly is depicted in Figures 1.1 through 1.4 of the SARP. The packaging outer container is a 35-gallon removable-head drum designed and fabricated in accordance with 49 CFR 178 Subpart L. The drum and its lid are fabricated of 18-gauge (0.048 inches) Type 304L stainless steel. Drum welds satisfy the requirements of the ASME B\&PV Code, Section III, Subsection NF. Four $1 / 2$-inch diameter vent holes are drilled into the drum approximately $90^{\circ}$ apart, 1 inch below the drum flange, and they are covered with a plastic Caplug ${ }^{\circledR}$ (fusible plug).

The drum lid is bolted to a $1 \frac{1}{4}$-inch-wide by $1 / 8$-inch-thick angle flange welded to the top of the drum body using $24,1 / 2$-inch high-strength bolts. The lid is recessed 0.55 inches below the top

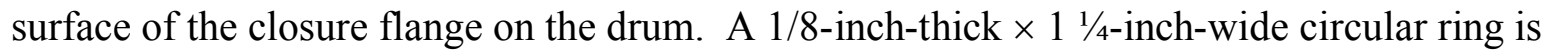
welded to the outer section of the lid. Visual examination of the welds will be performed in accordance with the ASME B\&PV Code, Subsection NF, and the American Welding Society structural welding code for Stainless Steel, D1.6. ${ }^{[1-14]}$ The ring serves to reinforce the lid and prevents it from shearing away from the bolts during a Hypothetical Accident Condition (HAC) event. Four $1 / 2$-inch pins, asymmetrically positioned on the lid bolt circle, function as alignment keys, restricting the lid installation to a single orientation. A 0.31-inch diameter hole drilled in the alignment pins and 0.19-inch hole drilled in the shank of each lid bolt is used to install a tamper-indicating device (TID).

Insulation: The material that surrounds the containment vessels is regular-grade wall sheathing, softwood-based or cane fiberboard-based Celotex ${ }^{\mathrm{TM}}$, manufactured per ASTM Specification C-208-95. The softwood-based or cane fiberboard-based Celotex ${ }^{\mathrm{TM}}$ insulation consists of a series of $1 / 2$-inch-thick sheets bonded together into top and bottom subassemblies with water-based carpenter's glue. The radial thickness of the insulation is $4 \frac{3}{4}$ inches. In the 
axial direction, the top thickness of cane fiberboard is 3.5 inches and the bottom thickness is 3.4 inches. A stainless steel air shield is placed over and glued to the top fiberboard subassembly. This thin-walled shield inhibits smoldering of the top fiberboard layers when exposed to air in a fire. A length of sash chain welded to the top of the air shield serves as a handle for removing the top subassembly.

A filler pad consisting of a ceramic fiber blanket $\left(\right.$ Kaowool $\left.^{\circledR}\right)$, encapsulated in stainless steel foil, and heat sealed (Firemaster ${ }^{\mathbb{R}}$ ) is required between the top insulation subassembly and the drum lid.

Shielding: Radiation shielding is provided by a lead cylinder assembly that surrounds the primary Containment Vessel /Secondary Containment Vessel double-containment assembly. (Note: Although double containment is no longer required by the regulations, the applicant has elected to retain the older, double containment design from the Model 9975-85.). The shielding assembly consists of an approximately $7 \frac{1}{2}$-inch ID by 20 -gauge $304 \mathrm{~L}$ stainless steel cylinder with a 20 -gauge bottom, surrounded by 0.47 to 0.51 inches of lead. An aluminum lid, $1 / 2$-inch thick, completes the assembly. The lid has four equally spaced bolt holes near the edge for attachment to the cylinder body ( $1 / 4-20$ UNC threaded steel inserts). This is per Drawing R-R2-F-0020-A, 9975 Shielding Body Subassembly. Lead Shielding Bodies have a 20-year minimum service life from the data of manufacture.

To preclude lead carbonate corrosion, an alternate Lead Shielding Body design (Drawing R-R2-F-0020-C) incorporates a SS outer jacket which creates a barrier between the lead of the body and the air environment within the packaging. The Drawing R-R2-F-0020-C design has the same overall dimensions as Drawing R-R2-F-0020-A, but the jacket replaces the outermost 0.036 inches of lead is also made from a 20-gauge $304 \mathrm{SS}$ cylinder and a 20-gauge $304 \mathrm{SS}$ bottom sheet. The inner 0.036-inch SS liner remains, and the lead is 0.434 inches thick. Individually, the wall and the bottom thickness of the Lead Shielding Body remain at 0.506 inches.

After March 1, 2018, the Lead Shielding Body must be in accordance with Drawing R-R2-F-0020-C, as per Section 7.2.1 of the SARP.

Bearing Plates: Two, $1 / 2$-inch thick aluminum bearing plates provide load bearing surfaces against the cane fiberboard insulation.

Primary Containment Vessel: The PCV consists of a stainless steel pressure vessel designed in accordance with Section III, Subsection NB of the ASME B\&PVC, 2004 edition, with a design condition of $900 \mathrm{psig}$ at $300^{\circ} \mathrm{F}$. The PCV is fabricated from 5-inch Schedule 40, seamless, Type 304L stainless steel pipe (0.258-inch nominal wall), and has a standard Schedule 40, Type 304L stainless steel pipe cap (0.258-inch nominal wall) at the blind end. A stayed head, machined from a 6-inch diameter by $2 \frac{1}{4}$ inches long Type 304L SS bar, is welded to the pipe top end. The head is machined to include $5 \frac{1}{2}-12 \mathrm{UN}-2 \mathrm{~B}$ internal thread and a female cone-seal surface with a 32- $\mu$ in. finish. 
Both vessel body joints are circumferential full-penetration, complete fusion butt welds examined by radiographic and liquid penetrant methods. These welds satisfy ASME B\&PVC, Section III, Subsection NB requirements.

The PCV closure assembly consists of a male-female cone joint with surfaces that have been machined to identical angles so that they mate with essentially zero clearance. Two grooves for O-rings are machined into the face of the Type 304L stainless steel male cone seal plug. A leak test port is provided between the two O-ring grooves. Two, Viton ${ }^{\text {TM }}$ GLT or Viton ${ }^{\text {TM }}$ GLT-S fluoroelastomer O-rings (lubricated with silicone high vacuum grease) are placed in the grooves to form a leaktight seal (less than $10^{-7} \mathrm{ref} \cdot \mathrm{cm}^{3} / \mathrm{sec}$ ). The zero clearance design for the malefemale cone joint prevents extrusion of the O-rings and loss of sealing ability at design pressures and temperatures. The cone seal nut, which forces the male cone seal plug against the female cone, is threaded into the containment vessel body. Dissimilar materials were selected for the cone seal nut (Nitronic 60) and the containment vessel body (Type 304L stainless steel) to minimize galling. For plutonium/uranium oxide contents, per Content Envelope C.4, the PCV is backfilled with at least $75 \%$ carbon dioxide gas prior to closing. For neptunium oxide contents, per Content Envelope C.8, the PCV is backfilled with argon gas, such that the oxygen content is no greater than $3 \%$ by volume at closure.

Secondary Containment Vessel: The SCV consists of a stainless steel pressure vessel designed in accordance with Section III, Subsection NB of the ASME B\&PVC, 2004 edition, with a design condition of 800 psig at $300^{\circ} \mathrm{F}$. The SCV is fabricated from 6-inch, Schedule 40, seamless, Type 304L stainless steel pipe (0.280-inch nominal wall), and has a standard Schedule 40, Type 304L stainless steel pipe cap (0.280-inch nominal wall) at the blind end. A

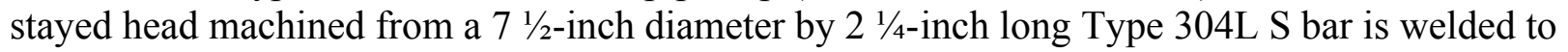
the pipe top end. The head is machined to include $6 \frac{1}{2}-12 \mathrm{UNS}-2 \mathrm{~B}$ internal threads and a female cone-seal surface with a 32- $\mu$ in. finish. Both vessel body joints are circumferential full-

penetration, complete fusion butt welds examined by radiographic and liquid penetrant methods. These welds satisfy ASME B\&PVC Section III, Subsection NB requirements. The SCV closure is virtually identical to that used on the PCV, except that SCV is 1 inch larger in diameter. Also, for neptunium oxide contents, per Content Envelope C.8, the SCV is backfilled with argon gas, such that the oxygen content is no greater than $3 \%$ by volume at closure.

PCV Bottom Spacer: The PCV bottom spacer is made of pre-crushed aluminum honeycomb, and is contoured to fit the curved bottom of the PCV cavity. The spacer is flat which provides a level surface to support the content assemblies in the PCV. The spacer is fabricated from 0.003-inch-thick (minimum) foil, and is rated for an axial compressive strength before deformation of $1,500 \pm 500$ psi.

SCV Impact Absorbers: Pre-crushed aluminum honeycomb impact absorbers are used in the SCV to reduce the impact loads transmitted between the containment vessels. The SCV bottom impact absorber is contoured to fit the curved bottom of the SCV cavity providing a level surface on which the PCV can stand. The SCV top impact absorber is shaped like a thick ring and separates the top of the PCV cone seal nut from the underside of the SCV cone seal plug. The impact absorbers are fabricated from 0.003-inch-thick (minimum) foil and are rated for an axial compressive strength before deformation of 1,500 \pm 500 psi. 
PCV Sleeve: The PCV is fitted with an aluminum sleeve to fill the space between the contents (food-pack cans and hex cans) and the inner wall of the PCV (Drawing R-R4-F-0055-B). The PCV sleeve is fabricated from 6061-T6 seamless aluminum tubing. The sleeve is 14.15 inches tall, with a 5.00-inch OD with a 0.3 -inch wall thickness. With the PCV sleeve in place, the maximum gap that may be formed, considering tolerances and off-center effects, is $3.0 \mathrm{~mm}$ between the outer sleeve wall and the inner wall of the PCV. For hex-cans, a tube spacer and hex-can spacers are used in addition to the PCV sleeve.

3013 Top Spacer: The 3013 top spacer is fabricated from 6061-T6 seamless aluminum tubing and is 5.06 inches tall, with a 4.92 -inch OD and a 0.3 -inch wall thickness (Drawing R-R4-F-0055-C). It is placed on top of the 3013 container to take up the remaining axial space in the PCV cavity. With the 3013 top spacer in place, the maximum gap that may be formed, considering tolerances and off-center effects, is $5.0 \mathrm{~mm}$ between the spacer and the inner wall of the PCV. This gap is identical to the gap between the 3013 outer container OD and the PCV ID.

\subsubsection{Contents}

Type B quantities of radioactive material, including fissile materials, may be shipped in the Model 9975-96 Package. The double containment Model 9975-96 Package may be used to ship plutonium compounds in amounts exceeding 20 curies. Specifically, the allowable contents for the Model 9975-96 Package include:

- Uranium Metal or Oxide, as specified in Content Envelope C.1 in Table 1.2 of the SARP;

- ${ }^{238}$ Plutonium Heat Sources, as specified in Content Envelope C.2 in Table 1.2 of the SARP;

- Plutonium and/or Uranium Metal, as specified in Content Envelope C.3 in Table 1.2 of the SARP;

- Plutonium and/or Uranium Oxide, as specified in Content Envelope C.4 in Table 1.2 of the SARP;

- Plutonium Composites, as specified in Content Envelope C.5 in Table 1.2 of the SARP;

- Plutonium/Tantalum Composites, as specified in Content Envelope C.6 in Table 1.2 of the SARP;

- ${ }^{238}$ Plutonium Oxide/Beryllium Metal, as specified in Content Envelope C.7 in Table 1.2 of the SARP; and/or

- Neptunium Oxide, as specified in Content Envelope C.8 in Table 1.2 of the SARP.

Additional content restrictions/limits are listed as footnotes following Content Table 1.2 of the SARP. Additional Container Arrangement/Configurations and Content Envelope Configurations are noted in Sections 1.2.3.1 and 1.2.3.2 of the SARP, respectively. In all cases, the content configuration requirements, listed in Sections 1.2.3.1 and 1.2.3.2, respectively, and the specific restrictions/limits listed for each of the Content Envelopes in Table 1.2 and Table 1.3 of the SARP, shall be met for shipping. 


\subsubsection{Compliance with 10 CFR 71}

\subsubsection{Statement of Compliance}

Section 1.1 of the SARP states that the Model 9975-96 Package satisfies the regulatory requirements of 10 CFR $71^{[1-1]}$ and IAEA Safety Standards, Safety Series No. TS-R-1. ${ }^{[1-2]}$

\subsubsection{Summary of Evaluation}

A Summary of Evaluation section has been included in the SARP as Section 1.2.4.2. Included in the summary are sub-sections and discussions pertaining to the following:

- Structural and Thermal Performance under Testing for NCT (10 CFR 71.71) and HAC (10 CFR 71.73);

- General Requirements for All Packages (10 CFR 71.43);

- Structural Requirements for Lifting and Tie-Down Devices (10 CFR 71.45);

- External Radiation Requirements (10 CFR 71.47);

- Requirements for Type B Packages (10 CFR 71.51);

- Criticality Requirements (10 CFR 71.15, 10 CFR 71.55, and 10 CFR 71.59);

- Special Requirements for Plutonium Packages (10 CFR 71.63);

- Requirements for Operating Controls and Procedures (10 CFR 71, Subpart G); and

- Requirements for Quality Assurance (10 CFR 71, Subpart H).

\subsubsection{Appendices}

There are three Appendices associated with Chapter 1 of the SARP.

Appendix 1.1, entitled Drawings, where the Drawings for the Model 9975-96 Packaging are provided, as detailed, in the table below.

\begin{tabular}{|l|l|}
\hline \multicolumn{1}{|c|}{ Drawing Number } & \multicolumn{1}{c|}{ Drawing Title } \\
\hline R-R2-F-0026, Rev. 4 & 9975 Shipping Package Drum with Flange Closure \\
\hline R-R2-F-0019, Rev. 7 & 9975 Shipping Package Insulation Assembly, Subassemblies and Details \\
\hline R-R2-F-0020, Rev. 10 & 9975 Shipping Package Shielding \\
\hline R-R2-F-0025, Rev. 4 & 9975 Drum with Flange Closure Subassembly and Details \\
\hline R-F2-F-0018, Rev. 9 & $\begin{array}{l}\text { 9975 Shipping Package Primary and Secondary Containment Vessel } \\
\text { Subassemblies }\end{array}$ \\
\hline R-R3-F-0016, Rev. 12 & 9975 Shipping Package Containment Vessel Weldments \\
\hline R-R3-F-0015, Rev. 5 & 9975 Shipping Package Air Shield Weldment \\
\hline R-R4-F-0054, Rev. 13 & $\begin{array}{l}\text { 9975 Shipping Package Primary (PCV) and Secondary (SCV) } \\
\text { Containment Vessel Details }\end{array}$ \\
\hline R-R4-F-0055, Rev. 4 & 9975 Shipping Package PCV Sleeve and 3013 Spacer Details \\
\hline R-R2-F-0037, Rev. 1 & 9975 Packaging Alternate 3013 Spacer Component Details \\
\hline
\end{tabular}

Appendix 1.2, Limiting Material Container Dimensions. 
Appendix 1.3, DOE-STD-3013 Storage Container Configurations.

\subsection{Evaluation Findings}

\subsubsection{Findings}

Based on review of the statements and representations in the SARP, the staff concludes that the design of the Model 9975-96 Package, as described in Revision 0 of S-SARP-G-00003, has been adequately described to meet the requirements of 10 CFR 71. By meeting the requirements of 10 CFR 71, the Model 9975-96 Packaging also meets the requirements of IAEA Safety Series No. TS-R-1.

In the next revision, it is recommended the minimum weight of the jacketed shielding body assembly be noted as $130.3 \mathrm{lb}$ for R-R2-F-0020-C, only, in Section 1.2.1.3 of the SARP. Also, Note 6 in R-R2-F-0025, Rev. 4, is missing its number.

\subsubsection{Conditions of Approval}

In addition to a summary package description and specifications of authorized contents, the following other conditions of approval are applicable to the General Information review of the Model 9975-96 Package:

- The maximum decay heat per package may not exceed 19 watts;

- The maximum weight of all material (radioactive contents, product cans, spacers, etc.) inside the PCV may not exceed $20.1 \mathrm{~kg}(44.4 \mathrm{lb})$;

- Contents are restricted to those described in Table 1.2, Content Envelopes, of the SARP, with additional restrictions provided by the applicable Table 1.2 footnotes, and the Summary of Requirements by Content and Configuration in Table 1.3 must be adhered to for packaging;

- Content Envelope loading configurations are further restricted to those described in Section 1.2.3.1, Container Arrangements/Configurations, and Section 1.2.3.2, Content Envelope Configurations, of the SARP, as applicable;

- Except as stated in Table 1.2 of the SARP, small concentrations ( $<1000 \mathrm{ppm}$ each) of other actinides, fission products, decay products, and neutron activation products are permitted;

- Except as stated in Table 1.2 of the SARP, inorganic material impurity quantities of less than 100 ppm each are permitted, so long as the total mass is less than 0.1 weight percent of the total content mass;

- All food-pack, 3013, or hex cans must be examined for post-sealing bulging or buckling prior to placement inside the PCV. No can that has visibly bulged or buckled may be transported in the package;

- Food-pack, 3013, or hex cans shall be inspected upon removal from the PCV after shipment. Any visible bulging, buckling, or evidence of corrosion shall be reported immediately to the DOE Headquarters Certifying Official;

- $\mathrm{Pu} / \mathrm{U}$ content bulk densities shall be and no greater than $19.84 \mathrm{~g} / \mathrm{cc}$; no minimum bulk density is required; 
- The Criticality Safety Index is 2.0;

- For Content Envelope C.8, neptunium oxide, the food-pack cans, PCV, and SCV must be inerted with argon such that the oxygen content is a maximum 3 vol\%. For Content Envelope C.4, plutonium/uranium oxides, the PCV atmosphere is diluted with carbon dioxide to at least $75 \mathrm{vol} \%$. The 3013, food-pack can, or hex-can atmosphere must be a maximum of $5 \mathrm{vol} \%$ oxygen using helium or nitrogen diluent; and

- The PCV bottom spacer is required.

Drawings that define the package design for the Model 9975-96 Package SARP are delineated above, in Section 1.3.4.

\subsection{References}

[1-1] Nuclear Regulatory Commission, 10 CFR Part 71, Compatibility with IAEA Transportation Standards (TS-R-1) and Other Transportation Safety Amendments; Final Rule, 69 F.R. 3698, pp. 3698-3814, January 26, 2004, as amended.

[1-2] Regulations for the Safe Transport of Radioactive Material, Safety Requirements, IAEA Safety Standards Series No. TS-R-1, 1996 Edition (As Amended 2003) International Atomic Energy Agency, Vienna, Austria (July 2004).

[1-3] Washington Savannah River Company, Safety Analysis Report for Packaging, Model 9975, S-SARP-G-00003, Revision 0, Savannah River Packaging Technology, Savannah River National Laboratory (January 2008).

[1-4] Nuclear Regulatory Commission, 10 CFR Part 71, Compatibility with International Atomic Energy Agency (IAEA), Final Rule, 60 F.R. 50248, pp. 50248-50289, September 28, 1995.

[1-5] Regulations for the Safe Transport of Radioactive Materials, International Atomic Energy Agency, Safety Series No. 6, 1985 Revised Edition (as Amended).

[1-6] Nuclear Regulatory Commission, 10 CFR Part 71, Compatibility with IAEA Transportation Standards (TS-R-1) and Other Transportation Safety Amendments, 67 F.R. 21390, pp. 21390-21484, April 30, 2002.

[1-7] NRC Final Rule Change and Impact to the 9975 SARP for -96 Certification, J.L. Murphy and D.S Hoang, Savannah River National Laboratory, SRNL-IES-2007-00090 (November 2007).

[1-8] U.S. Department of Energy, Safety Evaluation Report for Addendum 1 to the Safety Analysis Report for Packaging for the 9975 Package, Docket No. 05-7-9975, July 5, 2005.

[1-9] Safety Analysis Report for Packaging, Model 9975, B(M)F-85, Revision 0, WSCR-SA-2002-0008, Radioactive Materials Packaging Technology, Savannah River Technology Center, Westinghouse Savannah River Company, December 2003.

[1-10] Safeguards and Security Program, DOE Order 470.4A, U.S. Department of Energy, Washington, DC (May 25, 2007).

[1-11] U.S. Nuclear Regulatory Commission, Fabrication Criteria for Shipping Containers, NUREG/CR-3854, Washington, DC, March 1985. (See also, L.E. Fischer and W. Lai, Fabrication Criteria for Shipping Containers, Lawrence Livermore National Laboratory, UCRL-53544, Livermore, CA, April 1984.

[1-12] Specifications for Packagings, Code of Federal Regulations, Title 49, Part 178, Washington, DC (October 2005). 
[1-13] American Society for Testing and Materials, Standard Specification for Cellulosic Fiber Insulating Board, ASTM C208-95 (Reapproved 2001), Philadelphia, PA, 1995.

[1-14] American Welding Society, Structural Welding Code - Stainless Steel, AWS D1.6:1999, Miami, FL 1999. 


\section{STRUCTURAL REVIEW}

\subsection{Areas of Review}

Chapter 2, Structural Review, of the Safety Analysis Report for Packaging, Model 9975 ${ }^{[2-1]}$ for the Model 9975-96 Package was reviewed to address the structural performance of the package design for the tests specified under Normal Conditions of Transport (NCT) and Hypothetical Accident Conditions (HAC). The review also compares the package design requirements to the structural requirements of 10 CFR 71. ${ }^{[2-2]}$ The review includes an evaluation of the SARP with respect to the requirements specified in International Atomic Energy Agency (IAEA) Safety Standards Series No. TS-R-1. ${ }^{[2-3]}$

As identified in the Overview of this TRR, the Model 9975-96 Package under review is different from the licensed Model 9975-85 Package. The following are the major differences in structural design and requirements:

- The Model 9975-96 Package, being a Type B package, which may contain more than $10^{5} \mathrm{~A}_{2}$ fissile material, must be so designed that its undamaged containment system can withstand an external water pressure of $2 \mathrm{MPa}(290 \mathrm{psi}$ ) for a period of not less than one hour without collapse, buckling, or inleakage of water, in compliance with the "deepsubmersion" requirement of the current 10 CFR 71 and IAEA Safety Standard Series No. TS-R-1. ${ }^{2-3]}$

- The Model 9975-96 Package has two, an outer and an inner, stainless steel liners for the lead shield, while the Model 9975-85 Package has only the inner stainless steel liner. The double-liners design of the Model 9975-96 Package is intended to prevent corrosion of the lead shield by acetic acid coming from the Celotex ${ }^{\text {TM }}$ overpack.

- The Model 9975-96 Package has slightly higher torque values for the Cone Seal Plug, Cone Seal Nut, and fasteners in comparison to those used for the Model 9975-85 Package. The increased torque values are intended for improving the operability of the containment closure.

- The Model 9975-96 Package uses for its overpack either the softwood-based Celotex ${ }^{\text {тм }}$ fiberboard or the cane-based Celotex ${ }^{\text {TM }}$ fiberboard used in the Model 9975-85 Package. The softwood-based material must be used because the supplier has stopped producing the cane-based Celotex ${ }^{\text {TM }}$. The Applicant considers the two materials to be equivalent and, therefore, either one can be used.

- Similarly, two O-ring materials, Viton ${ }^{\circledR}$ GLT and Viton ${ }^{\circledR}$ GLT-S, may be used for the containment closures of the Model 9975-96 Package.

- The Model 9975-96 Package meets the 2004 edition of the ASME B\&PV Code Section III, while the Model 9975-85 Package follows the 1992 edition of the same Code. Using the latest engineering codes and standards for new products is a good common engineering practice.

The SARP demonstrates the compliance of the Model 9975-96 Package with 10 CFR 71 using the following new analyses and results: 
- The results of a buckling stress analysis, based on the methodology of the ASME B\&PV Code Section III, which show that the containment systems of the Model 9975-96 Package can withstand the "deep-immersion" pressure without buckling and exceeding the ASME Code stress limits.

- A white paper addresses the equivalence of softwood-based and cane-based Celotex ${ }^{\text {TM }}$ materials. The paper does not demonstrate the equivalence by directly measuring and comparing the controlling thermal and mechanical properties of the two materials. Instead, the paper concludes the material equivalence based on indirect evidence like similar chemical compositions, the same mass density, and the same ASTM specification for the materials.

- Results of impact and thermal analyses demonstrate insignificant differences in stresses and temperatures due to the single-liner and the double-liner designs for the lead shield.

- A report identifying the changes of the ASME B\&PV Code Section III from the 1992 edition to the 2004 edition. The report shows that the Code requirements are practically identical for the Model 9975-96 Package and the Model 9975-85 Package.

Based on these new analyses and results, the SARP concludes that the Model 9975-96 Package and the Model 9975-85 Package would have very similar structural behavior performance. Therefore, all the test and analysis results used for demonstrating compliance of the Model 9975-85 Package with the regulations can also be used for justifying the compliance of the Model 9975-96 Package with 10 CFR 71 and IAEA TS-R-1.

In general, the Staff accepts the new analysis results and their implications. However, the Staff considers the justifications for the equivalence of the softwood-based and cane-based Celotex ${ }^{\text {тм }}$ fiberboards to be indirect and weak. The Staff accepts this claim of material equivalence mainly because the containment systems of the Model 9975-96 Package have been shown by test and analysis to have an exceptional margin of safety. In addition, the Applicant has promised to keep the DOE Certifying Official informed of any unusual results from the planned Celotex ${ }^{\mathrm{TM}}$ surveillance program to be conducted at Savannah River National Laboratory (SRNL).

Given this potential weakness of the SARP, the Staff treated the Model 9975-96 Package as a new package in the structural review, examining all the evidence item-by-item in light of the uncertainties with Celotex ${ }^{\mathrm{TM}}$ materials. The following sections describe details of this review.

The structural design of the package was reviewed. The structural review included the following:

\subsubsection{Description of Structural Design}

- Design Features

- Codes and Standards

\subsubsection{Materials of Construction}

- Material Specifications and Properties

- Prevention of Chemical, Galvanic, or Other Reactions 
- Effects of Radiation on Materials

\subsubsection{Fabrication, Assembly, and Examination}

- Fabrication and Assembly

- Examination

\subsubsection{General Considerations for Structural Evaluations}

- Evaluation by Test

- Evaluation by Analysis

\subsubsection{Structural Evaluation for Normal Conditions of Transport}

- Heat

- Cold

- Reduced External Pressure

- Increased External Pressure

- Vibration

- Water Spray

- Free Drop

- Corner Drop

- Compression

- Penetration

- Structural Requirements for Fissile Material Packages

\subsubsection{Structural Evaluation for Hypothetical Accident Conditions}

- Free Drop

- Crush

- Puncture

- Thermal

- Immersion-fissile material

- Immersion-all packages

\subsubsection{Structural Evaluation of Lifting and Tie-Down Devices}

- Lifting Devices

- Tie-Down Devices

\subsubsection{Structural Evaluation for Special Pressure Conditions}

- Analysis of Pressure Test 


\subsubsection{Appendices (as applicable)}

\subsection{Regulatory Requirements}

The regulatory requirements of 10 CFR 71 applicable to the Structural review of the Model 9975-96 Package include the following.

- The package must be described and evaluated to demonstrate that it meets the structural requirements of $10 \mathrm{CFR} 71$. [\$71.31(a)(1), §71.31(a)(2), §71.33, §71.35(a)]

- The application must identify the established codes and standards used for the package design, fabrication, assembly, testing, maintenance, and use. In the absence of such codes, the application must describe the basis and rationale used to formulate the quality assurance program. [\$71.31(c)]

- The package must be made of materials of construction that assure there will be no significant chemical, galvanic, or other reactions, including reactions due to possible inleakage of water, among the packaging components, among package contents, or between the packaging components and the package contents. The effects of radiation on the materials of construction must be considered. [\$71.43(d)]

- The package design must meet the lifting and tie-down requirements of $\$ 71.45$.

- A fissile material packaging design to be transported by air must meet the requirements of $\S 71.55(\mathrm{f})$.

- A Type B package, containing more than $10^{5} \mathrm{~A}_{2}$, must be designed so that its undamaged containment system can withstand an external water pressure of $2 \mathrm{MPa}$ (290 psi) for a period of not less than one hour without collapse, buckling, or inleakage of water. [§71.61]

- The performance of the package must be evaluated under the tests specified in $\$ 71.71$ for normal conditions of transport. [\$71.41(a)]

- The package must be designed, constructed, and prepared for shipment so there would be no loss or dispersal of contents, no significant increase in external surface radiation levels, and no substantial reduction in the effectiveness of the packaging under the tests specified in $\S 71.71$ for normal conditions of transport. [\$71.43(f), $§ 71.51(\mathrm{a})(1)]$

- A package for fissile material must be so designed and constructed and its contents so limited to meet the structural requirements of $\$ 71.55(\mathrm{~d})(2)$ through $\$ 71.55(\mathrm{~d})(4)$ under the tests specified in $\S 71.71$ for normal conditions of transport.

- The performance of the package must be evaluated under the tests specified in $\$ 71.73$ for hypothetical accident conditions. [\$71.41(a)]

- The package design must have adequate structural integrity to meet the internal pressure test requirement specified in $\S 71.85(\mathrm{~b})$.

\subsection{Review Procedures}

The Structural review ensures that the package design has been adequately described and evaluated under the NCT and the HAC to demonstrate sufficient structural integrity to meet the requirements of $10 \mathrm{CFR} 71$. 
The Structural review is based in part on the descriptions and evaluations presented in the General Information and the Thermal Evaluation sections of the application. Similarly, results of the structural review are considered in the review of all other sections of the application.

\subsubsection{Description of Structural Design}

The SARP identifies the following components, which contribute directly or indirectly to the structural integrity of the packaging:

- Stainless steel drum with a bolted-flange closure;

- Cane/softwood fiberboard (Celotex $\left.{ }^{\mathrm{TM}}\right)$ impact-absorbing and insulating material;

- Stainless steel air shield;

- Secondary containment vessel (stainless steel);

- Primary containment vessel (stainless steel);

- Containment closure nut and seals;

- Aluminum honeycomb impact absorbers;

- Lead shield; and

- Ceramic-fiber thermal blanket.

Features of each of these components are summarized below.

\subsubsection{Design Features}

The Model 9975-96 Package has been designed to provide a containment system that can withstand loading resulting from NCT, as well as those associated with HAC.

Specifically, the Model 9975-96 Package is designed to:

- Withstand loads resulting from handling, transportation, and accidents;

- Provide double-containment under NCT that is leaktight to less than $10^{-7} \mathrm{std} \mathrm{cm}^{3} / \mathrm{sec}$ air as measured in accordance with American National Standards Institute (ANSI) ANSI N14.5; ${ }^{[2-4]}$

- Provide double containment under HAC. Each containment vessel will remain leaktight after an accident by demonstrating a post-accident leak rate of less than $10^{-7} \mathrm{std} \mathrm{cm} / \mathrm{sec}$ air;

- Include a leak-test port on the closure for post-load leakage tests;

- Protect the containment vessels from heat in a hypothetical fire;

- Provide cushioning to prevent mechanical damage to the containment in the event of impact; and

- Accept a 4.92-inch-diameter, plutonium storage container;

Table 2.3.1 provides a data summary of the important components of the Model 9975-96 Package. 
Table 2.3.1 Data Summary of Components of the Model 9975-96 Package

\begin{tabular}{|l|c|}
\hline \multicolumn{1}{|c|}{ Item } & Model 9975-96 \\
\hline Drum Material & SA-240 \\
\hline Drum size, gallons & 35 \\
\hline PCV & Yes \\
\hline SCV & Yes \\
\hline Lead shield & Yes \\
\hline Air shield and thermal blanket & Yes \\
\hline Fiberboard insulation & Yes \\
\hline
\end{tabular}

The Model 9975-96 Package has no lifting or tie-down components, but does have a lead shield whose structural integrity depends on the structural performance of the Celotex ${ }^{\text {TM }}$, aluminum honeycomb, and bearing plates. The lead is only required to reduce radiation dose under NCT. The package can meet the higher dose limit allowed following the HAC without lead shielding.

\subsubsection{Design Criteria}

The design and fabrication of the design of the Model 9975-96 Package are in accordance with 10 CFR 71; ${ }^{[2-2]} 49$ CFR 173 through 178; ${ }^{[2-5]}$ IAEA Safety Standard Series No. TS-R-1 (Safety Requirements); ${ }^{[2-3]}$ and Section III, Subsection NB of the ASME B\&PV Code, 2004 Edition. ${ }^{[2-6]}$ The compliance of the structural design of the Model 9975-96 Package is mainly based on more than 30 years testing and operational experience of the Model 9975-85 Package and similar/related packages. When structural analysis of the containment vessel was performed in support of the test findings, the analysis was conducted in accordance with the methodology of stress criteria specified in ASME Code Section III, Division 1, Subsection NB, and the Regulatory Guides 7.6 $6^{[2-7]}$ and 7.8. ${ }^{[2-8]}$ Identical selected analyses were performed on the Model 9975-96 Package and the Model 9975-85 Package to demonstrate that the structural performance of the package is practically unchanged by the slight design modifications from the Model 9975-85 Package to the Model 9975-96 Package.

The design criteria for NCT and HAC loadings are from packaging requirements based on content activity levels defined in Figure 2-2 of the Packaging Review Guide. For the package considered, activity levels of the plutonium product exceed 3,000 $\mathrm{A}_{2}$ and, therefore, the package is classified as Category I. The design information source or design specification of the principal components are listed in Table 2.3.2. 
Table 2.3.2 Critical Component Design Criteria

\begin{tabular}{|c|c|}
\hline Component & Design Information Source \\
\hline Drums & 49 CFR 178, Subpart L \\
\hline $\begin{array}{l}\text { Insulating and Impact Absorbing } \\
\text { Material }\end{array}$ & $\begin{array}{l}\text { Cane/softwood fiberboard per ASTM } \\
\text { Specification C } 208 ; \text { Density: nominally } \\
15 \text { pounds per cubic foot }\end{array}$ \\
\hline Primary Containment Vessel & $\begin{array}{l}\text { Section III, Subsection NB of the ASME } \\
\text { B\&PV Code, } 2004 \text { edition, } 900 \text { psig at } \\
300^{\circ} \mathrm{F}, \mathrm{SS} 304 \mathrm{~L}\end{array}$ \\
\hline Secondary Containment Vessel & $\begin{array}{l}\text { Section III, Subsection NB of the ASME } \\
\text { B\&PV Code } 2004 \text { edition, } 800 \text { psig at } \\
300^{\circ} \mathrm{F}, \text { SS } 304 \mathrm{~L}\end{array}$ \\
\hline Containment Vessel O-ring Seals & $\begin{array}{l}\text { Viton }{ }^{(B)} \text { GLT per Parker Compound No. } \\
\text { V0835-75, or Viton }{ }^{\circledR} \text { GLT-S per Parker } \\
\text { Compound No. VM835-75. Static seal } \\
\text { for continuous service of temperatures of } \\
-40^{\circ} \mathrm{F} \text { to } 400^{\circ} \mathrm{F} \text {. }\end{array}$ \\
\hline Leak-Test Port Plug & $\begin{array}{l}\text { Pressure Products Industries stainless steel } \\
\text { containment closure, Catalog No. P-110- } \\
034-60\end{array}$ \\
\hline $\begin{array}{l}\text { SCV Impact Absorbers and PCV } \\
\text { Bottom Spacer }\end{array}$ & $\begin{array}{l}\text { Aluminum honeycomb tube, } 0.003 \text {-inch } \\
\text { minimum foil, pre-crushed, crush strength } \\
\text { of } 1500 \pm 500 \text { psi; Hexcel Tube-Core or } \\
\text { equivalent }\end{array}$ \\
\hline Bearing Plate & Aluminum ASTM B-209 \\
\hline
\end{tabular}

\subsubsection{Drums}

The drum of the Model 9975-96 Package is constructed from stainless steel with a bolted-flange closure, manufactured as shown on the drawings in Appendix 1.1 of the SARP. The drum design and fabrication satisfy the requirements of Section III, Subsection NF, of the ASME B\&PV Code, 2004 edition. The drum and its lid are fabricated of 18-gauge (0.048 inches) Type 304L stainless steel. Four $1 / 2$-inch diameter vent holes are drilled into the drum and plugged with plastic BP Caplugs ${ }^{\circledR}$. The plugging device prevents water or moisture from entering the drum through the vent holes under NCT. In the event of a fire, the plugs melt, allowing the drum to vent gases, generated from the insulation, to prevent rupture of the drum. The drum lid is bolted, using $24,1 / 2$-inch high-strength bolts, to a $1 \frac{1}{4}$-inch-wide $\times 1 / 8$-inch-thick angle welded to the top of the drum body. The lid is recessed 0.55 inches. A $1 / 8$-inch thick $\times 1-1 / 4$-inch wide circular ring is welded to the outer section of the lid. The ring serves to reinforce the lid and prevents the lid from shearing away any bolts during an HAC event. Nuts are tack welded to the flange underside to ease assembly operations. The bolts are tightened to $30 \pm 5 \mathrm{ft}-\mathrm{lbs}$ of torque. (Note: No specific tightening sequence is required.) Bolts are then re-tightened to ensure none were missed on the first pass. Four, $1 / 2$-inch pins, asymmetrically positioned on the lid bolt circle, function as an alignment key, restricting lid installation to a single orientation. The pins are drilled with a 5/16-inch diameter hole for installation of a tamper-proof indicating device (TID) 
while the drums are in storage. A 1/8-inch diameter hole is drilled through the shank of each bolt for insertion of a TID during shipping operations. The drum chime includes a non-structural skip weld that serves as a TID to meet the IAEA requirement of demonstrating that the package has not been tampered with during use.

Each package is identified by a stainless steel data plate mounted on the outside of the drum. The plate labeling and mounting requirements are shown on drawings in Appendix 1.1 of the SARP. The Model 9975-96 Package is also affixed with a bar coded steel data plate. The drums will have no paint or other markings.

\subsubsection{Cane/Softwood Fiberboard}

Each drum package is lined with cane/softwood fiberboard that complies with ASTM Specification C208 ${ }^{[2-9]}$ and has a nominal density of $15 \mathrm{lb} / \mathrm{ft}^{3}$. The cane/softwood fiberboard protects the containment vessels during NCT and HAC by providing both impact protection and thermal insulation.

Cane/softwood fiberboard discs for the Model 9975-96 Package are held together with glue. Cutouts (see fiberboard assembly drawings in Appendix 1.1 of the SARP) are provided in the fiberboard discs at the top and bottom of the SCV to prevent or minimize tearing of fiberboard discs during HAC drops. Cutouts also help in providing softer impacts, which result in lower impact $g$ values.

\subsubsection{Containment vessels}

The containment vessels are sealed with dual concentric elastomer O-rings (Parker O-ring Compound V0835-75, VM835-75, or equivalent). The containment boundary is comprised of the containment vessel body, the cone-seal plug, outer O-ring, and leak-test port plug. An evacuation port is located between the O-rings to facilitate post-load leakage testing. A package assembly verification air leak rate of $10^{-3} \mathrm{std} \mathrm{cm}^{3} / \mathrm{s}$ must be demonstrated before the package is released for transport (refer to Chapter 4 of the SARP). This air leak rate assures effective Oring sealing. After the leak test, the evacuation port is sealed with an approved pressure plug and gland nut and then leak tested.

The requirements specified in 10 CFR 71.73(c) requires that the containment system be immersed in water such that the external pressure is equivalent to at least a 50-foot head of water, which equates to an external pressure of 21 psig. Immersion tests are described in Section 2.7.6 of the SARP.

To verify the capability of the system to maintain structural integrity, 10 CFR 71.85 (b) requires that the containment vessels be tested at an internal pressure at least $50 \%$ higher than the Maximum Normal Operating Pressure (MNOP) when MNOP exceeds 5 psig. Pressure tests to meet this requirement are described in Section 2.6.1.1 of the SARP.

The containment vessels of the Model 9975-96 Package are fabricated in accordance with ASME B\&PV, Section III. The design analysis for internal pressure and temperature loadings is performed in accordance with ASME Section III, Subsection NB as explained in the opening paragraph of Section 2.1.2. The Model 9975-96 Package has double containment vessels. The inside diameter of the PCV is sized to accept a 4.92-inch-diameter, plutonium storage container. 


\subsubsection{Air Shield}

A 24-gauge (0.0239-inch) thick stainless steel air shield is provided at the top of the Model 9975-96 Package to prevent air from coming into contact with fiberboard above the containment vessel during a fire accident and thus prevents higher temperatures near the closure seal of the containment vessels. The air shield design incorporates a gap of approximately 1/8-inch all around the shield, so that combustible gases can flow around and escape through the vents. From a structural standpoint, the shield is thin enough that it does not affect the energyabsorbing capacity of the fiberboard.

\subsubsection{Weights and Centers of Gravity}

The nominal component weights and the maximum content weights of the Model 9975-96 Package are provided in Table 2.3.3. The weight of the contents of the actual packages will be less. Packaging drop tests were performed at the approximate gross weight provided in Table 2.3.3.

The Center of Gravity of the Model 9975-96 Package is located on the longitudinal centerline, approximately $17 \frac{1}{2}$ inches from the bottom end.

Table 2.3.3 Model 9975-96 Package Component Weights

\begin{tabular}{|l|c|}
\hline \multicolumn{1}{|c|}{ Model 9975-96 Components } & $\begin{array}{c}\text { Weights } \\
\text { (lbs) }\end{array}$ \\
\hline 35-gal Drum and Insulation (Overpack) & 127 \\
\hline Primary Containment Vessel (nominal) & 34 \\
\hline Secondary Containment Vessel (nominal) & 56 \\
\hline $\begin{array}{l}\text { Aluminum Honeycomb Spacers (Impact } \\
\text { Absorbers) }\end{array}$ & 1 \\
\hline Lead Shielding Material & 142 \\
\hline Packaging Net Weight (maximum) & 370 \\
\hline Contents (maximum) & 44.4 \\
\hline Package Gross Weight (maximum) & 404 \\
\hline
\end{tabular}

\subsubsection{Conclusions}

- The Structural review confirmed that the text and sketches, describing the structural design features, are consistent with the engineering drawings and the models used in the structural evaluation.

- The criteria for design of the Model 9975-96 Package are in accordance with 10 CFR 71; 49 CFR 173 through 178; IAEA Safety Standard Series No. TS-R-1; and Section III, Subsection NB of the ASME B\&PVC, 2004 edition.

- Local buckling for the containment vessels is evaluated to the requirements of the ASME Code. Specifically, Code Case N-284 ${ }^{[2-10]}$ is used to evaluate the containment vessels for buckling. 
- To avoid brittle fracture problems, the selection of all material components was based upon the guidance provided by NRC Regulatory Guide $7.11 .^{[2-11]}$

- The Staff has confirmed that the application identifies the established codes and standards, which are judged by the Staff to be appropriate for the intended purpose and are properly applied.

\subsubsection{Materials of Construction}

\subsubsection{Material Specifications and Mechanical Properties}

The material specifications for the packaging components are provided in Table 2.4 of the SARP. Table 2.3.4 lists some of these components and specifications. These specifications are also provided in Appendix 1.1 of the SARP. The mechanical properties of the packaging materials are presented in Tables 2.5 through 2.9 of the SARP. Design temperature ranges are listed to establish allowable stresses, used in containment vessel design calculations and provided in Section 2.6.1.1 of the SARP. ASME Section III, Subsection NB allowable stresses for the containment vessels are provided in Table 2.10 of the SARP.

Mechanical properties are obtained from the ASME B\&PV Code, Section II, Part D, 2004. These properties are given from $-20^{\circ} \mathrm{F}$ and above. However, the lowest design temperature is $-40^{\circ} \mathrm{F}$ per $10 \mathrm{CFR} 71$ (see Table 2.5 of the SARP). In general, the mechanical properties, such as yield strength and tensile strength, increase with decreasing operating temperature and, therefore, are not a concern. However, fracture toughness decreases as the operating temperature decreases.

It is indicated in NRC Regulatory Guide $7.11,{ }^{[2-11]}$ that the austenitic steels are not susceptible to brittle fracture at transport temperatures and, therefore, failure due to brittle fracture in containment vessels at $-40^{\circ} \mathrm{F}$ is not a concern.

Table 2.3.4 Packaging Material Specifications

\begin{tabular}{|l|l|}
\hline \multicolumn{1}{|c|}{ Component } & \multicolumn{1}{c|}{ Specifications } \\
\hline Drum & 18-gauge stainless steel, Type 304L, ASME SA-240 \\
\hline Air Shield & 24-gauge stainless steel sheet, 300 series, ASME SA-240 \\
\hline Insulation & Cane/softwood fiberboard, Celotex, $14-16 \mathrm{lb} / \mathrm{ft}^{3}$, ASTM C208 \\
\hline Containment Vessels & Type 304L, ASME SA-312, SA-403, and SA-479 \\
\hline Bearing Plates & Aluminum, type 1100, ASTM B209 \\
\hline Lead Shielding & Lead, ASTM B749 \\
\hline Drum Vent Plugs & Caplugs ${ }^{\mathbb{R}}$, Model BP-1/2, Protective Closures, Co., Inc. \\
\hline Drum Bolts & $1 / 2$-13UNC-2A $\times 1.25$, ASME SA-320, Grade L7 \\
\hline Drum Nuts & Hex nut, $1 / 2-13 U N C-2 B$, ASME SA-194, Grade 8 \\
\hline Drum Washers & $1 / 2$-inch hardened circular washer, ASTM F-436 \\
\hline
\end{tabular}

Table 2.3.4 Packaging Material Specifications (Contd.)

\begin{tabular}{|l|c|}
\hline \multicolumn{1}{|c|}{ Component } & \multicolumn{1}{c|}{ Specifications } \\
\hline Angle & 1.25 in $\times 1.25$ in. $\times 0.125$ in. thick angle, 304 or $304 \mathrm{~L}$ stainless steel, \\
\hline
\end{tabular}




\begin{tabular}{|c|c|}
\hline & ASME SA-479 \\
\hline Pin & 304 or 304L stainless steel, ASME SA-479 \\
\hline Reinforcing Ring & $\begin{array}{l}20.85 \text { in. OD } \times 1.25 \text { in. wide } \times 0.125 \text { in. thick, } 304 \text { or } 304 \mathrm{~L} \text { stainless } \\
\text { steel, ASME SA- } 479 \text { bar }\end{array}$ \\
\hline Thermal Blanket & $\begin{array}{l}\text { Thermal Ceramics, Firemaster }{ }^{\mathbb{R}} \text { Encapsulated Blanket, Kaowool } \\
\text { Blanket Core }\left(6 \mathrm{lb} / \mathrm{ft}^{3}, 0.5 \text {-in. thick, } 12 \text {-in. diameter fully }\right. \\
\text { encapsulated in } 2 \mathrm{Mil} \text { stainless steel, diameter not to exceed } 18 \\
\text { inches }\end{array}$ \\
\hline Cone Seal Plug & 304L stainless steel, ASME SA-479 \\
\hline Cone Seal Nut & Nitronic-60 Stainless Steel alloy. UNS-S21800 alloy, ASME SA-479 \\
\hline Leak-Test Port Plug & PPI Catalog No. P-110-034-60, stainless steel \\
\hline Gland Nut & PPI Catalog No. P-130-246-60, stainless steel \\
\hline Retaining Ring & Commercial, Waldes Truarc \#5108-125 \\
\hline Grease & KRYTOX $^{\beta}$ fluorinated grease by E.I. du Pont, 240 AC \\
\hline O-rings & $\begin{array}{l}\text { Parker Viton }{ }^{B} \text { GLT Compound No. V0835-75 or Viton }{ }^{B} \text { GLT-S } \\
\text { Compound No. VM835-75, Parts AS-568-252 and AS-568-244 }\end{array}$ \\
\hline $\begin{array}{l}\text { SCV Top and Bottom } \\
\text { Impact Absorbers and } \\
\text { PCV Bottom Spacer }\end{array}$ & $\begin{array}{l}\text { Aluminum honeycomb tube. Minimum foil thickness is } 3 \text { mil. } \\
\text { Honeycomb crush strength } 1500 \pm 500 \text { psi (pre-crushed). Hexcel } \\
\text { Tube-Core or equivalent }\end{array}$ \\
\hline PCV Sleeve & Aluminum tubing, Type 6061-T6 \\
\hline 3013 Top Spacer & Aluminum tubing, Type 6061-T6 \\
\hline Shielding Lid & Aluminum, Type 1100, ASTM B-209 \\
\hline Shielding Lid Screws & 1/4-20UNC-2A × 3/4, ASME SA-320, Grade B8, Class 1 \\
\hline
\end{tabular}

\subsubsection{Conclusions}

- The material properties are appropriate for the load conditions (e.g., static or dynamic impact loading, hot or cold temperatures, and wet or dry conditions). Because the Celote ${ }^{\mathrm{TM}}$ insulating material can degenerate over time under wet conditions, drum overpacks are designed to minimize the infiltration of water under NCT.

- The temperatures at which allowable stress limits are defined are consistent with minimum and maximum service temperatures.

- The force-deformation properties for the cane-based Celotex ${ }^{\mathrm{TM}}$ energy-absorbing material are based on appropriate test conditions and temperatures.

- The materials of structural components have sufficient fracture toughness to preclude brittle fracture under NCT and HAC.

- The Staff has verified that the materials and coatings of the package will not produce significant chemical or galvanic reactions among packaging components, among packaging contents, or between the packaging components and the package contents.

- The possible generation of hydrogen due to radiolysis of the plastic bags has been addressed in Appendix 3.6 to Chapter 3 of the SARP. 


\subsubsection{Fabrication, Assembly, and Examination}

The Staff has confirmed that appropriate fabrication specifications are prescribed by codes or standards, and that the code or standard is identified on the engineering drawings, or in the text of the SARP. For the containment vessel components, the fabrication meets the requirements of the ASME B\&PV Code, Section III, Subsection NB. For components for which no fabrication code or standard is specified, control of the fabrication will be maintained by implementation of the Quality Assurance Plan through the procedural methodology described in Chapter 9.

The Staff has confirmed that the examination methods and acceptance criteria are dictated by the same code or standard used for the fabrication of a component. For components, for which no fabrication code or standard is specified, the examination will be controlled by implementation of the Quality Assurance Plan through procedural methodology described in Chapter 9.

\subsubsection{General Considerations for Structural Evaluations}

Structural evaluations of the package were performed by full-scale testing of prototype packages. The testing program was supplemented by analysis to extrapolate test conditions to other credible HAC and NCT conditions.

\subsubsection{Evaluation by Test}

- The Staff considered the description of the surface (e.g., material, mass, dimensions) used for the free drop and confirmed that it represents an essentially unyielding surface as specified in $\$ 71.73(\mathrm{c})(1)$.

- The Staff considered the description of the steel bar (e.g., material, dimensions, orientation, method of mounting) used for the puncture test and confirmed that it is securely attached to an essentially unyielding surface, has sufficient length to cause maximum damage to the package, and meets the other specifications of $\S 71.73(\mathrm{c})(3)$.

- The Staff verified that the test specimen had been fabricated using the same materials, methods, and quality assurance as specified in the design. The Staff identified differences between the materials and evaluated the effects in the application. Substitutes for the contents have the same representative weight as the actual contents.

- The Staff verified that the selected drop orientations consider the orientations for which maximum damage is expected, and that the selection was justified.

- The Staff verified that all test results are evaluated and their implications interpreted, including both interior and exterior damage of the test article. Unexpected or unexplainable test results, indicating possible testing problems or non-reproducible specimen behavior have been discussed and evaluated.

- The Staff evaluated the appropriate videos and/or photos of the tests.

- The Staff verified that the margin of safety of the package design has been adequately evaluated.

- The Staff addressed the criteria for evaluating pass/fail for the test conditions. The test results have been compared with these criteria. 


\subsubsection{Evaluation by Analysis}

- The Staff verified that a clear description of the calculations, and all assumptions, are included.

- The Staff verified that the models and material properties were appropriate for the load combinations considered, that the material properties (e.g., elastic, inelastic) were consistent with the analysis methods, that the application justified the strain rate at which the properties were determined, and that the analysis considered true stress-strain or engineering stress-strain, as applicable.

- The Staff has confirmed that bounding dynamic analyses were performed and that dynamic amplification of component stresses has been adequately addressed.

- The Staff is satisfied that the most unfavorable drop orientations were chosen for the simulated 30-ft drops.

- The Staff has confirmed that the analyses adequately account for varying impact-loading transmission to the contents, resulting in variable test conditions.

- The Staff verified that the computer codes, if applicable, are appropriately used and benchmarked.

- The Staff verified that the response of the package to loads, in terms of stress and strain to components and structural members, is shown, and that the structural stability of individual members, as applicable, was evaluated.

- The Staff examined the summary table of the results of the analyses, compared the results with the acceptance criteria provided, and verified that the acceptance criteria have been met, and the criteria are in accordance with appropriate codes and standards.

\subsubsection{Structural Evaluation for Normal Conditions of Transport}

\subsubsection{Heat}

- If exposed to direct radiation at $100^{\circ} \mathrm{F}$ ambient temperature, the drum outer surface and containment vessel assembly (with the source) will reach maximum temperatures as shown in Table 3.2 of the SARP. These temperatures are consistent with those in the Thermal Evaluation Chapter.

- The review also verified that any differential thermal expansions and possible geometric interferences have been considered and that the stresses are within the limits for normal condition loads.

- Structural adequacy of the containment vessels for prolonged service under hightemperature environments is demonstrated by comparison with the test results from the tests conducted on containment vessels of the Model 9965 and Model 9968 Packages. During the test, the specimens were pressurized to 1,000 psig and held at a temperature of $600^{\circ} \mathrm{F}$ for 16 hours. At the conclusion of the test, helium leakage from the containment vessels was not detectable with a helium detector. The test results show that the O-rings meet the leakage criteria with an internal pressure of 1,000 psig (which is far greater than the MNOP) and a temperature of $600^{\circ} \mathrm{F}$ for 16 hours. Interpolation of the test results 
indicates that the containment will remain leaktight for approximately 1,000 hours at the $500^{\circ} \mathrm{F}$ design temperature, which is found to be acceptable.

\subsubsection{Cold}

- A regulatory cold test required per 10 CFR 71 was performed on the Model 9965 Package PCV at $-40^{\circ} \mathrm{F}$. A helium leakage test was conducted on the PCV, per NRC Regulatory Guide $7.4^{[2-12]}$ and ANSI N 14.5, 1987, using the bell jar method. The PCV

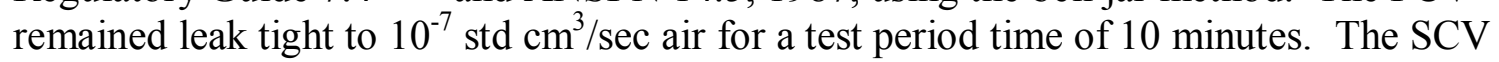
is nearly identical to the PCV in design, with the exception of a slightly larger diameter and length. The cold test results for the PCV are applicable to the SCV as well. The temperatures under the cold test condition are consistent with the Thermal Chapter. The cane fiberboard assembly properties at $-40^{\circ} \mathrm{F}$ lead to load/deflection data that show a significant stress spike during impact loading. However, the duration of the spike is too short to cause any significant stress amplification in the containment vessels. Therefore, containment vessel response to impact loads at $-40^{\circ} \mathrm{F}$ will be similar to the response at room temperature.

- The packages contain no liquids or other materials that could freeze or otherwise be adversely affected by ambient temperatures of $-40^{\circ} \mathrm{F}$.

- The Staff has verified that no component stress allowables are exceeded by normal condition loading.

\subsubsection{Reduced External Pressure}

- Reducing the external pressure to 3.5 psia combined with maximum internal pressurization could cause increased pressure loading on the containment vessel walls. An analysis of the vessels for an internal pressure differential of 150 psi was conducted. This analysis bounds the possible effects of reduced external pressure.

- For the Model 9975-96 Package, the SCV experiences the effect of the reduced external pressure. For these vessels, the maximum pressure differential will be $102.2 \mathrm{psi}$ if external pressure of 3.5 psia is assumed. This pressure differential is enveloped by the internal design pressure differential of 150 psi used in the analysis.

- The drums are protected from reduced external pressure transients by the vent holes covered by Caplugs ${ }^{\circledR}$.

- It is determined that the application adequately evaluates the package design for the effects of reduced external pressure equal to $25 \mathrm{kPa}(3.5 \mathrm{psi})$ absolute and that the application considers the greatest possible pressure difference between the inside and outside of the package.

\subsubsection{Increased External Pressure}

- Increased external pressure to 20 psia combined with minimum internal pressurization will not cause localized buckling of the containment vessel walls. A buckling analysis for the vessels, per ASME Code Case N-284, for an external pressure differential of 20 psi was conducted. 
- The drums are protected from an increased external pressure transient by the cane/softwood fiberboard which is capable of withstanding an additional load of more than 5.3 psi (=20 psi-14.7 psi).

- It is determined that the application adequately evaluates the package design for the effects of increased external pressure equal to $140 \mathrm{kPa}(20 \mathrm{psi})$ absolute. In the evaluation, the application considered this loading condition in combination with minimum internal pressure, the greatest possible pressure difference between the inside and outside of the package as well as the inside and outside of the containment system, and the possibility of buckling.

\subsubsection{Vibration}

A random vibration analysis, based on power spectral density for the SST, was performed to demonstrate that vibration and shock loadings are small and would not cause any fatigue concerns. Though the analysis neglected the load transmission characteristics of the vehicle's suspension, the application indicates that similar packaging (Department of Transportation [DOT] Specification 6M) has withstood years of transport with no significant damage occurring from normal vibration. The containment vessels for the application are smaller than the largest vessels permitted by DOT Specification 2R. Therefore, the containment vessels are less susceptible to vibration damage than the DOT Specification 2R containment vessel. The cone closure is tightened to a predetermined torque, which results in the closure joint components fitting metal-to-metal. The compressed O-rings and the metal friction of the closure thread lock the joint, preventing loosening from vibration. Since the containment vessel components have the same coefficient of thermal expansion, no thermal loosening of the cone-seal nut will occur. Use of required torque values over several years of successful operation has verified that vibration, caused by NCT, will not result in loosening the cone-seal nut.

Therefore, it is determined that the application adequately evaluated the package design for the effects of vibration normally incident to transport. A fatigue analysis was provided for highly stressed systems, considering the combined stresses due to vibration, temperature, and pressure loads, and closure bolt preload.

\subsubsection{Water Spray}

Water spray would cause no damage to the outer drum. The stainless steel drum of the Model 9975-96 Package is not affected by corrosion. The drum closure is weather sealed, along with the four, sealed vent holes. The containment vessels, which are fabricated from austenitic stainless steel, are not affected by water. A corrosion study shows that water-induced corrosion is insignificant in this package.

\subsubsection{Free Drop}

The application indicates that a free drop through a distance of 4 feet onto a flat, essentially unyielding, horizontal surface, striking the surface in a position for which maximum damage is expected, would not reduce the effectiveness of the packaging. This is indicated by the fact that no drum and containment vessel failures are observed as a result of the $30-\mathrm{ft}$ drop tests performed on the Model 9975-85 Package with the 4-ft drop tests performed prior to the 30-ft drops. Table 2.20 of the SARP identifies the SARP sections in which the tests supporting this indication are described. Section 2.6.7 of the SARP presents only the supporting analytical 
argument based on the 55-ft special-drop analysis result. The present Staff reviewing the Model 9975-85 Package has questioned the validity of this argument. The present Staff reviewing the Model 9975-96 Package also rejects the argument as adequate evidence.

\subsubsection{Corner Drop}

This test is not required for the Model 9975-96 Package because the total weight of the package exceeds $220 \mathrm{lb}$.

\subsubsection{Compression}

A compression test using a load of 2,061 pounds on the top of the Model 9975-85 Package for a minimum of 24 hours yielded no effect on the package.

\subsubsection{Penetration}

Penetration testing was performed on a modified $6 \mathrm{M}$ package with a drum overpack similar to the Model 9975-96 Package.

The application indicates that a 13-lb. vertical steel rod, 1-1/4 inches in diameter was dropped from a height of 4 feet onto the most vulnerable surface of each of several different sizes of drums with the cane fiberboard in place for the modified 6M package. Maximum deflection of the drum surface was $1 / 4$ inch. No rupture of the drum or damage to the insulation occurred.

\subsubsection{Structural Requirements for Fissile Material Packages}

The SARP structural analysis demonstrates that the following conditions are met for fissile material packages:

- The form of the contents is not substantially altered. (Note that the SARP criticality evaluation assumes the contents are in the most reactive configuration.)

- The containment system precludes the in-leakage of water following NCT and HAC tests.

- The total effective packaging on which nuclear criticality safety is assessed is not reduced following NCT tests.

- The total effective spacing between fissile contents and the outer surface of the package is unchanged following NCT tests.

- The outer surface of the package does not have an opening large enough to pass a $10-\mathrm{cm}$ cube following the HAC test.

\subsubsection{Structural Evaluation for Hypothetical Accident Conditions}

\subsubsection{Free Drop}

- Structural integrity of the packages against 30-ft drops onto a flat, essentially unyielding horizontal surface was demonstrated by prototype testing. The unyielding impact surface is constructed from a 6.25-inch thick armor plate, a specialty, very-high-strength steel used in armored vehicles to resist penetration from high-velocity impacts, approximately 5 feet square. The plate is anchored in a 30-inch-thick reinforced concrete slab that is insulated from the existing building concrete floor. The impact target weighs 
approximately $15,600 \mathrm{lb}$, which is nearly forty times the weight of the Model 9975-96 Package. The plate is level with the surrounding floor in the test facility. This impact surface has been used for a number of years for drop testing of the nuclear material packages. There is no visible evidence of bending, cracking, or movement of the impact surface relative to the surrounding floor.

- For the Model 9975-96 Package, three drop tests (a $10^{\circ}$ slap down, and two shallow $\left(17.5^{\circ}\right.$ and $\left.22.5^{\circ}\right)$ side impacts to the closure end were conducted at ambient normal, i.e., test facility environment, conditions. The acceptance of the package against $30-\mathrm{ft}$ drop impacts is based on these three tests for ambient normal conditions and finite element analysis (FEA) for high/low temperature desiccated, normal, and moist (saturated) environmental conditions.

- Earlier testing of prototype packages provided information on pressure vessel and aluminum honeycomb response to HAC tests.

- Extensive dynamic impact tests were performed on the cane fiberboard Celotex ${ }^{\mathrm{TM}}$ impact cushioning/insulating material incorporated in the Model 9975-85 Package. For use in the Model $9975-85$ Package, $1 / 2$-inch Celotex ${ }^{\mathrm{TM}}$ sheets were cut to form by abrasive waterjets, and bonded together by wood glue. The test samples, cut from the glued assemblies used in the package, were pre-conditioned to represent the high/low temperature desiccated, normal, and moist (saturated) environmental conditions that were not evaluated by physical drop testing of the Model 9975-85 Package. The results of this testing effort were used to benchmark and validate the material models used in the FEA simulated 30-ft drops at high/low temperature desiccated, normal, and moist (saturated) environmental conditions.

- The FEA simulations found that impact loading of the containment vessels during a $30-\mathrm{ft}$ side drop is sensitive to the widths of the glue layers in the bonded Celotex ${ }^{\mathrm{TM}}$ assemblies at high/low temperature desiccated and low temperature moist (saturated) environmental conditions. However, further finite element analysis on a package modified by excluding the outer drum and Celotex ${ }^{\mathrm{TM}}$ was performed. A simulated 55- $\mathrm{ft}$ drop was performed and the results show that no buckling occurred and there was no extensive plastic deformation in the closure region. Therefore, based on actual physical testing and finite element analysis, it is demonstrated that the Model 9975-96 Package can withstand a 30-ft drop under all environmental conditions required by 10 CFR 71 and maintain acceptable structural integrity with adequate margin.

\subsubsection{Crush}

A crush test is not applicable to this package. This is due to the package density being greater than $1,000 \mathrm{~kg} / \mathrm{m}^{3}$.

\subsubsection{Puncture}

Three puncture tests were performed on Model 9975-85 Package. The case judged, in situ, as being most vulnerable to further damage via puncture bar impact was the case where a local closure buckling occurred in the $30-\mathrm{ft}$ slap-down drop test. A 1- $\mathrm{ft}$ angled top-down drop on the 40-inch puncture bar was performed to exploit the lid buckle, and attempt to tear open a gap. 
The test results demonstrate the acceptance of the Model 9975-96 Package as having sufficient margin against failure by puncture.

\subsubsection{Thermal}

Compliance with the thermal requirements of HAC is demonstrated by analysis and by fire testing on packages Model 9973 Package and Model 9975-85 Package. When exposed to $1,475^{\circ} \mathrm{F}$ fire, the drum outer surface and the containment vessel assembly (with the source) will reach the maximum temperatures which are well below the design temperature of $500^{\circ} \mathrm{F}$. Peak temperatures calculated in the thermal analysis were compared with the temperatures recorded during the fire tests on Model 9973 Package and Model 9975-85 Package, and were found to be consistently higher than the test temperatures. The calculated temperatures were then used to calculate peak vessel pressures and stresses. The stresses were found to be within the allowables. Peak temperatures during and after the fire test were consistent with temperatures used to determine the limiting stresses.

\subsubsection{Immersion -Fissile Material}

The construction of the overpack for the Model 9975-96 Package is similar to that of the earlier Model 9966 Package. The water immersion test requirement for these packages is satisfied by the tests done on the Model 9966 Package.

\subsubsection{Immersion-All Packages}

The response of a separate, undamaged specimen subjected to water pressure equivalent to

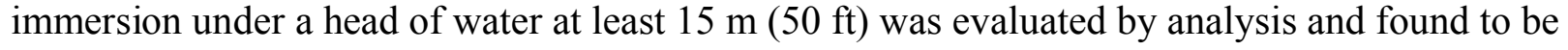
acceptable.

\subsubsection{Lifting and Tie-Down Standards for All Packages}

This package has no lifting or tie-down devices.

\subsubsection{Structural Evaluation of Special Pressure Conditions}

The contents of this package contain no irradiated nuclear fuel.

\subsubsection{Special Requirement for a Type B Packages Containing More Than $10^{5} \mathrm{~A}_{2}$}

The response of a separate, undamaged containment system specimen subjected to an external water pressure of $2 \mathrm{MPa}$ (290 psi) was evaluated by analysis and found to be acceptable.

\subsubsection{Analysis of Pressure Test}

The response of a separate, undamaged containment system specimen subjected to $150 \%$ of its MNOP was evaluated by analysis and found to be acceptable.

\subsubsection{Appendices}

The Appendix includes background calculations and other appropriate supplemental information. In particular, the seven Appendices address:

(i) Selected Packaging Components and Material Data (Appendix 2.1);

(ii) Design Calculations for the 9975 Packaging (Appendix 2.2); 
(iii) 9965 Cone Seal Closure Performance at $-40^{\circ} \mathrm{F}$ (Appendix 2.3);

(iv) Evaluation of 9975 Shipping Container Flange Closure (Appendix 2.4)

(v) 9975 Packaging Comparisons with the 9966, 9967, 9968, 9973, 9974, and 9975 Prototype (Appendix 2.5).

(vi) Dynamic Analysis of 55-ft Drop for 9975 Package with Steel Outer Sleeve on Lead Shielding and without Overpack (R-R2-F-0020-C Shielding Body) (Appendix 2.6).

(vii) Dynamic Analysis of 55-ft Drop for 9975 Package without Overpack (R-R2-F-0020-A Shielding Body) (Appendix 2.7).

\subsection{Evaluation Findings}

\subsubsection{Findings}

Based on review of the statements and representations in the application, the Staff concludes that the structural design has been adequately described and evaluated and that the package has adequate structural integrity to meet the requirements of 10 CFR 71 . By meeting the requirements of 10 CFR 71, the package also meets the requirements of IAEA Safety Standard Series No. TS-R-1. It is recommended that in the next revision of the SARP, the following corrections/improvements be implemented:

- The tensile-strength unit in Table 2.7 for cane fiberboard to be corrected to $\mathrm{lb} / \mathrm{ft}^{2}$ (psf);

- Section 2.6.7 of the SARP, Free Drop, to be revised to include past 4-ft drop-test results as the primary evidence of compliance with the regulation;

- In Table 2.21 of the SARP, the Calculated-HAC-Pressure values for PCV and SCV to be interchanged to match the PCV and SCV values given in Table 3.3 of the SARP;

- A requirement to be added to the regular maintenance procedures to inspect for and record indications of the formation of lead carbonate or other corrosion products/deposits on the lead shield; and

- The Applicant shall report any unusual behavior of the Celotex ${ }^{\mathrm{TM}}$ overpack identified in the SRNL Celotex ${ }^{\mathrm{TM}}$-overpack surveillance program.

\subsubsection{Conditions of Approval}

- Maximum weight of the package shall not exceed $183 \mathrm{~kg}$ (404 pounds).

- Maximum weight of the contents shall not exceed $20.1 \mathrm{~kg}$ (44 pounds).

\subsection{References}

[2-1] Washington Savannah River Company, Safety Analysis Report for Packaging, Model 9975, S-SARP-G-00003, Revision 0, Savannah River Packaging Technology, Savannah River National Laboratory (January 2008).

[2-2] Nuclear Regulatory Commission, 10 CFR Part 71, Compatibility with IAEA Transportation Standards (TS-R-1) and Other Transportation Safety Amendments; Final Rule, 69 F.R. 3698, pp. 3698-3814, January 26, 2004, as amended. 
[2-3] Regulations for the Safe Transport of Radioactive Material, Safety Requirements, IAEA Safety Standards Series No. TS-R-1, 1996 Edition (As Amended 2003) International Atomic Energy Agency, Vienna, Austria (July 2004).

[2-4] Institute of Nuclear Materials Management, American National Standard for Radioactive Materials, Leakage Tests on Packages for Shipment, ANSI N14.5-1997, New York.

[2-5] Department of Transportation, Research and Special Programs Administration, 49 CFR Parts 171, 172, et al., Hazardous Materials Regulations; Compatibility with the Regulations of the International Atomic Energy Agency; Final Rule, 69 F.R. 3632, January 26, 2004, as amended.

[2-6] ASME Boiler and Pressure Vessel Code, Section III, Rules for construction of Nuclear Power Plant Components, Division 1, American Society of Mechanical Engineers, New York, New York (2004).

[2-7] U.S. Nuclear Regulatory Commission, Design Criteria for the Structural Analysis of Shipping Package Containment Vessels, Regulatory Guide 7.6, Revision 1, March 1978.

[2-8] U.S. Nuclear Regulatory Commission, Load Combinations for the Structural Analysis of Shipping Packages for Radioactive Material, Regulatory Guide 7.8, Revision 1, March 1989.

[2-9] American Society for Testing and Materials, Standard Specification for Cellulosic Fiber Insulating Board, ASTM C208-95 (Re-approved 2001), Philadelphia, Pennsylvania (1995).

[2-10] American Society for Mechanical Engineers, Metal Containment Shell Buckling Design Methods, Code Case N-284, Section III, Division 1, Calls MC (August 25, 1980).

[2-11] U.S. Nuclear Regulatory Commission, Fracture Toughness Criteria of Base Material for Ferritic Steel Shipping Package Containment Vessels with a Maximum Wall Thickness of 4 Inches (0.1 m), Regulatory Guide 7.11, June 1991.

[2-12] U.S. Nuclear Regulatory Commission, Leakage Tests on Packages for Shipment of Radioactive Materials, Regulatory Guide 7.4, June 1975. 


\section{THERMAL EVALUATION}

\subsection{Areas of Review}

Chapter 3, Thermal Evaluation, of the Safety Analysis Report for Packaging, Model 9975, Model 9975, B(M)F-96, was reviewed for the adequacy of the thermal design features of the Model 9975-96 Package. ${ }^{[3-1]}$ The review includes an evaluation of the SARP with respect to the requirements specified in 10 CFR 71, ${ }^{[3-2]}$ and in International Atomic Energy Agency (IAEA) Safety Standards Series No. TS-R-1. ${ }^{[3-3]}$

Included in the Thermal Evaluation were the following:

\subsubsection{Description of Thermal Design}

- Design Features

- Decay Heat of Contents

- Codes and Standards

- Summary Tables of Temperatures

- Summary Table of Maximum Pressures

\subsubsection{Material Properties, Thermal Limits, and Component Specifications}

- Material Properties

- Temperature Limits

- Component Specifications

\subsubsection{General Considerations for Thermal Evaluations}

- Evaluation by Analysis

- Evaluation by Test

- Margins of Safety

\subsubsection{Thermal Evaluation under Normal Conditions of Transport}

- Initial Conditions

- Effects of Tests

- Maximum Normal Operating Pressure

- Maximum Thermal Stresses

\subsubsection{Thermal Evaluation under Hypothetical Accident Conditions}

- Initial Conditions

- Effects of Thermal Tests

- Maximum Temperatures and Pressures 
- Maximum Thermal Stresses

\subsubsection{Thermal Evaluation of Maximum Accessible Surface Temperature}

\subsubsection{Appendices (as applicable)}

- Description of Test Facilities and Equipment

- Test Results

- Applicable Supporting Documents or Specifications

- Analyses Details

\subsection{Regulatory Requirements}

Regulatory requirements of 10 CFR 71 applicable to the thermal evaluation are as follows:

- The package design must be described and evaluated to demonstrate that it satisfies the thermal requirements of 10 CFR 71. [§71.31(a)(1), §71.31(a)(2), §71.33, §71.35(a)]

- The application must identify the established codes and standards used for the package design, fabrication, assembly, testing, maintenance, and use. In the absence of such codes, the application must describe the basis and rationale used to formulate the quality assurance program. [\$71.31(c)]

- The package must be made of materials of construction that assure there will be no significant chemical, galvanic, or other reactions, including reactions due to possible inleakage of water, among the packaging components, among package contents, or between the packaging components and the package. The effects of radiation on the materials of construction must be considered. [\$71.43(d)]

- The package must be designed, constructed, and prepared for transport so that in still air at $38^{\circ} \mathrm{C}\left(100^{\circ} \mathrm{F}\right)$ and in the shade the accessible surface temperature does not exceed $50^{\circ} \mathrm{C}\left(122^{\circ} \mathrm{F}\right)$ in a nonexclusive-use shipment or $85^{\circ} \mathrm{C}\left(185^{\circ} \mathrm{F}\right)$ in an exclusive-use shipment. $[\S 71.43(\mathrm{~g})]$

- The package design must not rely on mechanical cooling systems to meet containment requirements. [\$71.51(c)]

- A fissile material packaging design to be transported by air must meet the requirements of $\S 71.55(f)$.

- The performance of the package must be evaluated under the tests specified in $\$ 71.71$ for normal conditions of transport. [\$71.41(a)]

- The package must be designed, constructed, and prepared for shipment so there would be no loss or dispersal of contents, no significant increase in external surface radiation levels, and no substantial reduction in the effectiveness of the packaging under the tests specified in $\S 71.71$ for normal conditions of transport. [§71.43(f), $§ 71.51(\mathrm{a})(1)]$

- The performance of the package must be evaluated under the tests specified in $\$ 71.73$ for hypothetical accident conditions. [\$71.41(a)] 


\subsection{Review Procedure}

The Model 9975-96 Package SARP includes the information essential for a thermal evaluation including drawings and the content decay heat. Of particular importance is the response of the containment vessel(s) and associated O-rings, the shielding, and the contents of the Model 9975-96 Package to the imposed NCT (10 CFR 71.71) and HAC (10 CFR 71.73). ${ }^{[3-2]}$

\subsubsection{Description of Thermal Design}

\subsubsection{Design Features}

The applicant described the packaging components that control the response of the Model 9975-96 Package to the thermal environment. These components, which primarily include the cane/soft wood fiberboard overpack and the containment vessel(s), are described in sufficient detail in Section 1.2.1 of the Model 9975-96 Package SARP to provide a sufficient basis for the thermal evaluation of the Package.

The primary design features intended to protect the containment vessel(s) and O-rings of all the packages as well as the lead shielding of the Model 9975-96 Package from structural damage and overheating are:

- A cane/soft wood fiberboard overpack confined in a stainless steel drum which acts as impact limiter and insulation during a hypothetical accident;

- The stainless steel pressure vessel with cone seal plug and nut which provides the containment system of the package contents during NCT-and HAC-imposed structural loads. In each containment vessel, two Viton ${ }^{\circledR}$ O-rings (inner O-ring and outer O-ring) are used between the cone seal plug and the vessel to form a leaktight seal. The containment boundary for each vessel is formed by the containment vessel body, the cone-seal plug, outer O-ring and the leak-test port plug; and,

- The containment system of the Model 9975-96 Package utilizes two nested concentric containment vessels due to the double containment regulatory requirement of earlier version of 10 CFR 71.

All contents are packaged in either DOE-STD-3013 cans, ${ }^{[3-4]}$ the LLNL Hex Cans, or nested food-pack cans. For the contents identified in Table 1.2 of the SARP as Content Envelopes C.1, C.2, C.3, C.5, C.6 and C.7, the content cans, the primary containment vessel (PCV) and the secondary containment vessel (SCV) need not be inerted. For plutonium/uranium oxide contents identified as Content Envelope C.4, the inner cans must be inerted to less than 5\% oxygen with helium or nitrogen, and the PCV must be diluted with a minimum of $75 \% \mathrm{CO}_{2}$. For the neptunium oxide contents identified as Content Envelope C.8, the inner cans, the PCV, and the SCV must be inerted to less than 3\% oxygen with argon.

\subsubsection{Contents Decay Heat}

The maximum content decay heat rate for the Model 9975-96 Package is given in Tables 3.4 and 3.7 of the SARP. The maximum allowable decay heat rate for the contents of 19 watts was used in the review of the thermal evaluation of the Model 9975 Package. This conforms to about 640 curies of plutonium isotopes with about 5-MeV alpha decay products. 


\subsubsection{Codes and Standards}

The structural materials used in the package conform to Section III of the ASME B\&PVC. ${ }^{[3-5]}$ The cane/soft wood fiberboard used in the overpack conforms to ASTM Specification C208. ${ }^{[3-6]}$ The cast lead shield material conforms to ASTM B749. ${ }^{[3-7]}$ The plutonium metal and oxide contents defined in Table 1.3 in the SARP conform to the DOE-STD-3013.

\subsubsection{Summary Tables of Temperatures}

The maximum temperatures reached in the Model 9975-96 Package components during NCT are given in Tables 2.15 and 3.2 of the SARP. These temperatures, for a 3013 can, bound the various content configurations described in Figure 1 and Tables 5 and 6 of Appendix 3.3.

The minimum temperature is $-40^{\circ} \mathrm{C}$ based on the assumption that the package is without content heat generation in the shade.

For a $100^{\circ} \mathrm{F}$ environment temperature in the shade, the Model 9975-96 Package has the maximum accessible surface temperature below the limit of $122^{\circ} \mathrm{F}$ allowed for nonexclusive-use shipments.

The applicant presents the maximum temperature in the Model 9975-96 Packaging components during a hypothetical accident fire in Tables 2.21 and 3.2 of the SARP. The post-fire cool-down did include insolation. These results are based on tests as well as analysis of an undamaged Model 9975 Package with a simulated 19-watt content decay heat rate. Table 2 of Appendix 3.4 lists the maximum temperatures of a damaged Model 9975 Package, determined by analysis, with 19-watt content decay heat rate and post-fire insolation, for the lead shield and the secondary containment vessel (including the O-ring). The temperatures of the other components presented in this table have not yet reached their maximum value 4 hours following cessation of the fire. However, the temperatures for NCT bound the maximum temperatures of these components.

\subsubsection{Summary Tables of Maximum Pressures in the Containment System}

The MNOP in the PCV and SCV cavities of the Model 9975-96 Package for NCT are given in Tables 2.14 and 3.3 of the Model 9975-96 Package SARP. The maximum pressures in the Model 9975 Package containment system cavities during a hypothetical accident fire are given in Tables 2.21 and 3.3 of the Model 9975-96 Package SARP.

The pressures in the Model 9975-96 Package containment vessels are lower for the HAC than the MNOP. The initial temperatures prior to the hypothetical accident are based on the absence of insolation, while the temperatures for the maximum normal operating condition are based on insolation on the package surface.

Per 10 CFR 71.4, the package must be designated as a Type B(M), since the MNOP is greater than $700 \mathrm{kPa}$ (100 psig). 


\subsubsection{Material Properties and Component Specifications}

\subsubsection{Material Thermal Properties}

The required thermal properties for all the materials used in the fabricated Model 9975-96 Packaging were presented in Section 3.2 of the Model 9975-96 Package SARP. A small volume of the cane/soft wood fiberboard exceeds the allowable temperature limit of $121^{\circ} \mathrm{C}\left(250^{\circ} \mathrm{F}\right)$ during normal operating conditions. However, the cane/soft wood fiberboard (Celotex ${ }^{\mathrm{TM}}$ ) can be held at $300^{\circ} \mathrm{F}$ for an extended length of time without indication of decomposition (Appendix 3.16). A region of the cane/soft wood fiberboard decomposes during the hypothetical thermal accident resulting in a change of the thermal properties during and following the thermal event. These properties were determined experimentally by the applicant (Hensel and Gromada, $1994^{[3-8]}$ ). The properties were reviewed by the Staff and determined to be acceptable in both detail and accuracy.

\subsubsection{Temperature Limits}

The temperature limits of the lead shield, the primary and secondary containment vessels and their O-rings, and the fiberboard are given in Table 3.1 of the SARP. The pressure limits of the primary and secondary containment vessels are also given in Table 3.1 of the SARP.

\subsubsection{Component Specifications}

The component specifications for the overpack drum, insulation, and containment vessels are presented in the SARP. Included in the component specifications are the emissivity and absorptivity of the overpack drum, the identification of the ASTM Specification C208 and temperature limits of the $15 \mathrm{lb} / \mathrm{ft}^{3}$ cane/soft wood fiberboard insulation, and the temperature limits of the Viton ${ }^{\circledR}$ GLT or Viton ${ }^{\circledR}$ GLT-S fluorocarbon elastomer O-rings used as closure seals.

\subsubsection{General Considerations}

\subsubsection{Evaluation by Analysis}

The applicant performed thermal evaluations using the finite element code $\mathrm{P} /$ Thermal with the pre- and post-processing software package PATRAN. The axisymmetric models were used for each package. The thermal properties of the packaging materials including the lead (where applicable), the insulation, and the air are appropriate for the thermal analyses of the package. The expressions for the various modes of heat transport at the package boundaries are appropriate. The PATRAN-PLUS ${ }^{[3-9]}$ and P/Thermal descriptions are given in Appendix 3.12 of the SARP. The material properties, convection coefficients, radiation surface properties, and internal and solar heat source data input to P/Thermal are also given in Appendix 3.12 of the SARP. The benchmarking of $\mathrm{P} /$ Thermal against a documented shipping package problem is described in Appendix 3.11 of the SARP.

The analyses of the undamaged Model 9975 Package for both the NCT and the HAC fire were benchmarked against experiments as discussed in Appendices 3.1 and 3.2 of the SARP. The analysis of the hypothetical accident fire of the damaged package utilized the cane/soft wood fiberboard thermal properties inferred from experiments. 


\subsubsection{Evaluation by Test}

Tests, described in Appendix 3.5 of the Model 9975-96 Package SARP, were performed on a prototype of the Model 9975 Packaging (described in Appendix 3.1 of the Model 9975-96 Package SARP) not significantly different from the production design with a 21-watt heater to simulate the content decay heat rate. These tests were used to benchmark the analyses of the package. The package was tested for 120 hours in a building with an ambient temperature ranging between $77^{\circ} \mathrm{F}$ and $80^{\circ} \mathrm{F}$. The measured temperatures in the package were used to benchmark the analyses of the Model 9975 Packages for NCT as described in Appendix 3.1 of the Model 9975-96 Package SARP.

Immediately following the test on the Model 9975 Packaging for NCT, the package was tested in a vertical orientation in a radiant heat facility for greater than 30 minutes as described in Appendix 3.5 of the SARP. The temperature of the 35-gallon drum outer confinement vessel exceeded $1,500^{\circ} \mathrm{F}$ for approximately 45 minutes. The insulation that covered the top and bottom of the facility to prevent heat loss, during the heating cycle, was removed, and the package was allowed to cool 15 hours by radiation and natural convection to the ambient air near $100^{\circ} \mathrm{F}$ while remaining in the test facility. A member of the SARP review team witnessed this test. The Staff has determined that is was appropriate not to furnish excess oxygen to replenish the oxygen depletion during the heating portion of this test. The measured temperatures in the package were used to benchmark the analyses of the Model 9975 Package under HAC as described in Appendix 3.2 of the Model 9975-96 Package SARP. The drop and puncture tests of the HAC had not been performed on the prototype Model 9975 Packaging tested.

\subsubsection{Margins of Safety}

The temperatures and pressures for both the NCT and HAC are, with the exception of the cane/soft wood fiberboard, substantially less than the allowable design limits given in Table 3.1 of the SARP. For NCT, the temperature of the cane/soft wood fiberboard may exceed the allowable design limit by only a few degrees over a small, thin volume of material located near the bottom of the secondary containment vessel of a package that sits on an adiabatic surface. This "excess" temperature of the cane/soft wood fiberboard will not adversely affect the package components important to containment, subcriticality, or shielding.

\subsubsection{Thermal Evaluation for Normal Conditions of Transport}

The applicant performed thermal evaluations of the various packages for NCT using analyses benchmarked against the experiment on the Model 9975 Packaging using a 21-watt heater to simulate the content decay heat rate. The use of nominal thermal conductivity properties of the cane/soft wood fiberboard results in the calculation of higher temperature gradients in the insulation than were measured in the experiment. The cane/soft wood fiberboard properties were not adjusted in the analytical model to duplicate the experimental results because the analytical results are conservative, producing higher values of temperatures in the package components important to safety.

The minimum temperature of $-40^{\circ} \mathrm{C}$ in the package occurs when the content decay heat load is zero in an environment at $-40^{\circ} \mathrm{C}$. As noted in Section 2.3.5.2 of this TRR, the Cold condition of $-40^{\circ} \mathrm{C}$ ambient temperature will not result in a degradation of the Model 9975-96 Package. The 304L austenitic stainless steels, used for the containment vessels and the overpacked drum, do 
not have a ductile-to-brittle transition temperature above $-40^{\circ} \mathrm{C}$. The secondary stresses from the differential thermal contraction for the Cold condition are less than those from the differential thermal expansions for the Heat condition.

The applicant performed a thermal evaluation for the Model 9975 Packages under NCT thermal conditions with insolation applied to the surfaces of the package in $100^{\circ} \mathrm{F}$ still air. The insolation is based on the appropriate values given in 10 CFR 71, Section 71(c) for a 12-hour time period. The solar absorptivity of the stainless steel drum surface was assumed to be 1.0 while the surface emissivity was assumed to be 0.21 . The applicant evaluated two 3013 content configurations for shipping plutonium metal and one 3013 content configuration for shipping plutonium oxides in Appendix 17 of the SARP. For each 3013 content configuration, the applicant determined (by analysis) the component temperatures for the package in the shade (steady state) as well as with insolation. The content decay heat rate of 19 watts was used in the analyses of the Model 9975 Packages. The maximum component temperatures are given in Table 3.2 of the SARP as described in Section 3.3.1.4, above. Confirmatory calculations by the Staff of the package surface temperature and the content envelope surface temperature verify that the above results were reasonable and conservative. The steady-state temperatures of the package components during NCT do not compromise the functions of the packaging.

The MNOP in the Model 9975-96 Package primary containment vessel with oxide contents is due to the increased temperature of the cavity air initially at atmospheric pressure and $70^{\circ} \mathrm{F}$ temperature. In addition, the helium from the decay of the plutonium contents or neptunium oxide contents, the decomposition of 25 grams of moisture into hydrogen, and by thermal decomposition of the plastic bags per Appendix 3.14 of the SARP also contribute to the MNOP. The MNOP, calculated by the applicant, is given for the PCV and the SCV in the Summary Table 3.3 of the SARP, and is given in Section 3.3.1.5, above. This pressure, obtained for the case of oxide in food cans, is an upper bound for the containment vessels with metal oxide contents in a 3013 container. As shown in Chapter 2 of this TRR, this pressure does not produce stresses in the confinement vessel that exceed the allowable stress limits. A review of the calculations of the MNOPs confirmed that the pressure results were reasonable and conservative.

Pressures were estimated for the deflagration of the hydrogen, produced from the decomposition of the 25 grams of moisture in a package with the oxide contents in a 3013 container, and are given in Appendix 3.8 of the SARP. The peak pressure in the PCV is less than that given in Summary Table 3.3 of the SARP. The peak pressure in the SCV exceeds that given in Summary Table 3.3, but is substantially less than the design pressure of the SCV. A review of the calculations of the deflagration pressures confirmed that the pressure results were reasonable and conservative.

The potential for detonation of the hydrogen produced from the decomposition of the 25 grams of moisture in a package with the oxide contents in a 3013 container was investigated in Appendix 3.9 of the SARP. The use of an inerted 3013 container to less than $5 \%$ oxygen, with the primary containment vessel diluted by a minimum of $75 \% \mathrm{CO}_{2}$ and with the secondary containment vessel filled with air is sufficient to prevent detonation within either the PCV or $\mathrm{SCV}$. An independent analysis of the maximum cell size to prevent detonation within the 3013 container, the PCV, and the SCV was performed. This analysis confirmed that, with the inerted 3013 container and the primary containment vessel diluted by a minimum of $75 \% \mathrm{CO}_{2}$, 
the maximum cell size is larger than the maximum gaps and free spaces in the PVC and SCV of the Model 9975 Package with 3013 containers or food-pack cans. This is sufficient to prevent detonation within either the PCV or SCV. To the extent that an inert diluent other than $\mathrm{CO}_{2}$ or nitrogen is used, the food-pack cans, the PVC, and the SVC shall be inerted such that the oxygen content in all void spaces is less than $5 \%$ of volume at closure.

The thermal stresses in the Model 9975-96 Package due to the differential thermal expansions between the package components are small as shown in Chapter 2.

The Staff finds that the containment vessels of the Model 9975-96 Package remain fully effective as containment boundaries for the payloads during the NCT or in the event of deflagration of hydrogen gases within the containment vessels. The resultant deformations, if any, of the vessel will not impair the containment, shielding, or criticality functions of the package. The Staff finds that detonation of hydrogen gases within the containment vessels will not occur for an inerted 3013 container, hex can, or food-pack can, the primary containment vessel diluted by a minimum of $75 \% \mathrm{CO}_{2}$ and with the secondary containment vessel filled with air. The Staff also finds that the NCT does not impair the ability of the Model 9975-96 Package to withstand the HAC discussed below.

\subsubsection{Thermal Evaluation of Hypothetical Accident Conditions}

The thermal evaluations of the HAC [10 CFR 71 Section 73(c)(4)] were performed on the Model 9975 Package by test and analyses. The analysis was benchmarked against the experiment on the Model 9975 Packaging that used a 21-watt heater to simulate the content decay heat rate. The use of the nominal cane/soft wood fiberboard thermal conductivity properties results in the calculation of larger temperature gradients in the insulation for the initial conditions than measured in the experiment. For the HAC, the cane/soft wood fiberboard properties were adjusted in the analytical model to duplicate the experimental results to more accurately produce the temperatures measured in the HAC benchmark test of the Model 9975 Package.

The undamaged Model 9975 Package was tested for 120 hours in a building with an ambient temperature ranging between $77^{\circ} \mathrm{F}$ and $80^{\circ} \mathrm{F}$. Immediately following the test on the Model 9975 Packaging, the package was tested in a vertical orientation in a radiant heat facility for greater than 30 minutes. The temperature of the drum surface exceeded $1,500^{\circ} \mathrm{F}$ for approximately 45 minutes. The package was allowed to cool 15 hours by radiation and natural convection to the ambient air near $100^{\circ} \mathrm{F}$ while remaining in the test facility. An analysis was performed to determine the response of the Model 9975 Package to the experimental fire test conditions, based on the initial conditions determined above. The analyses used the thermal properties of the charred and uncharred cane/soft wood fiberboard based on the applicant's high temperature tests, specifically designed and performed to develop thermo-physical property models.

The measured temperatures in the Model 9975 Package were used to benchmark the analyses of HAC for the Model 9975-96 Packages. The calculated internal Model 9975-96 Package temperature histories compare well with the measured histories.

The fire test analyses were modeled as an undamaged package and used the thermal properties of the uncharred and charred cane/soft wood fiberboard based on the applicant's high temperature 
tests specifically designed and performed to develop thermo-physical property models. The analysis of the drum wall temperature compares well with the experimental measurements, demonstrating that the analytical boundary conditions used in the analyses were appropriate. The calculated SCV seal and side temperatures were within $20^{\circ} \mathrm{F}$ greater than the measured temperatures. Because the calculated temperatures overestimated the measured temperatures of the package internals, the analytical models with the appropriate content heat were used to calculate the thermal response of the Model 9975-96 Packages to the regulatory HAC of a 30 -minute, $1,475^{\circ} \mathrm{F}$ fire. The maximum temperatures experienced by the Model 9975 Package components during the regulatory HAC (fire and post-fire cool down) are given in Table 3.2 of the Model 9975-96 Package SARP as described in Section 3.3.1.4, above. The temperatures of the package components during a HAC do not compromise the functions of the packaging.

A 9-m (30-ft), low-angle drop test of a Model 9975 Package resulted in gaps forming between the radial cane/soft wood fiberboard sheets. A hypothetical accident thermal analysis of a Model 9975 Package with a separation between the radial cane/soft wood fiberboard sheet caused by the 9-m, low-angle drop was performed. The first table of Appendix 3.4 in the SARP lists the maximum temperatures of a damaged Model 9975 Package determined by analysis, with 19-watt content decay heat rate and post-fire insolation, for the lead shield and the secondary containment vessel (including the O-rings). The temperatures of the other components presented in this table have not yet reached their maximum value 4 hours following cessation of the fire. However, their temperatures for NCT bound the maximum hypothetical accident temperatures of these components.

The maximum pressure in the containment vessels is due to the increase of the temperature of the cavity air initially at atmospheric pressure and $70^{\circ} \mathrm{F}$ temperature, helium from the decay of the plutonium contents, the hydrogen and oxygen produced by radiolysis (per Appendix 3.6 of the SARP) of the moisture associated with the ${ }^{239} \mathrm{PuO}_{2}$ or $\mathrm{NpO}_{2}$ contents, the saturated water vapor, and the hydrogen produced by the radiolysis of the plastic bags used with food cans (per Appendix 3.14 of the SARP). The maximum pressure in a hypothetical accident, calculated by the applicant for oxide contents, is given for the PVC and the SCV in Table 3.3 of the SARP, as described in Section 3.3.1.5, above. These pressures bound the pressures produced in the containment vessels with metal contents. As shown in Chapter 2 of the TRR, these pressures do not produce stresses in the confinement vessel that exceed the allowable stress limits. A review of the calculations of the pressures produced during a hypothetical accident confirmed that the pressure results were reasonable and conservative. Also, as shown in Chapter 2, the thermal stresses in the Model 9975-96 Package, due to the differential thermal expansions between the package components, are small.

The Staff finds that the containment vessels of the Model 9975-96 Package remain fully effective as containment boundaries and shielding for the payloads of plutonium metal or oxides during the HAC. The resultant deformations, if any, of the vessel will not impair the containment function of, or allow water leakage into, the payload. While the applicant has conservatively assumed the lead shield is absent and that the shielding of the radiation from the metal contents furnished by the containment vessel will satisfy 10 CFR 71.51(2) as given in Chapter 5 of this TRR, the Staff finds that the lead shielding of the Model 9975-96 Package remains fully effective as a shield for the payload source term during the HAC, and that the resultant 
deformations, if any, of the lead shield will not impair the shielding function of the payload source term. Thus, the functions of the Model 9975-96 Package are not affected by the HAC.

\subsubsection{Thermal Evaluation of Maximum Accessible Surface Temperature}

The maximum accessible surface temperatures of the Model 9975 Package with the 19-watt content decay heat rate were determined without insolation, based on the surface heat flow by natural convection and thermal radiation to the environment at an ambient temperature of $100^{\circ} \mathrm{F}$. This surface temperature is less than $122^{\circ} \mathrm{F}$, which is one condition for allowing the package to be transported as a non-exclusive-use shipment. The Staff concurs with this analysis and conclusion. Thus, 10 CFR 71 Section $43(\mathrm{~g})$ is satisfied.

\subsubsection{Appendices}

There are 19 Appendices associated with Chapter 3 of the Model 9975-96 Package SARP. They are discussed briefly in the following paragraphs.

The evaluations of several thermal properties of the packaging components are presented in the Appendices to Chapter 3 of the SARP. These properties include the thermal radiation properties of stainless steel at $400 \mathrm{~K}$ (Appendix 3.13) as well as the calculations of the thermal properties of the aluminum honeycomb used as an impact absorber and spacers in and between the containment vessels (Appendix 3.10).

Thermal tests were performed on the Celotex ${ }^{\mathrm{TM}}$ insulation for normal conditions of transport (Appendix 3.16). These tests conclude that the Celotex ${ }^{\mathrm{TM}}$ can be used at uniform temperatures of $300^{\circ} \mathrm{F}$ with occasional temperature excursions up to $325^{\circ} \mathrm{F}$ without apparent degradation to the thermal insulation or structural properties.

The PATRAN-PLUS and P/Thermal codes, used in the analyses of the thermal responses of the Model 9975 Packages to normal operating conditions and a hypothetical fire, are described. Included in the description are the listings of the material properties data file, the file containing the convection correlation parameters, and the radiative surface properties. The file contains internal and solar heat source data (Appendix 3.12). The benchmark of the P/Thermal code against a documented shipping package thermal problem is also presented (Appendix 3.11). The results indicate that the analysis code $\mathrm{P} /$ Thermal computes the thermal response of the benchmark problem to an acceptable accuracy.

The thermal tests were performed on the Model 9973 and Model 9975 (Chalfant design series) Packages. The package configurations most vulnerable to a fire were selected for testing. The most vulnerable damaged package is the Model 9973 Package after an axial drop, while the most vulnerable undamaged package is the Model 9975 Package (Appendix 3.15). The thermal tests of the Model 9973 and Model 9975 Packages were performed at Sandia National Laboratories, in Albuquerque, New Mexico. ${ }^{[3-10]}$ The hypothetical fire was simulated in Sandia's radiant heat facility. The test report, including the test plan and the assembly instructions for the instrumented Model 9973 and Model 9975 Packages, is presented (Appendix 3.5). The Model 9975 Package included the 21-watt heater to simulate the content decay heat source. The content decay heat simulator preheated the undamaged package until the package reached normal operating conditions, at which time the package was placed in the radiant heat facility. The damaged Model 9973 Package, which did not contain a content heat simulator, was placed 
directly into the radiant heat facility. The test report includes the measured temperature histories of various components.

The analyses of the Model 9975 Package using P/Thermal were compared to the results obtained from the tests of the package. The analytical model was adjusted to bring the calculated temperatures of the Model 9975 Package under NCT into near compliance with the measured results (Appendix 3.1), and the calculated temperatures of the Model 9975 Package under the thermal portion of the HAC into near compliance with measured results (Appendix 3.2). The benchmarked models were then used to perform the analyses of all the Model 9975 Packages with their content decay heat sources for NCT with 3013 contents and under HAC were performed (Appendix 3.3). A hypothetical accident analysis of a Model 9975 Package with a separation between the radial cane/soft wood fiberboard sheet caused by a 9-m (30-ft), low-angle drop was also performed (Appendix 3.4).

The pressures in the containment system (PCV and SCV) are due to the fill gas, the decomposition of the O-ring seals, helium from the decay of the plutonium contents, the hydrogen produced by decomposition of the moisture associated with the $\mathrm{PuO}_{2}$ contents, and the hydrogen produced by the decomposition of the plastic bags used with food cans. The pressure due to the decomposition of the plastic bags was estimated for food-pack cans (Appendix 3.14). The total pressure from impure plutonium oxides in a 3013 system from the fill gas, helium generation, and hydrogen, generated from the decomposition of moisture in the PCV, was analyzed (Appendix 3.6). The 3013 system does not include plastic bags. The pressure in the secondary containment vessel—assuming a leaking primary containment vessel—and 3013 system were calculated (Appendix 3.7).

An analysis of the pressure produced from the deflagration of flammable gas mixtures from the hydrogen, produced from the decomposition of the moisture associated with plutonium oxides in both the primary and secondary containment vessels, was performed for both food-pack cans and the 3013 vessel (Appendix 3.8). An analysis was also performed on the effect of (1) inerting the 3013 container to less than 5\% oxygen for oxide contents and (2) diluting the primary containment vessel by a minimum of $75 \%$ with $\mathrm{CO}_{2}$ (Appendix 3.8).

Detonation cell widths in the Model 9975 Package, with $\mathrm{CO}_{2}$ diluting the primary containment vessel, were estimated (Appendix 3.9). Stack-up dimensions of the Model 9975 Packaging components in NCT and HAC were determined (Abramczyk, 2001 ${ }^{[3-11]}$ ). The maximum allowable gap sizes were determined and can be compared to the maximum detonation cell sizes.

The current Model 9975-96 Package incorporates a design change to the lead shield configuration. Specifically, the lead shield now has a thin-walled stainless steel jacket. Appendix 3.19 addresses the effect of this design change on the thermal response of the package during both NCT and HAC for the most limiting thermal condition. The conclusion is that the design change has no significant effect on the thermal response of the package.

\subsection{Evaluation Findings}

\subsubsection{Findings}

Based on review of the statements and representations in the application, the Staff concludes that the thermal design of the Model 9975-96 Package with the Content Envelopes described in 
Table 1.2 of the SARP have been adequately described and evaluated, and that the thermal performances of the Model 9975-96 Package meets the thermal requirements of 10 CFR 71. By meeting the requirements of 10 CFR 71, the package also meets the requirements of IAEA Safety Standards Series No. TS-R-1. ${ }^{[3-3]}$

\subsubsection{Conditions of Approval}

- The conditions of approval for the Model 9975-96 Package for the shipment of the content envelopes that conform to Table 1.2 of the Model 9975-96 Package SARP and to the DOE-STD-3013, the Hex-Can, or the food-pack cans must include a content decay heat limit of 19 watts. For low density Content Envelope C. 4 contents, the maximum decay heat limits need to be reduced to the amounts listed in Table 3.4 of the SARP.

- The quantity polyethylene in the package contents of the Model 9975-96 Package is limited to a total of 100 grams (food-pack cans Content Envelopes C.1, C.3, C.4, C.5, C.6, and C.8).

- The 3013 container, the Hex-Can, or the food-pack cans must be inerted to less than 5\% oxygen for plutonium/uranium oxide contents (Content Envelope C.4).

- The primary containment vessel for plutonium/uranium oxide contents must be diluted by a minimum of $75 \%$ with $\mathrm{CO}_{2}$ (Content Envelope C.4).

- For the neptunium oxide contents, the inner can(s), the primary containment vessel, and the secondary containment vessel must be inerted with argon such that the oxygen content is less than 3\%, by volume (Content Envelope C.8).

\subsection{References}

[3-1] Washington Savannah River Company, Safety Analysis Report for Packaging, Model 9975, S-SARP-G-00003, Revision 0, Savannah River Packaging Technology, Savannah River National Laboratory (January 2008).

[3-2] Nuclear Regulatory Commission, 10 CFR Part 71, Compatibility with IAEA Transportation Standards (TS-R-1) and Other Transportation Safety Amendments; Final Rule, 69 F.R. 3698, pp. 3698-3814, January 26, 2004, as amended.

[3-3] Regulations for the Safe Transport of Radioactive Material, Safety Requirements, IAEA Safety Standards Series No. TS-R-1, 1996 Edition (As Amended 2003) International Atomic Energy Agency, Vienna, Austria (July 2004).

[3-4] Stabilization, Packaging, and Storage of Plutonium-Bearing Materials, DOE Standard, DOE-STD-3013-2000, U.S. Department of Energy, Washington, DC (March 2004).

[3-5] Rules for Construction of Nuclear Power Plant Components, ASME Boiler and Pressure Vessel Code, Section III, Subsection NB, American Society of Mechanical Engineers, New York, NY (2004).

[3-6] Standard Specification for Cellulosic Fiber Insulating Board, ASTM C208-95, American Society for Testing and Materials (Reapproved 2001).

[3-7] Standard Specification for Lead and Lead Alloy Strip, Sheet, and Plate Products, ASTM B749, American Society for Testing and Materials (1995). 
[3-8] Development of a Simulation (Thermophysical Property) Model for Cane Fiberboard Packages Subjected to a Hypothetical Accident Fire, S.J. Hensel and R.J. Gromada, DOE Defense Programs Packaging Workshop, Knoxville, Tennessee (1994).

[3-9] PATRAN-PLUS, PDA Engineering, PATRAN Division, Costa Mesa, California (March 1993).

[3-10] Test Report, Simulated Fire Tests of the 9973 and 9975 Packagings, D.H. Schulze, R. Moreno, and W. Gill, 6324AK2801, Sandia National Laboratory, Albuquerque, New Mexico (June 1994).

[3-11] Stack-up Dimensions of the 9975 Packaging Components in Normal Conditions of Transport (NCT) and Hypothetical Accident Conditions (HAC), G.K. Abramczyk, MM-CLC-0177, Rev. 0, Westinghouse Savannah River Company, Radioactive Materials Packaging Technology, Savannah River Technology Center (June 2001). 
3. Thermal Review

This Page Intentionally Blank. 


\section{CONTAINMENT REVIEW}

\subsection{Areas of Review}

Chapter 4, Containment Review, of the Safety Analysis Report for Packaging, Model 9975, Model 9975-96, B(M)F-96, was reviewed for the adequacy of the containment design features of the Model 9975-96 Package. ${ }^{[4-1]}$ The review includes an evaluation of the SARP with respect to the requirements specified in 10 CFR $71,{ }^{[4-2]}$ and in International Atomic Energy Agency (IAEA) Safety Standards Series No. TS-R-1. ${ }^{[4-3]}$

Included in the Containment Review were the following:

\subsubsection{Description of Containment Design}

- Design Features

- Codes and Standards

- Special Requirements for Plutonium

\subsubsection{General Considerations for Containment Evaluations}

- General Containment Considerations for Type B Packages

- Combustible-Gas Generation

\subsubsection{Containment under Normal Conditions of Transport}

- Containment Design Criterion

- Demonstration of Compliance with Containment Design Criterion

\subsubsection{Containment under Hypothetical Accident Conditions}

- Containment Design Criterion

- Demonstration of Compliance with Containment Design Criterion

\subsubsection{Leakage Rate Tests for Type B Packages}

\subsubsection{Appendices (as applicable)}

\subsection{Regulatory Requirements}

The regulatory requirements of 10 CFR 71 applicable to the Containment review of the Model 9975-96 Package are as follows:

- The package design must be described and evaluated to demonstrate that it meets the containment requirements of 10 CFR 71. [\$71.31(a)(1), §71.31(a)(2), §71.33, §71.35(a)]

- The application must identify the established codes and standards used for the package design, fabrication, assembly, testing, maintenance, and use. In the absence of such codes, the application must describe the basis and rationale used to formulate the quality assurance program. [\$71.31(c)] 
- The package must include a containment system securely closed by a positive fastening device that cannot be opened unintentionally or by pressure that may arise within the package. $[\S 71.43(\mathrm{c})]$

- The package must be made of materials and constructed to assure that there will be no significant chemical, galvanic, or other reactions, including reactions due to possible inleakage of water, among the packaging components, among package contents, or between the packaging components and the contents. The effects of radiation on the materials of construction must be considered. [\$71.43(d)]

- Any valve or similar device on the package must be protected against unauthorized operation and, except for a pressure relief valve, must be provided with an enclosure to retain any leakage. $[\S 71.43(\mathrm{e})]$

- The package must be designed, constructed, and prepared for shipment to ensure no loss or dispersal of radioactive contents under the tests specified in $\S 71.71$ ("Normal conditions of transport") there would be no loss or dispersal of radioactive contents. $[\S 71.43(\mathrm{f})]$

- The package may not incorporate a feature intended to allow continuous venting during transport. [\$71.43(h)]

- A Type B package must meet the containment requirements of $\$ 71.51(\mathrm{a})(1)$ under the tests specified in $\$ 71.71$ for Normal Conditions of Transport.

- A Type B package must meet the containment requirements of $\$ 71.51(\mathrm{a})(2)$ under the tests specified in $§ 71.73$ for Hypothetical Accident Conditions.

- The maximum activity of radionuclides in a Type A package must not exceed the limits of 10 CFR 71, Appendix A, Table A-1. For a mixture of radionuclides, the provisions of Appendix A, paragraph IV apply, except that for krypton-85, where an effective $\mathrm{A}_{2}$ equal to $10 \mathrm{~A}_{2}$ may be used. [Appendix $\mathrm{A}, \S 71.51(\mathrm{~b})$ ]

- Compliance with the permitted activity release limits for Type B packages may not rely on filters or on a mechanical cooling system. [\$71.51(c)]

- For packages that contain radioactive contents with activity greater than $10^{5} \mathrm{~A}_{2}$, the requirements of $\S 71.61$ must be met. $[\$ 71.51(\mathrm{~d})]$

- A Type B package containing more than $10^{5} \mathrm{~A}_{2}$ must be designed so that its undamaged containment system can withstand an external water pressure of $2 \mathrm{MPa}$ (290 psi) for a period of not less than 1 hour without collapse, buckling, or inleakage of water. [\$71.61]

- A package containing plutonium in excess of $0.74 \mathrm{TBq}(20 \mathrm{Ci})$ must have the contents in solid form for shipment. [§71.63]

\subsection{Review Procedures}

The following procedures were employed in the review of Chapter 4, Containment, of the SARP. These procedures correspond to the Areas of Review listed in Section 4.1 of this TRR. 


\subsubsection{Description of the Containment Design}

\subsubsection{Design Features}

4.3.1.1.1 Containment Boundary

The Model 9975-96 Package has an inner containment boundary, also known as the primary containment boundary, or PCV; and an outer containment boundary, also known as the secondary containment boundary, or SCV. The double containment feature is neither required, nor prohibited, by the regulations.

The containment boundary for the PCV is adequately described in Section 1.2.1.5 of the SARP. The containment boundary for the SCV is adequately described in Section 1.2.1.6 of the SARP. And both are described in additional detail in Section 4.1 of the SARP.

The containment boundaries for both the PCV and the SCV consist of the containment vessel body, the male cone-seal plug, the outermost of two O-rings, and the leak-test port plug. The closure seal is formed with the O-rings between the female cone-sealing surface on the containment vessel body and the male cone-sealing plug surface. The O-rings are secured by tightening down the cone-seal nut against the male cone-seal plug. The leak test port is sealed by tightening the gland nut, which presses the tip of the leak-test port plug into the port. The seal is formed by the metal-to-metal contact between the conical tip of the leak-test port plug and the corresponding conical surface of the outer edge of the port. The components of the containment system are shown in the following SARP drawings: R-R2-F-0018, Rev. 9; R-R3-F-0016, Rev. 12; and R-R4-F-0054, Rev. 13.

\subsection{Containment Boundary Penetration}

The Model 9975-96 Package has a single containment boundary penetration, i.e., the leak test port described in the previous section. As was noted in the previous section, the leak-test port is sealed by tightening the gland nut, which presses the tip of the plug into the port. The seal is formed by the metal-to-metal contact between the conical tip of the plug and the corresponding conical surface of the outer edge of the port.

\section{$\underline{\text { 4.3.1.1.3 Seals and Welds }}$}

The seals and welds on the containment boundary are adequately described in Section 4.1 .3 of the SARP. Although two O-rings are used to seal the containment vessel, the outer O-ring is considered part of the containment boundary. The inner O-ring is used to facilitate leakage testing. To prevent movement, each $\mathrm{O}$-ring is placed in a machined groove on the conical surface of the male cone-seal plug. The seal is formed when the male cone-seal plug is pressed against the female conical surface on the inner wall of the containment vessel body. To meet the design criteria for this application, the O-rings must maintain their seal at internal temperatures of up to $400^{\circ} \mathrm{F}$, and internal pressures of up to $900 \mathrm{psig}$. The elastomer selected for the O-rings is a Viton ${ }^{\circledR}$ GLT or Viton ${ }^{\circledR}$ GLT-S fluorocarbon (Parker Compound V0835-75 or V835-75). The normal operating range for the Viton ${ }^{\circledR}$ GLT O-rings is $-40^{\circ} \mathrm{F}$ to $400^{\circ} \mathrm{F}$. Under NCT, the maximum temperature that the $\mathrm{O}$-rings are expected to reach is $272^{\circ} \mathrm{F}$ in the primary containment vessel and $268^{\circ} \mathrm{F}$ in the secondary containment vessel. Under HAC, the maximum temperature that the O-rings are expected to reach is $197^{\circ} \mathrm{F}$ in the primary containment vessel and $192^{\circ} \mathrm{F}$ in the secondary containment vessel. The review confirmed that the maximum and minimum temperatures of seals, under NCT and HAC, are within the manufacturer's 
recommended operating ranges. The O-ring lid seals are appropriate for use in the Model 997596 Package, as long as the seal grooves are properly sized.

The leak-test port plug is a $1 / 4$-inch 316 SS plug designed for high-pressure service. The leak-test port plug forms its seal at the outer edge of the leak-test port in the top of the male cone-seal plug.

Each containment vessel has two circumferential, full-penetration, complete fusion butt welds. The top circumferential weld joins the female conical section to the Schedule 40 vessel-body pipe section. The bottom circumferential weld joins the standard weight pipe cap to the Schedule 40 vessel-body pipe section. Welding qualifications are established in accordance with Section III, Subsection NB of the ASME B\&PVC, 2004 Edition, which invokes Section IX. ${ }^{[4-4]}$ The welds are examined with liquid penetrant, and are fully radiographed after completion.

\subsection{Containment Closure}

The containment vessel closures are adequately described in Section 4.1.4 of the SARP. Closure of the containment boundaries is virtually identical for the PCV and the SCV, and is accomplished by forming a leaktight seal with the Viton ${ }^{\circledR}$ GLT or Viton ${ }^{\circledR}$ GLT-S O-rings between the female conical section of the containment vessel and the male cone plug wall. The female conical surface (10-degree included angle) is machined into the inner wall of the containment vessel weldment and finished to a 32- $\mu$ in. surface finish. Female threads are cut into the containment vessel wall outboard of the conical surface. A male cone-seal plug, also with a 10-degree included angle, forms the removable plug for the containment.

Two O-ring grooves are cut into the conical surface of the male cone-seal plug. The O-ring and its groove volume are equal. This provides sealing on all four surfaces of each groove, and aids in providing very low leakage and permeation rates. The male cone-seal plug is pressed into place by a threaded nut made from a dissimilar material (Nitronic 60 stainless steel alloy) to prevent galling with the Type 304L stainless steel containment vessel and cone seal.

A shallow circumferential rectangular groove $(0.063$-inches wide $\times 0.060$-inches deep) between the O-rings is also machined into the male cone-seal plug. The rectangular groove intersects with the leak-test port plug opening at the cone surface between the two O-ring grooves. The rectangular groove provides a channel to ensure that the test gas is applied against the entire inner and outer O-ring sealing surface during leakage testing.

A point of reference is established for tightening the male cone-seal nut by first seating the joint metal-to-metal. This is first accomplished by assembling the closure and tightening the coneseal nut to the prescribed torque values of $55 \pm 5 \mathrm{ft}-\mathrm{lb}$ and $110 \pm 10 \mathrm{ft}-\mathrm{lb}$, for the PCV and SCV, respectively (no O-rings present). The point of reference is established following the hydrostatic pressure test. A radial line is then scribed across both the top of the cone-seal nut and the top of the containment vessel body. When the cone-seal closure is assembled with the O-rings installed, the two radial lines must line up to within 1-inch arc length of each other when the prescribed torque is applied. With this match, a maximum radial clearance of 0.0007 -inches exists between the male and female cone-seal components. This clearance is adequate to prevent the O-rings from extruding from the grooves under design conditions. The prescribed torque prevents the containment vessels from opening during NCT and HAC. It was verified, through 
coordination with the structural review, that the specified torque values provide proper compression for containment seals.

It was verified that the method of closure for the containment boundary penetrations is adequately described and that the containment system is securely closed by a positive fastening device that cannot be opened unintentionally or by a pressure that may arise within the package.

\subsubsection{Codes and Standards}

The review verified that the codes or standards applicable to the containment design of the package were identified and appropriate, including those for material specifications and fabrication. The review ensured that such codes and standards were consistent with those specified in the General Information, and the Structural, and Thermal Evaluation chapters of the SARP. The review determined that these codes or standards specify temperature limits for materials, that the temperatures of all the containment system components are within their respective allowable temperature limits, and that the temperatures used are consistent with those used in the Thermal and Structural chapters of the SARP.

The review confirmed that the evaluation of release rates and performance of leakage testing was in accordance with the American National Standard for Radioactive Materials - Leakage Tests on Packages for Shipment, ANSI N14.5. ${ }^{[4-5]}$

\subsubsection{Special Requirements for Plutonium}

Although no longer necessary for the shipment of plutonium, the applicant has elected to use the double-containment approach for the shipment of plutonium-bearing materials. The review verified that each containment system separately satisfies the requirements of $\$ 71.51(\mathrm{a})(1)$, for normal conditions of transport, and $§ 71.51(\mathrm{a})(2)$, for hypothetical accident conditions.

Because the Model 9975-96 Package is to be used for the shipment of unirradiated plutoniumbearing materials, additional requirements for spent nuclear fuel are not applicable to this TRR.

\subsubsection{General Considerations for Containment Evaluations}

\subsubsection{Type B Packages}

The Model 9975-96 Package is a Type B package and must satisfy the quantitative release rates specified in $\S 71.51(\mathrm{a})(1)$ and $\S 71.51(\mathrm{a})(2)$ for normal conditions of transport, and hypothetical accident conditions, respectively. As is also noted in the NRC's Regulatory Guide $7.4,{ }^{[4-6]}$ the methods outline in ANSI N14.5 provide an acceptable method to determine the maximum permissible volumetric leakage rates for both containment vessels based on the allowable release rates as specified in $\S 71.51(\mathrm{a})(1)$, and $\$ 71.51(\mathrm{a})(2)$, respectively.

In order to meet the requirements specified in $\S 71.51(\mathrm{a})(1), \S 71.51(\mathrm{a})(2)$, and Regulatory Guide 7.4, the applicant has elected to adopt the ANSI N14.5 definition of leaktight, for both containment boundaries, for both normal conditions of transport and hypothetical accident conditions. (Note: According to ANSI N14.5, leaktight is defined as being a leakage rate of air that is less than or equal to $1 \times 10^{-7}$ reference $\mathrm{cm}^{3} / \mathrm{sec}$, at an upstream pressure of 1 atmosphere and a downstream pressure of 0.01 atmosphere or less, regardless of the type or the form of radioactive contents. By adopting the ANSI N14.5 definition of leaktight, the applicant is no 
longer required to show any calculations to justify their position. This has been the position adopted by the applicant, and has been verified during the process.) In order to verify that the ANSI N14.5 specification of leaktight can be met for all required leakage tests, a sensitivity of $5.0 \times 10^{-8}$ reference $\mathrm{cm}^{3} / \mathrm{sec}$ has also been adopted by the application.

The review also verified that the package does not incorporate a feature intended to allow continuous venting during transport, and that the containment system does not rely on filters or a mechanical cooling system.

\subsubsection{Combustible-Gas Generation}

The Staff has reviewed the proposed contents described in Section 1.2.3 of the SARP and determined that there should be no combustible-gas generation issues that should normally be associated with the shipment of Content Envelopes C.1, C.2, C.3, C.5, C.6, and/or C.7. Although a similar finding also pertains to the shipment of proposed Content Envelope C.8, the applicant has elected to adopt a more conservative approach, electing instead to adopt an inerting methodology that more closely follows the pattern set forth by the adoption of DOE-STD-3013-2000 (i.e., the 3013 Standard). ${ }^{[4-7]}$ (See below.) A similar methodology has also been adopted for the shipment of the contents described by Content Envelope C.4.

For the shipment of the plutonium/uranium oxides described by Content Envelope C.4, plutonium/uranium oxides, the applicant has concluded that the atmosphere inside the contents cans (i.e., the product cans and/or the 3013 cans or hex cans) shall be inerted with helium or nitrogen such that the oxygen content in all void spaces is no greater than $5 \mathrm{vol} \%$ at the time the PCV is closed. The applicant has also concluded that the atmosphere inside the PCV shall be diluted to at least $75 \mathrm{vol} \% \mathrm{CO}_{2}$, as per Section 7.2.2 of the SARP. Additional content can size and spacer requirements are further defined in Section 1.2.3.2.2 of the SARP. Based on deflagration-to-detonation (DDT) cell-size calculations provided by the applicant, the review Staff has concluded that a detonation event inside the PCV should not be possible; and even if a deflagration event were to occur inside the PCV, it would not result in conditions that are outside of the allowable design conditions. The applicant has finally concluded that, and the review Staff concurs that, there is no need to perform any inerting operations on the SCV prior to shipment.

For the shipment of the neptunium oxide described by Content Envelope C.8, neptunium oxide, the applicant has concluded that, and the review Staff agrees that, the atmosphere inside the contents cans (i.e., the food-pack cans) shall be inerted with argon such that the oxygen content in all void spaces is no greater than 3 vol\% by volume at the time the PCV is closed. Following a methodology similar to that used for plutonium/uranium oxides, the applicant has further concluded that the atmosphere inside the PCV shall be diluted with argon so that it contains no more than $3 \mathrm{vol} \%$ oxygen at the time of closure, as per Section 7.2.2 of the SARP. Finally, because argon is not as good a diluent/inertant for DDT cell-size calculations, the applicant has further concluded that, the SCV shall also be diluted with argon so that it also contains no more than $3 \mathrm{vol} \%$ oxygen at the time of closure. (See Section 7.2.3 of the SARP.) With respect to this last step, the review Staff has concluded that it probably unnecessary because the specific activity of neptunium oxide should be about two orders of magnitude lower than that of the plutonium/uranium oxides described by Content Envelope C.4, and that this, by itself, should more than compensate for any perceived deficiencies in the calculated DDT cell-size differences. 


\subsubsection{Containment under Normal Conditions of Transport (Type B Packages)}

Containment under NCT is addressed in Section 4.2 of the SARP.

\subsubsection{Containment Design Criterion}

As noted in Section 4.3.2.1 of this TRR, the applicant has elected to adopt the ANSI N14.5 definition of leaktight, for both containment boundaries, for normal conditions of transport. This was verified as part of the Containment review.

The review also verified that the maximum normal operating pressure and maximum temperature under normal conditions of transport are consistent with those determined in the Thermal Evaluation chapter of the SARP.

\subsubsection{Demonstration of Compliance with Containment Design Criterion}

The applicant has demonstrated the containment design and performance criteria by test. The review confirmed that the SARP demonstrates that the package meets the containment requirements specified in $\S 71.51(\mathrm{a})(1)$ for normal conditions of transport.

\subsubsection{Containment under Hypothetical Accident Conditions (Type B Packages)}

The review procedures for containment under HAC were similar to those under NCT. Containment under HAC is addressed in Section 4.3 of the SARP.

\subsubsection{Containment Design Criterion}

As noted in Section 4.3.2.1 of the TRR, the applicant has elected to adopt the ANSI N14.5 definition of leaktight, for both containment boundaries, for hypothetical accident conditions. This was verified as part of the Containment review.

\subsubsection{Demonstration of Compliance with Containment Design Criterion}

The applicant has demonstrated the containment design and performances criteria by test. Also, as was demonstrated in the Structural and Thermal evaluation chapters of the SARP, the package closure system is not degraded by any of the hypothetical accident condition tests. The review confirmed that the SARP demonstrates that the package meets the containment requirements specified in $\S 71.51(\mathrm{a})(2)$ for hypothetical accident conditions.

\subsubsection{Leakage Rate Tests for Type B Packages}

The review confirmed that the maximum allowable leakage rates were determined in accordance with ANSI N14.5. The fabrication, periodic, and maintenance leakage rate test criteria are each specified to meet the ANSI N14.5 definition of leaktight, i.e., $\leq 1 \times 10^{-7}$ reference $\mathrm{cm}^{3} / \mathrm{sec}$, under reference air leakage test conditions. This was also verified in the Acceptance Test and Maintenance Program chapter of the SARP, Chapter 8. The pre-shipment leakage rate test criterion is $1 \times 10^{-3}$ reference $\mathrm{cm}^{3} / \mathrm{sec}$, which is also consistent with ANSI N14.5. This was verified in the Operating Procedures chapter of the SARP, Chapter 7.

\subsubsection{Appendices}

There are no Appendices associated with Chapter 4 of the SARP. 


\subsection{Evaluation Findings}

The review ensured that the information presented in the SARP supports a conclusion that the regulatory requirements in Section 4.2 above are satisfied.

Based on review of the statements and representations in the SARP, the Staff concludes that the containment design has been adequately described and evaluated, and that the package design meets the containment requirements specified in 10 CFR 71.

\subsubsection{Conditions of Approval}

Other than the conditions specified in Sections 1, 7, 8, and 9, of this TRR, there are no additional containment-related conditions of approval that need to be added for the approval of this application.

\subsection{References}

[4-1] Washington Savannah River Company, Safety Analysis Report for Packaging, Model 9975, S-SARP-G-00003, Revision 0, Savannah River Packaging Technology, Savannah River National Laboratory (January 2008).

[4-2] Nuclear Regulatory Commission, 10 CFR Part 71, Compatibility with IAEA Transportation Standards (TS-R-1) and Other Transportation Safety Amendments; Final Rule, 69 F.R. 3698, pp. 3698-3814, January 26, 2004, as amended.

[4-3] Regulations for the Safe Transport of Radioactive Material, Safety Requirements, IAEA Safety Standards Series No. TS-R-1, 1996 Edition (As Amended 2003) International Atomic Energy Agency, Vienna, Austria (July 2004).

[4-4] ASME Boiler and Pressure Vessel Code, Section III, Rules for Construction of Nuclear Power Plant Components, Division I, Subsection NB, American Society of Mechanical Engineers, New York, NY (2004).

[4-5] Institute of Nuclear Materials Management, American National Standard for Radioactive Materials, Leakage Tests on Packages for Shipment, ANSI N14.5-1997, New York.

[4-6] U.S. Nuclear Regulatory Commission, Leakage Tests on Packages for Shipment of Radioactive Materials, Regulatory Guide 7.4, June 1975.

[4-7] U.S. Department of Energy Standard, Stabilization, Packaging, and Storage of Plutonium Bearing Materials, DOE-STD-3013-2000, March 2004, Washington, DC. 


\section{SHIELDING REVIEW}

\subsection{Areas of Review}

Chapter 5, Shielding, in the Safety Analysis Report for Packaging, Model $9975,{ }^{[5-1]}$ was reviewed for external radiation requirements. The review includes an evaluation of the SARP with respect to the requirements specified in $10 \mathrm{CFR} 71,{ }^{[5-2]}$ and in International Atomic Energy Agency (IAEA) Safety Standards Series No. TS-R-1. ${ }^{[5-3]}$

The Shielding review included the following:

\subsubsection{Description of Shielding Design}

- Design Features

- Codes and Standards

- Summary Table of Maximum Radiation Levels

\subsubsection{Radiation Source}

- Gamma Source

- Neutron Source

\subsubsection{Shielding Model}

- Configuration of Source and Shielding

- Material Properties

\subsubsection{Shielding Evaluation}

- Methods

- Input and Output Data

- Flux-to-Dose-Rate Conversions

- External Radiation Levels

\subsubsection{Appendices (as applicable)}

\subsection{Regulatory Requirements}

Regulatory requirements of 10 CFR 71 applicable to the shielding review are as follows:

- The package design must be described and evaluated to demonstrate that it meets the shielding requirements of 10 CFR 71. [\$71.31(a)(1), §71.31(a)(2), §71.33, §71.35(a)]

- The application must identify the established codes and standards used for the package design, fabrication, assembly, testing, maintenance, and use. In the absence of such codes, the application must describe the basis and rationale used to formulate the quality assurance program. [\$71.31(c)] 
- Under the tests specified in $\$ 71.71$ for normal conditions of transport, the external radiation levels must meet the requirements of $\S 71.47(\mathrm{a})$ for nonexclusive-use or $\S 71.47(\mathrm{~b})$ for exclusive-use shipments. [ $\$ 71.47]$

- The package must be designed, constructed, and prepared for shipment so that the external radiation levels will not significantly increase under the tests specified in $\$ 71.71$ for normal conditions of transport. [\$71.43(f), §71.51(a)(1)]

- Under the tests specified in $\$ 71.73$ for hypothetical accident conditions, the external radiation level must not exceed $10 \mathrm{mSv} / \mathrm{h}(1 \mathrm{rem} / \mathrm{h})$ at one meter from the surface of a Type B package. $[\$ 71.51(\mathrm{a})(2)]$

\subsection{Review Procedures}

Chapter 5 of the Model 9975-96 Package SARP includes the information essential for a shielding evaluation including: the drawings, the packaging materials and densities, and the radioisotopic composition and mass. The shielding information in the Model 9975-96 Package SARP was reviewed by the Staff for completeness and compliance with regulatory requirements. The eight content envelopes, listed in Table 1.2 were evaluated for shipment.

\subsubsection{Description of Shielding Design}

\subsubsection{Design Features}

Photon (gamma radiation) shielding for the side and bottom is provided primarily by the shielding body assembly. The shielding body assembly consists of a nominally $1 / 2$-inch thick lead cylinder that surrounds the Primary Containment Vessel (PCV) and the Secondary Containment Vessel (SCV) double containment assembly. The bottom of the shielding body assembly is also lead that is nominally $1 / 2$-inch thick, whereas the lid is $1 / 2$-inch thick aluminum. The shielding body assembly does not employ a lead lid because the PCV and SCV stainless steel closures provide adequate shielding for the top of the drum. In the present design of the packaging, the addition of an outer liner of stainless steel to the shielding body reduces the effective nominal thickness of the lead by the nominal thickness of the liner. The outer liner has a nominal thickness of 0.036-inch making the nominal lead shield thickness 0.434 -inch as compared with the original thickness of 0.47 -inch. The overall thickness of the shield assemblythe inner and out liners plus the lead- remains at 0.506 inch.

The PCV and the SCV also provide photon shielding. The PCV consists of a cylindrical pressure vessel constructed from 5-inch, Schedule 40, Type 304L stainless steel pipe. The SCV is constructed from 6-inch, Schedule 40, Type 304L stainless steel pipe. The PCV is placed within the SCV. The PCV-SCV combination is placed within a specially fabricated 35-gallon removable-head drum constructed of Type 304L stainless steel with a minimum OD of 18.22 inches (the drum rolling hoops are somewhat larger and are responsible for a slightly larger minimum diameter). The PCV-SCV combination and the lead shield are kept centered within the drum by about a 5-inch thick layer of fiberboard insulation material.

Neither the package geometry nor its materials of construction are specifically designed to provide neutron shielding. Neutron dose rate attenuation is provided primarily by the distance between the source and points external to the package, with some additional attenuation provided 
by the materials of the PCV, SCV, lead, Celotex ${ }^{\mathrm{TM}}$, and the drum. The presence of material containers inside of the PCV has insignificant impact on the dose rate.

The Model 9975-96 Package design includes a double containment system. The radioisotopic contents are generally placed in a product or convenience can. For metals, from one to three product cans may be placed within the PCV. Plutonium oxides may be enclosed in a 3013 container, food-pack can, or hex-can which in turn is placed within the PCV.

The design of the Model 9975-96 Package does not include specific neutron-absorbers, but it does include hydrocarbon insulating-spacing material for thermal insulation. This insulation material also serves as a neutron moderator for neutron dose shielding, although no credit is taken for it in HAC studies. Shielding control, through package geometry, occurs because the minimum package length and diameter provide a minimum separation between the radioisotopes and the package surface. Therefore, the various dose measurements required must be at least an assured minimum distance from the radioisotopic sources.

The Staff confirms that the shielding design features presented in the General Information and Shielding Evaluation chapters of the SARP are consistent and complete concerning location, dimensions, tolerances, and densities of material for gamma and neutron shielding, including those packaging components considered in the shielding evaluation. In addition, the structural components that maintain the integrity of the shielding and the contents in restricted locations within the package are sufficient. The thermal evaluation shows that charring of some of the Celotex ${ }^{\mathrm{TM}}$ insulation occurs during HAC, but that the temperature of the lead shield remains below its melting temperature. However, for conservatism, all packaging materials outside of the SCV are assumed in the shielding evaluation to be lost during HAC.

The Staff confirms that the text and sketches describing the shielding design features are consistent with the engineering drawings and the models used in the shielding evaluation. The Staff concludes that the Model 9975-96 Package conforms to the general standards for all packages as prescribed by 10 CFR 71 [§71.31(a)(1), §71.31(a)(2), §71.31(c), §71.33, §71.35(a)].

\subsubsection{Codes and Standards}

The flux-to-dose-rate conversion factors are listed in Appendix 5.1 and are consistent with ANSI 6.1.1-1977..$^{5-4]}$

\subsubsection{Summary Table of Maximum Radiation Levels}

Table 5.1 of the SARP shows the maximum radiation levels for NCT and HAC. All dose rates are within the regulatory limits for non-exclusive use. For Contents C.3 and C.4 further restrictions on impurity content are required as discussed in Appendix 5.8. However, the impurity content or the plutonium isotopic composition is not quantified for many content packages. For these content packages a program of measurement of the dose rate at the surface of the Model 9975-96 shipping container as described in Appendix 5.1 will be used to determine whether a package can be shipped under Normal Conditions of Transport. Packages that do not meet the measurement limit will be evaluated on a case by case basis. All the radiation levels are identical to the ones approved previously for the Model 9975-85 Package, ${ }^{[5-5]}$ except for Content Envelopes C.3b and C.4, with C.4 bounding C.3b when no impurities are present. 


\subsubsection{Radiation Source}

Table 1.2 of the SARP presents the details of the content envelopes intended for shipment in this package. All of these content envelopes have been approved under previously issued Certificates of Compliance. The Content Envelopes C.3 and C. 4 were evaluated ${ }^{[5-6]}$ with the increase in the sum of ${ }^{241} \mathrm{Am}$ and ${ }^{241} \mathrm{Pu}$ to 15 weight percent and the addition of $1 \mathrm{~kg}$ of ${ }^{232} \mathrm{Th}$. The reduction in the nominal lead thickness, noted above in Section 5.3.1.1 of this TRR, will, by itself, not impact the source terms for any of the content envelopes.

\subsubsection{Gamma Source}

The SARP used the ORIGEN-S ${ }^{[5-7]}$ computer code to calculate the activity of daughter products, and the RASTA ${ }^{[5-8]}$ computer code to calculate the energy-dependent gamma source term. The ORIGEN-S code is part of the NRC-sponsored SCALE ${ }^{[5-9]}$ code package. With the exception of Content Envelope C.4, the calculated photon source terms, shown in Table 5.3 of the SARP, are identical to the previously approved set of photon source terms for each of the other content envelopes. The photon source term for Content Envelope C. 4 was not previously calculated.

As neutrons dominate the dose rate for Content Envelope C.4, the photon source strength presented in the SARP was based on the same composition as the neutron source strength. The photon source strength for content envelope C.4 was determined by doubling the photon source for 15 weight percent ${ }^{241} \mathrm{Am}$ with no ${ }^{232} \mathrm{Th}$ and no impurities. The source term for the thorium analysis included the quantities of daughter products derived using ORIGEN-S to decay the source material 75 years. The photons in the $2-3 \mathrm{MeV}$ range (from the decay of ${ }^{208} \mathrm{Tl}$ ) increase by a factor of 2.18 when $1,000 \mathrm{~g}$ of ${ }^{232} \mathrm{Th}$ is added to $4,400 \mathrm{~g}$ of plutonium. However, this is the only energy group that has an increase greater than $26 \%$. Therefore, the Staff agrees that doubling the entire photon source term is conservative.

In the present submittal, the gamma source term, presented in the SARP for Content Envelope C.4, is consistent with confirmatory analyses performed by the Staff.

\subsubsection{Neutron Source}

The SARP used the computer code RASTA to calculate the energy-dependent neutron source term. The calculated neutron source term is shown in Table 5.4 of the SARP. The effect of subcritical multiplication is not included in the source term but is accounted for within the Monte Carlo Nuclear Particle (MCNP) radiation transport calculation. ${ }^{[5-10]}$ With exception of Content Envelope C.4, the calculated neutron source terms shown in Table 5.4 of the SARP are identical to the previously approved set of neutron source terms for each of the other content envelopes. The neutron source term for Content Envelope C.4 presented in the SARP is without any beryllium impurities. When impurity levels are not known for the content envelope (plutonium metal, Content Envelope C.3b, bounds oxide when impurities are included), a program of measurements will be used on a case-by-case basis.

The Staff's independent estimation of the neutron source term for Content Envelope C.4 is consistent with that provided in the SARP. 


\subsubsection{Shielding Model}

The Staff concurs that the models used for each of the contents in Table 1.2 in the shielding calculations are consistent with the effects of the NCT and HAC tests on the Model 9975-96 Package. Section 5.3.3 applies to all content envelopes in Table 1.2.

\subsubsection{Configuration of Source and Shielding}

The dimensions of the source and packaging used in the shielding models correspond to those given in the SARP drawings. The contents are positioned at appropriate locations, considering tolerances, and with appropriate densities that ensure that maximum external radiation levels are calculated. Conservative choices were used for both NCT and HAC package models. The lead shield was modeled with a thickness of 0.47 inches without the outer stainless steel liner. The impact of the thinning of the shield to 0.434 inches was separately estimated. This impact was roughly estimated, and separate radiation transport calculations were not performed with the thinner lead shield in the present design.

The dose point locations in the shielding model are given at the package surface and $1 \mathrm{~m}$ from that surface as prescribed in 10 CFR 71 [\$71.47(a)], for NCT non-exclusive use shipments. Also, the dose point locations in the shielding model are given at $1 \mathrm{~m}$ from the package surface for HAC as prescribed in $10 \mathrm{CFR} 71$ [§71.51(a)(2)]. The points chosen give the location of the maximum radiation levels expected from each payload. All voids, streaming paths, and irregular geometries are treated in an adequate manner.

\subsubsection{Material Properties}

Accepted values for the density of all package materials are used in the SARP. Accepted values for the source-material densities are used in the shielding calculations in the SARP. The NCT tests demonstrated that there was no significant damage to the package or packaging materials that would significantly affect the shielding of source radiation. The Staff concludes that the shielding properties of the lead layer and the fiberboard insulation and spacer will not degrade during the normal service life of the packaging. The HAC shielding studies assumed that all packaging materials outside the containment system are absent, even though the HAC tests demonstrated that most would survive. The Staff agrees this is a conservative assumption.

\subsubsection{Shielding Evaluation}

\subsubsection{Methods}

All dose rates on the Model 9975-96 Package were determined using the three-dimensional Monte Carlo transport code, MCNP. This is an acceptable code to use for these calculations. The MCNP computer program is referenced properly. The cross sections used in MCNP were taken from the MCNP (ENDF/B-V) libraries.

Secondary gamma production is included in the analyses. Subcritical neutron multiplication is accounted for explicitly in MCNP.

Confirmatory calculations show that streaming paths do not play a significant role in the dose rates determined in this SARP. Although streaming paths could potentially arise in the Model 9975-96 Package for HAC conditions, the SARP, HAC-shielding model excludes all packaging materials outside the SCV. Therefore steaming paths are irrelevant. 


\subsubsection{Input and Output Data}

Key input data for the shielding calculations are identified for the computer codes employed. Representative input files, used in the analyses, are presented in Appendix 5.6. The shielding model input parameters were properly entered into MCNP input listings in Appendix 5.6. A sample output listing for each of the three codes (ORIGEN, RASTA, and MCNP), used in the analyses, is included in Appendix 5.6 of the SARP.

\subsubsection{Flux-to-Dose-Rate Conversion}

The SARP evaluation properly converts the gamma and neutron fluxes to dose rates. The fluxto-dose rate conversion factors (from ANSI 6.1.1-1977 ${ }^{[5-4]}$ ), used in the shielding calculation, are properly tabulated as a function of the energy group structure in Appendix 5.7.

\subsubsection{External Radiation Levels}

The NCT tests caused no significant damage to the packaging that would alter its shielding effectiveness or its ability to prevent loss or dispersal of radioactive contents. The SARP evaluation properly addresses package damage due to the HAC tests by ignoring all protective packaging outside the containment system. This is conservative since the HAC tests did not cause much damage.

Analyses performed by the Staff confirmed that the SARP dose rate values for the Content Envelope C.4 are reasonable. All the external dose rates are within the 10 CFR Part 71 limits with adequate margins. ${ }^{[5-3]}$ The classified Content Envelope C.7 is very close to the limit at the bottom of the package $(199.8 \mathrm{mrem} / \mathrm{hr}$, compared to the limit of $200 \mathrm{mrem} / \mathrm{hr})$. This Content Envelope was also approved under previously issued Certificates of Compliance (see WSRC-SA-2002-00008, Revision $0^{[5-5]}$ ).

The SARP presents the sensitivity of the gamma dose rate from plutonium sources to the thinning of the lead shield to be about $33 \%$. This increase would be partially offset by the replacement of the lost lead by the outer stainless steel liner. The SARP also presents the argument that the reduction in the lead shield thickness will have negligible impact on the neutron dose rate which dominates the over all external radiation levels. Therefore, the SARP concludes that the thinning of the lead shield would have negligible overall effect on external radiation levels. For the case of the uranium contents, the SARP estimates an $8 \%$ increase in the dose rate because of the reduction in the lead shield thickness. Given these sensitivities, the Staff re-examined the shielding analyses for Content Envelope C.7 since the dose rate for this Content Envelope was very close to the regulatory limit. The Staff concluded that the analyses had sufficient conservatisms included to more than offset the effect of a reduction in the lead thickness.

\subsubsection{Appendices}

There are eleven Appendices associated with Chapter 5. The SARP Appendices provide supplementary information.

- Appendix 5.1, Dose Measurement Basis for the Package.

- Appendix 5.2, Source Term Calculations.

- Appendix 5.3, Shielding Codes. 
- Appendix 5.4, Modeling Details.

- Appendix 5.5, Material Properties.

- Appendix 5.6, Input/Output Computer Files.

- Appendix 5.7, Shielding Analysis of the 9975 Shipping Container.

- Appendix 5.8, Effect of Impurities.

- Appendix 5.9, Instrumentation Uncertainties Evaluation E-600/WENDI-2 Neutron Monitor.

- Appendix 5.10, Instrumentation Uncertainties Evaluation NRD Neutron Monitor.

- Appendix 5.11, 9975 Shipping Container Additional Americium and Thorium Content.

\subsection{Evaluation Findings}

\subsubsection{Findings}

The Model 9975-96 Package design has been shown to meet the shielding requirements of 10 CFR 71 [\$71.31(a)(1), §71.31(a)(2), §71.33, §71.35(a)] for each of the content envelopes in Table 1.2. The Model 9975-96 Package has been shown to be designed, constructed, and prepared for shipment so that the external radiation levels will not significantly increase under the tests specified in $\S 71.71$, as required by $\S 71.43(\mathrm{f})$ and $\S 71.51(\mathrm{a})(1)$.

Content Envelope C.7 is very close to the limit of $200 \mathrm{mrem} / \mathrm{hr}$ at the bottom surface of the package. The dose rate of $199.8 \mathrm{mrem} / \mathrm{hr}$ was calculated based on the original lead shield thickness of 0.47 inch. The gamma contribution to this dose rate presented in the SARP is $18.5 \mathrm{mrem} / \mathrm{hr}$. The SARP also presents the sensitivity of the gamma dose rate for plutoniumbased sources to the reduction in the lead thickness as a $33 \%$ increase while the Staff estimated this to be about $20 \%$. Regardless of this difference, it takes only an approximate $1-2 \%$ increase in the gamma dose rate to push this dose rate over the limit. However, upon examination of the shielding analysis for this Content Envelope, the Staff agrees with the statement in the SARP that there was a sufficient level of conservatism included to offset any increase in the dose rate caused by the reduction in the lead shield thickness.

It is noted that when Content Envelopes C.3b (plutonium metal) or C4 (plutonium oxide) have non-negligible or unknown amounts of impurities, or the impurity limits that exceed those presented in Appendix 5.8 of the SARP, measurement of the dose rates at the required location shall be made as described in Appendix 5.1. The Staff finds this approach acceptable. All other content envelopes have sufficient margins.

Based on review of the statements and representations in the application, the Staff concludes, with the exceptions discussed above, that the shielding design has been adequately described and evaluated and that the package meets the external radiation requirements of 10 CFR 71 and the IAEA Safety Standards Series No. TS-R-1. The radiation dose rates for the Model 9975-96 Package are less than the limits prescribed in 10 CFR 71 [\$71.47(a)] with a Transport Index less than 10. Therefore, this package and payload can be shipped by non-exclusive use and no specific dimensions of the transport vehicle are required. However, measurements as prescribed in Appendix 5.1 should be made prior to shipments of Content Envelopes, C.3b, C.4, and C.7. 
None of the NRC rule changes that went into effect on October 1, 2004 impact the Model 9975-96 Package SARP for a “-96" certification, from the viewpoint of external radiation.

\subsubsection{Conditions of Approval}

Section 5 of the Certificate of Compliance must contain the restriction that the Model 9975-96 Package be constructed as specified on the engineering drawings in the SARP. The CoC must also contain the restriction that the contents be bounded by Table 1.2 of the SARP.

For Content Envelopes C.3b and C.4 with unknown or non-negligible quantities of impurities as set forth in Appendix 5.8, measurements must be made as described in Appendix 5.1 to ensure compliance with regulatory limits on external radiation. A comparable requirement has also been included in Chapter 7, Operating Procedures, of the SARP.

\subsection{References}

[5-1] Washington Savannah River Company, Safety Analysis Report for Packaging, Model 9975, S-SARP-G-00003, Revision 0, Savannah River Packaging Technology, Savannah River National Laboratory (January 2008).

[5-2] Nuclear Regulatory Commission, 10 CFR Part 71, Compatibility with IAEA Transportation Standards (TS-R-1) and Other Transportation Safety Amendments; Final Rule, 69 F.R. 3698, pp. 3698-3814, January 26, 2004, as amended.

[5-3] Regulations for the Safe Transport of Radioactive Material, Safety Requirements, IAEA Safety Standards Series No. TS-R-1, 1996 Edition (As Amended 2003) International Atomic Energy Agency, Vienna, Austria (July 2004).

[5-4] American Nuclear Society, American National Standard for Neutron and Gamma-Ray Flux to Dose Rate Factors, ANSI/ANS 6.1.1-1977, LaGrange Park, Illinois.

[5-5] Safety Analysis Report for Packaging, Model 9975, B(M)F-85, Revision 0, WSCR-SA-2002-0008, Radioactive Materials Packaging Technology, Savannah River Technology Center, Westinghouse Savannah River Company, December 2003.

[5-6] U.S. Department of Energy, Safety Evaluation Report for Addendum 1 to the Safety Analysis Report for Packaging for the 9975 Package, Docket No. 05-7-9975, July 5, 2005.

[5-7] Hermann, O.W. and Westfall, R.M., ORIGEN-S: Scale System Module to Calculate Fuel Depletion, Actinide Transmutation, Fission Product Buildup and Decay, and Associated Radiation Source Terms, NUREG/CR-0200, Revision 6, Volume 2, Section F7, Oak Ridge National Laboratory, Oak Ridge, TN (March 2000).

[5-8] Barnett, M.H., et al, Radiation Source Term Analysis Code, RASTA, Use Guide (U), WSMSCRT-97-0013, Revision 2, Westinghouse Safety Management Solutions, LLC, Aiken, SC (December 2001).

[5-9] SCALE: A Modular Code System for Performing Standardized Analyses for Licensing Evaluations, NUREG/CR-0200, Rev. 6 (ORNL/NUREG/CSD-2/R6), Vols. I, II, III, December 1999, RSICC Computer Code Collection CCC-545, SCALE v. 4.4a.

[5-10] Briesmeister, J.F., Ed., MCNP-A General Monte Carlo N Particle Transport Code, Version 4C, LA-13709 M, Los Alamos National Laboratory, Los Alamos, NM (March 2000). 
5. Shielding Review

This Page Intentionally Blank. 


\section{CRITICALITY REVIEW}

\subsection{Areas of Review}

Chapter 6, Criticality, of the Safety Analysis Report for Packaging, Model 9975, for the Model 9975-96 Package ${ }^{[6-1]}$ was reviewed for criticality safety requirements. The review includes an evaluation of the SARP with respect to the requirements specified in 10 CFR $71{ }^{[6-2]}$ and in International Atomic Energy Agency (IAEA) Safety Standards Series No. TS-R-1. ${ }^{[6-3]}$

The criticality review included the following:

\subsubsection{Description of Criticality Design}

- Design Features

- Codes and Standards

- Summary Table of Criticality Evaluations

\subsubsection{Fissile Material Contents}

\subsubsection{General Considerations for Criticality Evaluations}

- Model Configuration

- Material Properties

- Demonstration of Maximum Reactivity

- Computer Codes and Cross-Section Libraries

\subsubsection{Single Package Evaluation}

- Configuration

- Results

\subsubsection{Evaluation of Undamaged-Package Arrays (Normal Conditions of Transport)}

- Configuration

- Results

\subsubsection{Evaluation of Damaged-Package Arrays (Hypothetical Accident Conditions)}

- Configuration

- Results

\subsubsection{Transport Index for Nuclear Criticality Control}

\subsubsection{Benchmark Evaluations}

- Applicability of Benchmark Experiments

- Bias Determination 


\subsubsection{Appendices}

\subsection{Regulatory Requirements}

Regulatory requirements of $10 \mathrm{CFR} 71^{[6-2]}$ applicable to the criticality review of fissile material packages are as follows:

- The package design must be described and evaluated to demonstrate that it meets the criticality requirements of 10 CFR 71. [§71.31(a)(1), §71.31(a)(2), §71.33, §71.35(a)]

- The application must identify the established codes and standards used for the package design, fabrication, assembly, testing, maintenance, and use. In the absence of such codes, the application must describe the basis and rationale used to formulate the quality assurance program. [\$71.31(c)]

- A single package must be subcritical under the conditions of $\S 71.55(\mathrm{~b}), \S 71.55(\mathrm{~d})$, and $\S 71.55(\mathrm{e})$.

- A fissile material packaging design to be transported by air must meet the requirements of $\S 71.55(\mathrm{f})$.

- Shipments containing plutonium must be made with the contents in solid form, if the contents contain greater than $0.74 \mathrm{TBq}(20 \mathrm{Ci})$ of plutonium. [ $\$ 71.63]$

- An array of undamaged packages must be subcritical under the conditions of $\S 71.59(\mathrm{a})(1)$.

- An array of damaged packages must be subcritical under the conditions of $\$ 71.59(a)(2)$.

- A fissile material package must be assigned a criticality safety index for nuclear criticality control to limit the number of packages in a single shipment. [\$71.59(b), $\S 71.59(\mathrm{c}), \S 71.35(\mathrm{~b})]$

- The package must be designed, constructed, and prepared for shipment so that there will be no significant reduction in the effectiveness of the packaging under the tests specified in $\S 71.71$ for normal conditions of transport. [§71.43(f), $\S 71.51(\mathrm{a})(1), \S 71.55(\mathrm{~d})(4)]$

- A package used for shipment of fissile material must be designed and constructed and its contents so limited that under the tests specified in $\S 71.73$, the package would be subcritical.

- Unknown properties of fissile material must be assumed to be those that will credibly result in the highest neutron multiplication. [\$71.83]

\subsection{Review Procedures}

Chapter 6 of the Model 9975-96 Package SARP includes the information essential for a criticality evaluation including the drawings, the packaging materials and densities, and the fissile isotopic composition and mass. This criticality information in the Model 9975-96 Package SARP was reviewed by the Staff for completeness and compliance with regulatory requirements. Of particular importance are the subcriticality requirements per 10 CFR 71.55 and 10 CFR 71.59. 


\subsubsection{Description of Criticality Design}

\subsubsection{Design Features}

The Model 9975-96 Package has double containment. The fissile contents are generally placed in a product or convenience can. A product or convenience can may be placed in one or more low density polyethylene (LDPE) bags, provided that no more than 100 grams of polyethylene are involved. For metals, from one to three product cans may be placed within the PCV. Plutonium oxides may be enclosed in a 3013 container, food-pack can, or hex-can, which, in turn, is placed within the PCV.

The design of the Model 9975-96 Package does not include any specific neutron-absorbing material for criticality control. The package utilizes the geometry of the containment vessel and control of the quantity and composition of the fissile material to ensure that the single package contents are subcritical under NCT and HAC. In addition to the control of the geometry and specific fissile content, interaction control is also established by the fact that the containment is enclosed in a drum ensuring a center-to-center separation of at least the diameter of the drum in the lateral direction (perpendicular to the drum axis). Furthermore, the hydrocarbon insulatingspacing material (with a nominal minimum density of $0.24 \mathrm{~g} / \mathrm{cc}$ ) is a neutron moderator and acts to further isolate a package from neighboring packages. These features ensure that the arrays of packages are subcritical under NCT and HAC.

The Staff confirms that the text and sketches describing the criticality design features are consistent with the engineering drawings and the models used in the criticality evaluation. The Staff also concludes that the Model 9975-96 Package conforms to the general standards for all packages as prescribed by 10 CFR 71 (i.e., $§ 71.31(\mathrm{a})(1), \S 71.31(\mathrm{a})(2), \S 71.31(\mathrm{c}), \S 71.33$, and $\$ 71.35(\mathrm{a}))$. In addition, the Staff concludes that the SARP has assigned a proper CSI of 2.0 for the Model 9975-96 Package with metal or oxide payloads, as prescribed by 10 CFR 71 (i.e., $\S 71.59, \S 71.35(\mathrm{~b}))$.

The PCV for the Model 9975-96 Package consists of a cylindrical structure with a maximum 5.174-inch ID, Type 304L stainless steel pressure vessel. The SCV for the Model 9975-96 Package consists of a maximum 6.345-inch ID, Type 304L stainless steel cylindrical pressure vessel. Both the PCV and the SCV comply with the stress criteria of the ASME B\&PV Code Section III, Subsection NB. ${ }^{[6-4]}$ The PCV is placed within the SCV. The PCV-SCV combination is placed within a specially fabricated 35-gallon removable-head drum, constructed of Type 304L stainless steel, with a minimum OD of 18.22 inches (the drum rolling hoops are somewhat larger and are responsible for a slightly larger minimum diameter). The PCV-SCV combination is enclosed within a nominally 0.5 -inch-thick layer of lead, which is kept centered within the drum by about a 5-inch thick layer of fiberboard insulation material. An additional layer of stainless steel was added as an outer liner to the lead shield effectively reducing the shield thickness. However, the overall shield assembly with the lead and the inner and outer liners remained the same as in the earlier configuration, i.e. 0.506-inch thick.

\subsubsection{Codes and Standards}

The containment vessels are leak tested to the ANSI N14.5-1997 Standard. ${ }^{[6-5]}$ 
The Model 9975-96 Package containment vessel design for the PCV and the SCV complies with the stress criteria of the ASME B\&PV Code Section III, Subsection NB.

Single package subcriticality for solid plutonium and highly enriched uranium (HEU) contents was justified on the basis of ANSI/ANS-8.1-1998. ${ }^{[6-6]}$

\subsubsection{Summary Table of Criticality Evaluation}

The SARP summary table, Table 6.1, addresses the following cases for the Model 9975-96 Package: a single package, under the conditions of $\S 71.55(\mathrm{~b}),(\mathrm{d})$, and (e); an array of undamaged packages, under the conditions of $\$ 71.59(\mathrm{a})(1)$; and an array of damaged packages, under the conditions of $\S 71.59(\mathrm{a})(2)$. Table 6.1 includes the maximum value of the effective multiplication factor $\left(\mathrm{k}_{\mathrm{eff}}\right)$ for each package payload, including two standard deviations. It also lists the safe value for the multiplication factor $\left(\mathrm{k}_{\mathrm{safe}}\right)$, for which the appropriate bias and bias uncertainty have been subtracted from 0.95 (which includes the accepted criticality safety margin of 0.05). It also lists the number of packages evaluated in the arrays. The table either demonstrates appropriate subcriticality by showing that the value of $\mathrm{k}_{\mathrm{eff}}$ is less than $\mathrm{k}_{\mathrm{safe}}$ for that package and payload, or it invokes the ANSI/ANS 8.1-1998 subcritical limit to show sufficient subcriticality.

\subsubsection{Fissile Material Contents}

The contents used in the criticality analyses are consistent with those specified in the General Information section of the SARP. The density for any allowed fissile material is its maximum theoretical density. For the purpose of conservatism, the plutonium and uranium contents were assumed to be 100 weight percent ${ }^{239} \mathrm{Pu}$, and 100 weight percent ${ }^{235} \mathrm{U}$, respectively.

The Staff notes that the prior changes in Content Envelopes C. 3 and C.4, i.e., the increase in

${ }^{241} \mathrm{Pu}$ and ${ }^{241} \mathrm{Am}$ from 11 weight percent to 15 weight percent and the increase in the thorium content to a maximum of $1 \mathrm{~kg},{ }^{[6-7]}$ will not impact the conclusions of the criticality analysis presented in the SARP.

\subsubsection{General Considerations for Criticality Evaluations}

\subsubsection{Model Configuration}

The configurations for the calculational models for a single package and for the arrays of packages used to perform the criticality evaluation of the Model 9975-96 Package are described in Section 6.3 of the SARP.

The criticality modeling for the Model 9975-96 Package makes several assumptions for the package models to be used for a single package. The SARP presents different package models for the NCT and HAC array analyses.

The model for the single Model 9975-96 Package assumes that the PCV is a simple cylinder. The maximum inner cylinder diameter is chosen for the PCV, as this choice maximizes the PCV volume and the reactivity. The calculational model assumes full water reflection of the PCV, as required by 10 CFR $71.55(\mathrm{~b})$. 
For the single package analyses, the fissile materials are treated as being spherical metal with a beryllium shell and surrounded by water. Plutonium metal bounds plutonium oxide from a criticality standpoint, independent of whether the beryllium shell is present. Also the possible LDPE bags surrounding the fissile material in metal form are considered by allowing a 100-gram shell of $\mathrm{CH}_{2}$ to surround the fissile sphere. All three of these treatments maximize the reactivity. For neptunium oxide described by Content Envelope C.8, the evaluation used the same model as for Content Envelopes C.1 through C.7, except that the contents are modeled as a cylinder with polyethylene wrapped around the food-pack can container rather than the radioactive material. A theoretical density for neptunium oxide of $11.1 \mathrm{~g} / \mathrm{cm}^{3}$ is conservatively used, even though the bulk and tap densities of neptunium oxide were determined as 1.9 and $2.5 \mathrm{~g} / \mathrm{cm}^{3}$, respectively.

The NCT tests did not cause any damage to the Model 9975-96 Package that significantly affected criticality. Analyses reported in the SARP show that an infinite number of undamaged packages remain subcritical under the NCT conditions. The HAC tests did cause package damage that affected the criticality calculations. The HAC model conservatively took into account the Celotex ${ }^{\mathrm{TM}}$ burn test and drop test data. The displacements of the PCV in neighboring packages in an array are treated to maximize their interaction and produce maximum reactivity. This is a very conservative treatment of the HAC damage.

HAC array sensitivity calculations demonstrated that the most reactive configuration resulted when the damaged portion of the removed Celotex ${ }^{\text {TM }}$ within the drum was replaced by air and not by water of any density.

For the HAC array calculations, the fissile materials are located within the PCV to give the closest interaction with respect to the fissile materials in other neighboring packages. This treatment maximizes the reactivity.

The closest packed array of Model 9975-96 Packages achievable is hexagonal in a lateral plane (perpendicular to the package axes), but square in the vertical direction for subsequent layers of packages. The SARP analyses used square arrays in both directions, but decreased the lateral pitch by $7 \%$ to account for this approximation in the lateral-plane layers.

Because the Model 9975-96 Package has double containment and no inleakage occurred during HAC tests, the HAC array calculation model assumes that the PCV is dry. For single package calculations, the fissile materials are treated as spherical metal with a beryllium shell and in solution form surrounded by water. For the NCT and HAC calculations, the most reactive fissile material contents were used in the form of a dry sphere.

\subsubsection{Material Properties}

Accepted values for the density of all packaging materials are used in the SARP. The SARP used a density value for the fiberboard material of $0.20 \mathrm{~g} / \mathrm{cc}$ that is somewhat less than the nominal minimum density specified of $0.24 \mathrm{~g} / \mathrm{cc}$. (The minimum permissible density of fiberboard is greater than $0.20 \mathrm{~g} / \mathrm{cc}$.) This lower Celotex ${ }^{\mathrm{TM}}$ density is a conservative assumption for criticality analyses. Accepted maximum values for the fissile material densities are used in the SARP. The Staff concludes that the fissile material properties for the Model 9975-96 Package conform to 10 CFR 71.83. In addition, the Staff concludes that the properties of the 
fiberboard insulation-spacer affecting criticality will not degrade during the normal service life of the packaging.

\subsubsection{Demonstration of Maximum Reactivity}

Maximum reactivity was demonstrated for single packages with plutonium with an optimally thick shell of beryllium (see Section 6.3.4 in this TRR). For solid plutonium, an optimum thickness of shell corresponds to about 200 to 300 grams of beryllium. LDPE bags surrounding metal fissile material are treated as a 100 gram shell of $\mathrm{CH}_{2}$. Analyses of the configuration with the polyethylene shell give slightly more reactivity than without it. Maximum reactivity for single packages was also demonstrated with fissile material in solutions. Confirmatory calculations verify these conclusions.

The most reactive individual package appropriate to the specific conditions was used for NCT and HAC array analyses. Maximum reactivity was demonstrated for both NCT and HAC array analyses for the mass and position of fissile material, and internal and interspersed moderation (see Sections 6.3.5 and 6.3.6, respectively, in this TRR). Confirmatory calculations verify this conclusion.

The SARP analyzed the effect of surrounding the PCV with various reflective regions on its reactivity. The reference 3013 configuration was found to be the most reactive configuration for the single package, and was used to bound the other packaging options. The SARP analyzed the effect of various combinations of flooding and reflection of the PCV in determining the most reactive configuration. The Staff confirms that the SARP has used the most reactive configuration in demonstrating subcriticality.

\subsubsection{Computer Codes and Cross-Section Libraries}

The criticality studies used the 238-group cross-section library with CSAS25 in SCALE 4.4a. ${ }^{[6-8,6-9]}$ These computer codes and cross-section libraries are appropriate for the criticality calculations, and are consistent with the neutron spectrum of the package. Also, these cross-section libraries properly account for resonance absorption and self-shielding effects. The benchmark evaluations and resulting biases were determined using the same codes and crosssection sets.

The SARP study used about 400,000 neutron histories to obtain the $\mathrm{k}_{\mathrm{eff}}$ values. The number of neutron histories is adequate to assure that the fissile systems analyzed will be sampled in a statistically acceptable manner.

No output listings are included in the SARP, but were provided separately to the Staff. Confirmatory calculations verified these results. The model input parameters, material densities, and cross sections were properly entered into the CSAS25 input listings in Appendix 6.2.

It is noted that the Staff did not perform any additional confirmatory criticality safety calculations for the Model 9975-96 Package because the earlier calculations by the Staff, referred to in various sections of Chapter 6 of this document, are still valid since all the bounding configurations were unchanged. The addition of thorium to Content Envelopes C.3 and C.4, as well as the increase in the maximum weight percent of ${ }^{241} \mathrm{Pu}$ and ${ }^{241} \mathrm{Am}$ in these content envelopes, will not impact the bounding configurations analyzed. 


\subsubsection{Single Package Evaluation}

The Staff concludes that the Model 9975-96 Package conforms to the criticality requirements as prescribed by 10 CFR 71, i.e., $§ 71.43(\mathrm{f}), \S 71.51(\mathrm{a}), \S 71.55(\mathrm{~b}), \S 71.55(\mathrm{~d}), \S 71.55(\mathrm{e})$.

\subsubsection{Configuration}

The SARP determined that the maximum reactivity occurs when the PCV in the Model 9975-96 Package contains a solid $4.4 \mathrm{~kg}$ sphere of ${ }^{239} \mathrm{Pu}$ metal, with a tight fitting shell of beryllium of optimum thickness ( $4.4 \mathrm{~kg}$ includes both plutonium and beryllium), with both completely surrounded by water (fully flooded), and with full water reflection of the containment vessel, as required in $\S 71.55(\mathrm{~b})$.

\subsubsection{Results}

The Model 9975-96 Package also meets the additional specifications of 10 CFR 71.55(d)(2) through $\S 71.55(\mathrm{~d})(4)$ under NCT.

The criticality results of the most reactive case for the single package analysis are consistent with the information presented in the summary table discussed in Section 6.3.1 of this TRR.

ANSI-8.1-1998 gives $5.0 \mathrm{~kg}$ of ${ }^{239} \mathrm{Pu}$ metal as the subcritical limit. The SARP argues that a single Model 9975-96 Package with a solid $4.4 \mathrm{~kg}$ sphere of ${ }^{239} \mathrm{Pu}$ metal is subcritical because it is 600 grams less than the ANSI-8.1 subcritical limit, and that the packaging surrounding the PCV (lead, fiberboard, drum, etc.) is essentially statistically equivalent to water. The SARP shows that 600 grams of ${ }^{239} \mathrm{Pu}$ metal accounts for not less than approximately 0.034 of the package reactivity. The maximum additional reactivity effect of a beryllium shell (including reduced plutonium mass) is found to be about $1 \%$. Therefore, the surrounding beryllium reflector material increases $\mathrm{k}_{\text {eff }}$ much less than 600 grams of plutonium decreases $\mathrm{k}_{\text {eff. }}$. Mixing the beryllium homogeneously with the fissile material decreases $\mathrm{k}_{\mathrm{eff}}$. Therefore, $4.4 \mathrm{~kg}$ of ${ }^{239} \mathrm{Pu}$ metal in any configuration in a full water-flooded PCV and fully water-reflected containment vessel is appropriately subcritical. The Staff concurs with this assessment. This metal content bounds $4.4 \mathrm{~kg}$ of plutonium in $5.0 \mathrm{~kg}$ of plutonium oxide, independent of whether the beryllium shell is present.

Table 6.17 of the SARP shows the results of the criticality analysis of a single package containing neptunium oxide. The calculated $\mathrm{k}_{\text {eff }}$ values, approximately 0.40 , are all much lower than $\mathrm{k}_{\text {safe. }}$.

Confirmatory analyses were conducted using the criticality code MCNP (version 4b) ${ }^{[6-10]}$ with the point wise .60c cross-section sets (ENDF/B VI) where possible. These analyses verify that the SARP conclusions are valid.

For neptunium oxide described by Content Envelope C.8, the Staff concluded that the single package is subcritical based on ANSI/ANS-8.15-1981. ${ }^{[6-11]}$ Isotopes with an even number of neutrons, such as ${ }^{237} \mathrm{~Np}$, can be made critical, but the mass required is kilograms. The effect of moderation on these nuclides is to prevent, rather than enhance, criticality. These nuclides characteristically exhibit rather sharp thresholds in their fission cross sections, with little or no probability for sub-threshold fission. Since ${ }^{237} \mathrm{~Np}$ has a fission threshold of $\sim 600 \mathrm{keV}$, the 
critical mass increases with the addition of moderators. The subcritical mass limits for ${ }^{237} \mathrm{~Np}$ as oxide are $140 \mathrm{~kg}$, when reflected by water, and $90 \mathrm{~kg}$, when reflected by steel, respectively. With a mass of $6 \mathrm{~kg}$ of ${ }^{237} \mathrm{~Np}$, it is concluded that a single package is adequately subcritical.

\subsubsection{Evaluation of Undamaged-Package Arrays (Normal Conditions of Transport)}

The NCT tests did not result in any water leakage into the containment system or damage that significantly affected the criticality of the packages. The Staff concludes that the Model 9975-96 Package is designed, constructed, and prepared for shipment so that there will be no significant reduction in the criticality safety of any package during NCT. The Staff also concludes that the Model 9975-96 Package conforms to the NCT criticality requirements for all packages, as prescribed by 10 CFR 71.59(a)(1), §71.59(a)(3).

\subsubsection{Configuration}

The SARP evaluated the most reactive dry fissile contents in an undamaged Model 9975-96 Package for the NCT analyses. The most reactive dry fissile content was a solid $4.4 \mathrm{~kg}$ sphere of ${ }^{239} \mathrm{Pu}$ metal with an optimum thickness shell of beryllium $(4.4 \mathrm{~kg}$ includes both plutonium and beryllium) in a PCV. No water is present within the containment vessel, and there is no interspersed moderation between packages. The plutonium sphere with a beryllium shell is located within the center of each PCV. The SARP analyses evaluated an infinite array of packages to demonstrate subcriticality.

\subsubsection{Results}

The most reactive dry individual Model 9975-96 Package was used for the NCT analyses. No containment flooding or interspersed moderation is required for these NCT studies. The array analyses reported in the SARP showed that an infinite array of packages, with each fissile mass located at the center of the PCV in each package, is appropriately subcritical. A Criticality Safety Index (CSI) of 0.0 would result for the Model 9975-96 Package based on this NCT analyses.

Table 6.21 of the SARP shows the results of the criticality analysis of an array of packages containing neptunium oxide in NCT. The calculated $\mathrm{k}_{\text {eff }}$ values, around 0.41 , are all much lower than $\mathrm{k}_{\text {safe. }}$.

Confirmatory analyses were conducted using the criticality code MCNP (version 4b) with the point wise .60c cross-section sets (ENDF/B VI) where possible. These calculations used the actual hexagonal lattice packing for the lateral layers in order to confirm that the SARP results are acceptable. Confirmatory analyses verify that the SARP conclusions are valid.

For neptunium oxide described by Content Envelope C.8, the Staff concluded that an array of packages in NCT is subcritical. Isotopes with an even number of neutrons, such as ${ }^{237} \mathrm{~Np}$, can be made critical, but the mass required is kilograms. The effect of moderation on these nuclides is to prevent, rather than enhance, criticality. These nuclides characteristically exhibit rather sharp thresholds in their fission cross sections, with little or no probability for sub-threshold fission. Since ${ }^{237} \mathrm{~Np}$ has a fission threshold of $\sim 600 \mathrm{keV}$, the critical mass increases with the addition of moderators. The subcritical mass limits for ${ }^{237} \mathrm{~Np}$ as oxide are $140 \mathrm{~kg}$, when reflected by water, and $90 \mathrm{~kg}$, when reflected by steel, respectively. With a mass of $6 \mathrm{~kg}$ of ${ }^{237} \mathrm{~Np}$ in the package, 
and hydrogenous Celotex ${ }^{\mathrm{TM}}$ insulation surrounding each package in the array acting as a moderator, and the spacing maintained by the drum, it is concluded that an array of packages in NCT is adequately subcritical.

\subsubsection{Evaluation of Damaged-Package Arrays (Hypothetical Accident Conditions)}

The Staff concludes that the Model 9975-96 Package conforms to the HAC criticality requirements for all packages, as prescribed by 10 CFR 71.59(a)(2) and $\$ 71.59(\mathrm{a})(3)$.

\subsubsection{Configuration}

The SARP uses the most reactive contents in a damaged Model 9975-96 Package for the array calculations under HAC analyses. Since the Model 9975-96 Package has double containment and did not leak during HAC tests, and because the Model 9975-96 Package containment vessel design for the PCV and the SCV complies with the stress criteria of the ASME B\&PV Code Section III, Subsection NB, the PCV is assumed to not leak water. Therefore the contents are assumed to remain dry. The most reactive fissile content is a solid $4.4 \mathrm{~kg}$ sphere of ${ }^{239} \mathrm{Pu}$ metal with an optimum thickness beryllium shell ( $4.4 \mathrm{~kg}$ includes both plutonium and beryllium) within a PCV.

The most reactive configuration of packages in the HAC calculations is with no interspersed moderation between packages. The plutonium sphere with beryllium shell is located within each PCV so that the closest interaction exists between fissile masses in neighboring packages. In the damaged condition, the PCV and Celotex ${ }^{\mathrm{TM}}$ material, modified as described in Section 6.3.3.1 in this TRR, should also be displaced within the packages to give rise to the maximum interaction between neighboring packages. That is, the bottom level packages have the plutonium sphere with beryllium shell near the top of the PCV and moved laterally toward the PCV sidewall nearest the vertical axis through the packages. Each PCV-SCV assembly is then moved vertically near the top of the package and moved laterally toward the vertical axis through the center of the eight packages as much as allowed by the damaged condition of the insulation material, as given in Section 6.3.3.1 in this TRR. Whereas, the top level packages have the plutonium sphere with beryllium shell near the bottom of the PCV and moved laterally toward the PCV side wall nearest the vertical axis through the packages. Each PCV-SCV assembly is then moved vertically near the bottom of the package and moved laterally toward the vertical axis through the center of the eight packages as much as allowed by the damaged condition of the insulation material, as given in Section 6.3.3.1 in this TRR. The SARP evaluates a $5 \times 5 \times 2$ array to demonstrate subcriticality.

\subsubsection{Results}

The most reactive single Model 9975-96 Package with appropriate damage was used for the HAC, except without water flooding in the PCV. For the Model 9975-96 Package, this configuration is described in the preceding section. The array analyses performed assumed the plutonium sphere with beryllium shell was located within each PCV, and each damaged PCV-Celotex ${ }^{\mathrm{TM}}$ combination is displaced so that the closest separation exists between fissile masses in neighboring packages. This results when the plutonium spheres in each set of eight neighboring packages (4-in. top layer and 4-in. bottom layer immediately below them) are at their closest possible approach. This arrangement gives the maximum interaction between neighboring packages. The most reactive array is, in addition, when no interspersed moderation 
is present between packages. This is a very conservative model. The SARP analyses finds that a $5 \times 5 \times 2$ array of HAC packages is appropriately subcritical. Confirmatory calculations support this conclusion. A CSI of 2.0 is determined for 50 packages being subcritical for HAC.

Table 6.30 of the SARP shows the results of the criticality analysis of an array of packages containing neptunium oxide in HAC. The calculated $\mathrm{k}_{\text {eff }}$ values, around 0.42 , are all well below $\mathrm{k}_{\text {safe. }}$.

Confirmatory analyses were conducted using the criticality code MCNP (version 4b) with the point wise $.60 \mathrm{c}$ cross-section sets (ENDF/B VI) where possible. Confirmatory calculations used the actual hexagonal lattice packing for the lateral layers in order to confirm that the SARP results are acceptable. Confirmatory analyses verify that the SARP conclusions are valid.

For neptunium oxide described by Content Envelope C.8, the Staff concluded that an array of packages in HAC is adequately subcritical.

Table 6.31 of the SARP presents results from sensitivity studies to estimate the impact of change in the lead shield assembly (see Section 6.3.1.1 of this report). The SARP HAC analyses conclude that the impact is statistically insignificant. The Staff agrees with these conclusions.

\subsubsection{Criticality Safety Index for Nuclear Criticality Control}

A minimum criticality CSI of 2.0 is assigned to the Model 9975-96 Packages, based on the HAC array calculations showing that 50 packages in any configuration have a multiplication factor plus bias and uncertainties that is less than 0.95. The CSI is consistent with that reported in Chapter 1 on General Information in the SARP. The Staff concurs with this value.

\subsubsection{Benchmark Evaluations}

The SARP used the same criticality computer code, hardware, and cross-section library sets to determine the bias values from benchmark experiments as those used to calculate the multiplication factors for the packages. Additional benchmark information is given in Appendix 6.1 of the SARP.

\subsubsection{Applicability of Benchmark Experiments}

The benchmark experiments used in this study were taken from the various volumes of the International Handbook of Evaluated Criticality Safety Benchmark Experiments

(NEA 1998), ${ }^{[6-12]}$ and are appropriately referenced. This collection of benchmark experiments is the accepted standard in the criticality community.

The plutonium benchmark experiments are applicable to the actual packaging design and contents. The plutonium benchmark experiments have, to the maximum extent possible, the same fissile materials, moderation, neutron spectra, and configuration as the package evaluations.

There is currently only one benchmark experiment involving neptunium, which is not sufficient to determine a statistically significant bias for Content Envelope C.8. Therefore, consistent with the guidance provided in NUREG/CR-5661, ${ }^{[6-13]}$ the applicant establishes a margin of subcriticality greater than the $0.05 \Delta \mathrm{k}$ subcritical margin typically used for packaging. The 
applicant establishes a $\mathrm{k}_{\mathrm{safe}}$ of 0.90 , which is equivalent to a subcritical margin of $0.10 \Delta \mathrm{k}$. The applicant justifies this additional margin based on an evaluation of the single benchmark experiment, which showed a positive bias of $0.02 \Delta \mathrm{k}$; i.e., the code over-predicts $\mathrm{k}_{\text {eff, which is }}$ conservative. An additional evaluation of an infinite array of packages was run to compare four different cross-section libraries, and the resulting difference between the maximum and minimum was $0.02 \Delta \mathrm{k}$. Considering also the low values of $\mathrm{k}_{\mathrm{eff}}$ shown in the criticality evaluation, and the values of the subcritical mass limits from ANSI/ANS-8.15-1981, the Staff agrees that a $\mathrm{k}_{\text {safe }}$ of 0.90 includes an appropriate margin of subcriticality.

\subsubsection{Bias Determination}

Contributions from uncertainties in experimental data are included for all benchmark experiments reported in the Handbook. Also, a sufficient number of appropriate benchmark experiments are analyzed and the results of these benchmark calculations are used to determine an acceptable bias for each fissile payload. These bias values are then used in the calculation of a safe multiplication factor for the package payloads. The statistical and convergence uncertainties of the benchmark calculations and package evaluations are essentially consistent, and do not significantly affect the determination of bias values.

The SARP determined an acceptable value for the bias for plutonium metal. Acceptable statistical analyses demonstrate that this value is accurate, but conservative. The Staff concurs that the benchmark experiments and corresponding bias value are applicable and conservative as applied to the Model 9975-96 Package.

\subsubsection{Appendices}

There are four Appendices associated with Chapter 6. The Appendices provide various supplementary information.

- Appendix 6.1, Sensitivity Studies.

- Appendix 6.2, Reference 3013 Model.

- Appendix 6.3, Verification of Tantalum and Vanadium Cross Section Set.

- Appendix 6.4, Sample Input Files.

\subsection{Evaluation Findings}

\subsubsection{Findings}

Based on review of the statements and representations made in the SARP, the Model 9975-96 Package design has been shown to meet the criticality requirements of 10 CFR 71.31(a)(1), 10 CFR 71.31(a)(2), 10 CFR 71.33, and 10 CFR 71.35(a). The Model 9975-96 Package has also been shown to be designed, constructed, and prepared for shipment so that there will be no significant reduction in the effectiveness of the packaging under the tests specified in $\S 71.71$ for NCT, i.e., $\S 71.43(\mathrm{f}), \S 71.51(\mathrm{a})(1)$, and $\S 71.55(\mathrm{~d})(4)$.

The Model 9975-96 Package with Content Envelopes in Table 1.2 has been shown to meet the requirements of $\S 71.55(\mathrm{~b}), \S 71.55(\mathrm{~d})$, and $\S 71.55(\mathrm{e})$, under which a single package must be subcritical, and has been shown to meet the requirements of $\S 71.59(\mathrm{a})(1)$ and $\S 71.59(\mathrm{a})(2)$, under 
which an array of undamaged packages, and an array of damaged packages, must be subcritical, respectively.

Based on review of the statements and representations in the application, the Staff concludes that the nuclear criticality safety design has been adequately described and evaluated, and that the Model 9975-96 Package meets the subcriticality requirements of 10 CFR 71. By meeting the requirements of 10 CFR 71, the package also meets the requirements of IAEA Safety Standard Series No. TS-R-1. ${ }^{[6-3]}$

The NRC rule changes that went into effect on October 1, 2004 replaced the use of a Transport Index (TI) for criticality safety with a Criticality Safety Index. ${ }^{[6-2]}$ Paragraph 218 results in NRC incorporating a Criticality Safety Index in 10 CFR 71 that is determined in the same manner as current 10 CFR 71, "Transport Index for criticality control purposes," but now it must be displayed on shipments of fissile material (paragraphs 544-545) using a new "fissile material" label. NRC's adoption of TS-R-1 (paragraph 530) increases the CSI-per package limit from 10 to 50 for fissile material package shipments. (The previous Transport Index criticality limit was 10).

The SARP has complied with this change and replaced all references to the TI for criticality control in Chapter 6 with CSI.

\subsubsection{Conditions of Approval}

Section 6 of the certificate of compliance must contain the restriction that the Model 9975-96 Package must be constructed as specified on the engineering drawings in the SARP. The CoC must also contain the restriction that the contents be bounded by Table 1.2 of the SARP. The package is not authorized for transport by air.

\subsection{References}

[6-1] Washington Savannah River Company, Safety Analysis Report for Packaging, Model 9975, S-SARP-G-00003, Revision 0, Savannah River Packaging Technology, Savannah River National Laboratory (January 2008).

[6-2] Nuclear Regulatory Commission, 10 CFR Part 71, Compatibility with IAEA Transportation Standards (TS-R-1) and Other Transportation Safety Amendments; Final Rule, 69 F.R. 3698, pp. 3698-3814, January 26, 2004, as amended.

[6-3] Regulations for the Safe Transport of Radioactive Material, Safety Requirements, IAEA Safety Standards Series No. TS-R-1, 1996 Edition (As Amended 2003) International Atomic Energy Agency, Vienna, Austria (July 2004).

[6-4] ASME Boiler and Pressure Vessel Code, Section III, Rules for Construction of Nuclear Power Plant Components, Division I, Subsection NB, American Society of Mechanical Engineers, New York, NY (2004).

[6-5] Institute of Nuclear Materials Management, American National Standard for Radioactive Materials, Leakage Tests on Packages for Shipment, ANSI N14.5-1997, New York.

[6-6] Nuclear Criticality Safety in Operations with Fissionable Materials Outside Reactors, ANSI/ANS-8.1-1998. 
[6-7] U.S. Department of Energy, Safety Evaluation Report for Addendum 1 to the Safety Analysis Report for Packaging for the 9975 Package, Docket No. 05-7-9975, July 5, 2005.

[6-8] CSAS25. A functional criticality control module within the SCALE Code System. See SCALE 4.4a.

[6-9] Keno va. A three-dimensional criticality module within the SCALE Code System. See SCALE 4.4a.

[6-10] Briesmeister, J.F., Ed., MCNP-A General Monte Carlo N Particle Transport Code, Version 4b, LA-12625-M, Los Alamos National Laboratory, Los Alamos, NM (March 1997).

[6-11] Nuclear Criticality Control of Special Actinide Elements, ANSI/ANS-8.15-1981.

[6-12] International Handbook of Evaluated Criticality Safety Benchmark Experiments, Nuclear Energy Agency, Organization for Economic Co-Operation and Development, NEA/NSC Doc (95) 03 (September 1998).

[6-13] Recommendations for Preparing the Criticality Safety Evaluation of Transportation Packages, NUREG/CR-5661, Nuclear Regulatory Commission, Washington, DC (April 1997). 
6. Criticality Review

This Page Intentionally Blank. 


\section{OPERATING PROCEDURES}

\subsection{Areas of Review}

Chapter 7, Operating Procedures, of the Safety Analysis Report for Packaging, Model 9975, Model 9975, B(M)F-96, ${ }^{[7-1]}$ was reviewed to verify that it meets the requirements of 10 CFR $71,{ }^{[7-2]}$ and is adequate to assure that the package will be operated in a manner consistent with its evaluation for approval. The review includes an evaluation of the SARP with respect to the requirements specified in International Atomic Energy Agency (IAEA) Safety Standards Series No. TS-R-1. ${ }^{[7-3]}$

The Staff reviewed the controls and procedures to ensure that the Model 9975-96 Package will be operated in a manner consistent with its evaluation for approval. These are the generic operating procedures from which the formal, site-specific operating procedures will be developed.

The Operating Procedures Review included the following:

\subsubsection{Package Loading}

- Preparation for Loading

- Loading of Contents

- Preparation for Transport

\subsubsection{Package Unloading}

- Receipt of Package from Carrier

- Removal of Contents

\subsubsection{Preparation of Empty Package for Transport}

\subsubsection{Additional Procedures}

\subsubsection{Appendices (as applicable)}

\subsection{Regulatory Requirements}

The regulatory requirements of 10 CFR 71 applicable to the Operating Procedures review are as follows:

- The application must identify the established codes and standards used for the package design, fabrication, assembly, testing, maintenance, and use. In the absence of such codes, the application must describe the basis and rationale used to formulate the quality assurance program. [\$71.31(c)]

- The application must include any special controls and precautions for transport, loading, unloading, and handling of a fissile material shipment, and any special controls in case of accident or delay. [\$71.35(c)] 
- The transport index of a package in a nonexclusive-use shipment must not exceed 10, and the sum of the Criticality Safety Indices (CSI) of all packages in the shipment must not exceed 50. [\$71.47(a), $\$ 71.59(\mathrm{c})(1)]$

- Packages that require exclusive-use shipment because of increased radiation levels must be controlled by providing written instructions to the carrier. [ $\$ 71.47(\mathrm{~b}-\mathrm{d})]$

- The sum of the CSIs for nuclear criticality control of all packages in an exclusive-use shipment must not exceed 100. [§71.59(c)(2)]

- The application must include Package Operations that ensure that the package meets the routine-determination requirements of $\$ 71.87$. [ $\$ 71.81, \S 71.87]$

- Unknown properties of fissile material must be assumed to be those that will credibly result in the highest neutron multiplication. [\$71.83]

- A package must be conspicuously and durably marked with the model number, serial number, gross weight, and package identification number. [\$71.85(c), §71.19(a)(2), $\S 71.19(\mathrm{~b})(3)]$

- Prior to delivery of a package to a carrier, any special instructions needed to safely open the package must be provided to the consignee for the consignee's use in accordance with 10 CFR 20.1906(e). [\$71.89]

- Each type $\mathrm{B}(\mathrm{U})$ or Type $\mathrm{B}(\mathrm{M})$ package design must have on the outside of the outermost receptacle a fire resistance radiation symbol in accordance with 49 CFR 172.310(d).

\subsection{Review Procedures}

The following procedures are generally applicable to the review of the Operating Procedures chapter of the SARP. These procedures correspond to the Areas of Review listed in Section 7.1 of this TRR.

The operating procedures in the SARP should generally be listed in sequential order. Additional guidance on operating procedures is provided in the Guide for Preparing Operating Procedures for Shipping Packages (NUREG/CR-4775). ${ }^{[7]}$

\subsubsection{Package Loading}

\subsubsection{Preparation for Loading}

The procedures for loading the package are contained in Section 7.2 of the SARP. Section 7.2.1 covers the preparation of the package for loading. The following were identified, either directly or indirectly, as being part of the operating procedures:

- It was noted that the package will be loaded and closed in accordance with site-specific, written procedures.

- Special controls and precautions for loading and handling were noted and described.

- A requirement to verify that the package is in unimpaired physical condition, and that all required periodic maintenance requirements have been performed, is included. 
- A specific requirement to ensure that the package is conspicuously and durably marked with the model number, serial number, gross weight, and package identification number is included.

- A requirement is included to verify that the package is appropriate for the contents to be shipped.

- A requirement is included to ensure that the use of the package complies with all other conditions of approval in the CoC.

\subsubsection{Loading of Contents}

The procedures for loading the contents into the PCV of the package are contained in Section 7.2.2 of the SARP. The following were identified, either directly or indirectly, as being part of the operating procedures:

- Special handling equipment was specified, where needed.

- Special controls and precautions for loading were specified, where needed.

- The method of loading the contents was specified.

- Although there is no requirement to ensure that moderator or neutron absorbers are present and in proper condition, such a requirement is not necessary for the shipment of any of the Content Envelopes, C.1 through C.8. There is also a requirement to ensure that physical spacers are in place to minimize potential cell sizes and mitigate the potential for a deflagration-to-detonation transition for the shipment of oxides.

- Although there is no description of the method used to remove water from the package, such a requirement is not necessary for this package.

- Because the package is loaded at ambient pressures, there is no requirement to vent excess gases during the loading of the PCV or the SCV. There is, however, a requirement to inert the $\mathrm{PCV}$ for the shipment of plutonium/uranium oxides (Content Envelope C.4), with a minimum of $75 \%$, by volume $\mathrm{CO}_{2}$, to minimize the potential for the build-up of flammable gas mixtures in the PCV, should hydrogen gas leak from the inner convenience cans into the PCV. The inner cans are purged with helium or nitrogen to limit the oxygen to a maximum of $5 \%$, by volume. There is also a comparable requirement for the shipment of neptunium oxide (Content Envelope C.8). In this case, however, the requirement is to backfill both the PCV and the SCV with argon gas, to ensure that the oxygen content of both containment vessels is no more than $3 \%$, by volume. The food-pack can is also purged with argon to limit the oxygen to no more than $3 \%$, by volume.

- Specific requirements are in place to ensure that the closure devices of the package, including seals and gaskets, are properly installed, secured, and free of defects.

- A specific requirement is in place which notes that the cone-seal nut is to be sealed at a torque of $55 \pm 5 \mathrm{ft}-\mathrm{lbs}$ for the PCV and $110 \pm 10 \mathrm{ft}-\mathrm{lbs}$ for the SCV. The gland nut for the leak-test port plug for both the PCV and the SCV is sealed at a torque of $30(+5 /-0) \mathrm{ft}-\mathrm{lbs}$. Although it is noted that no specific tightening sequence is required, it is also noted that 
each bolt must be re-tightened to confirm that none of the bolts were omitted from the initial tightening sequence.

- Based on the procedures provided, it has been determined that the contents will be loaded correctly, and that the package will be closed appropriately.

\subsubsection{Preparation for Transport}

The procedures for preparation for transport are contained in Sections 7.2.3 and 7.2.4 of the SARP. The following were identified, either directly or indirectly, as being part of the operating procedures:

- Procedures are in place to ensure that the non-fixed (removable) radioactive contamination on the external surface of the package is as low as reasonably achievable, and within the limits specified in Appendix D of 10 CFR 835..$^{[7-5]}$

- Procedures are in place to ensure that the pre-shipment radiation surveys confirm that the allowable external radiation levels are as specified in $\$ 71.47$, and that they are not exceeded.

- Special procedures are in place for the shipment of Content Envelope C.3 to ensure that the allowable external radiation levels will not be exceeded at any time during transport. (See Section 7.2.3, Step 16 of the SARP; see also Section 5.4 of this TRR.)

- Although there are no specific temperature surveys required to verify that limits specified in $\S 71.43(\mathrm{~g})$ are not exceeded, such a requirement is not necessary for this package.

- Specifications are in place to require that the assembly verification leakage rate tests are performed, and to ensure that the package closures are leakage rate tested in accordance with ANSI N14.5-1997. ${ }^{[7-6]}$

- Although there are no requirements to ensure that any system for containing liquid is properly sealed and that it has adequate space or other specified provision for expansion of the liquid, such requirements are not necessary for this package.

- Although there are no requirements to verify that any pressure relief devices are operable and set, the design of the packaging does not incorporate the use of pressure relief devices.

- It is specifically noted in Section 7.2.4 of the SARP that the design of the packaging does not incorporate the use of lifting or tie-down structures.

- A specific requirement is in place to ensure that the tamper-indicating device has been installed.

- Although there are no specific requirements to ensure that impact limiters, personnel barriers, or similar devices have been properly installed or attached, the design of the packaging does not incorporate the use of such features.

- Although there are no requirements that describe, for fissile material shipments, any special controls and precautions for transport, loading, unloading, and handling and any appropriate actions in case of an accident or delay which should be provided to the carrier 
or consignee, all such requirements are provided indirectly by the inclusion of the Office of Safeguards Transportation (OST) procedures for the use of SSTs and/or SGTs.

- Although there are no specific requirements that identify any special controls which should be provided to the carrier for a package shipped by exclusive use under the provisions of $\S 71.47(\mathrm{~b})(1)$, all such requirements are provided indirectly by the inclusion of the OST procedures for the use of the SSTs/SGTs.

- Although there are no specific requirements that identify any special controls which should be provided to the carrier for a fissile-material package in accordance with $\$ 71.35(\mathrm{c})$, all such requirements are provided indirectly by the inclusion of the OST procedures for the use of the SSTs/SGTs.

- There are no specific requirements that describe any special instructions that should be provided to the consignee for opening the package in Section 7.1 of the SARP. These procedures are provided in Section 7.3 of the SARP, and in Section 7.3.2 of this TRR.

- There is a specific requirement to ensure that a Criticality Safety Index of 2.0 has been noted on the labels for each package. For the shipment of plutonium/uranium metals and alloys, i.e., Content Envelope C.3, there is also an additional procedure specified to ensure that the allowable external radiation levels will not be exceeded at any time during transport. (See also Section 7.3.1.3 of this TRR.)

\subsubsection{Package Unloading}

\subsubsection{Receipt of Package from Carrier}

The procedures for receipt of the package from the carrier are contained in Section 7.3 of the SARP. The following were identified, either directly or indirectly, as being part of the operating procedures:

- Specific procedures are in place to ensure that the package is examined for visible damage, status of the tamper-indicating device, surface contamination, and external radiation levels.

- Specific procedures are in place that describe any special actions to be taken if the package is damaged, if the tamper-indicating device is not intact, or if surface contamination or radiation survey levels are too high.

- Although there are no specific requirements that identify any special handling equipment needed, all such requirements are provided indirectly by the inclusion of the OST procedures for the use of the SSTs/SGTs.

- Specific procedures are in place, which describe any proposed special controls and precautions for handling and unloading.

\subsubsection{Removal of Contents}

The procedures for removal of contents are contained in Section 7.4 of the SARP. The following were identified, either directly or indirectly, as being part of the operating procedures:

- Specific procedures are in place that describe the appropriate method to open the package. 
- Specific procedures are in place that identify the appropriate method to remove the contents.

- Specific procedures are in place to ensure that the contents are completely removed.

\subsubsection{Preparation of Empty Package for Transport}

The procedures for the preparation of an empty packaging for transport are contained in Section 7.5 of the SARP. The following were identified, either directly or indirectly, as being part of the operating procedures:

- Specific procedures are in place to verify that the package is empty.

- Specific procedures are in place to ensure that the external surface contamination levels meet the requirements specified in Appendix D of 10 CFR 835. Specific procedures are also in place to ensure that an empty package that is internally contaminated should be prepared for shipment as specified in 49 CFR $173.421^{[7-7]}$ or 49 CFR $173.428,{ }^{[7-8]}$ depending on the level of residual contamination.

- Specific procedures are in place that describe packaging closure requirements.

- There is no specific requirement in place to note that, if the package is to be shipped as an Empty Radioactive Materials Packaging per 49 CFR 173.428, the labels and the nameplate are to be covered with tape and the package will be marked Empty.

\subsubsection{Additional Procedures}

The Operating Procedures of the SARP adequately describe the procedures to be used for the shipment of all shipments covered by Content Envelopes, C.1 through C.8:

- Additional measurement procedures have been specified for the shipment of plutonium/uranium metals, i.e., Content Envelope C.3, to ensure that allowable external radiation levels will not be exceeded at any time during transport.

- Additional inerting procedures have also been specified for the shipment of plutonium/uranium oxides, and neptunium oxide, i.e., Content Envelopes C.4 and C.8, respectively. (See below.)

\subsubsection{Appendices}

Two Appendices have been provided for Chapter 7 of the Model 9975-96 Packaging SARP:

- Appendix 7.1, Special Tools, does not specify any special tools.

- Appendix 7.2, $\mathrm{PCV} \mathrm{CO}_{2}$ Dilution Procedure for Plutonium and /or Uranium Oxide Content Envelope C.4 in the 9975 Package Primary Containment Vessel, includes a $\mathrm{CO}_{2}$ dilution procedure to be used for the shipment Content Envelope C.4.

Although there should have been at least one, additional appendix, one that described the argoninerting procedures to be used for the neptunium oxide, i.e., Content Envelope C.8, no such Appendix has been included. The reason given by the applicant for the lack of inclusion, in this case, is that the argon-inerting procedures are specific to the WSRC Site, only.

\subsection{Evaluation Findings}




\subsubsection{Findings}

The operating procedures presented in the SARP for the Model 9975-96 Package were reviewed by the Staff for completeness and compliance with the regulatory requirements. The information provided by the applicant was in the format prescribed directly by NRC Regulatory Guide 7.9. ${ }^{[7-9]}$ The information in Chapter 7 of the SARP was not provided in the format outlined in NUREG/CR-4775. However, the applicable information on operating requirements, general information, package loading, shipment preparation, package receipt, and package unloading was provided in the Operating Procedures chapter of the SARP, in the appropriate level of detail. Supplemental information on inspection and maintenance, and on records and reporting requirements, has also been provided in the appropriate level of detail in Chapters 8 and 9 of the SARP, respectively.

The contents described in Table 1.2 of the SARP as Content Envelopes C.1 through C. 8 are considered by the DOE to be Special Nuclear Material. As such, the additional requirements specified in the orders DOE O $470.4 \mathrm{~A}^{[7-10]}$ and any supplements, are also applicable.

Specifically, these orders are applicable to the nuclear materials accountability aspects, and to the transport of SNM.

Of particular importance to this TRR are the requirements specified in,DOE O 470.4A, which state that any form of plutonium, in quantities of $2 \mathrm{~kg}$ or more, shall be transported by OST. For the shipment of the materials requested, therefore, all shipments must be made in SSTs and/or SGTs. In addition, all shipments must also be made in accordance with the detailed operating procedures for SST/SGT shipments, as delineated in the appropriate OST documents.

Based on the review of the statements and representations in the application, the Staff concludes that the operating procedures meet the requirements of $10 \mathrm{CFR} 71$, and that the procedures are adequate to assure the package will be operated in a manner consistent with its evaluation for approval.

By meeting the requirements of $10 \mathrm{CFR} 71$, the package also meets the requirements of IAEA Safety Standards Series No. TS-R-1. ${ }^{[7-3]}$

\subsubsection{Conditions of Approval}

Because they represent the framework from which the formal, site-specific operating procedures will be developed for each user/shipper, the Staff concludes that the generic operating procedures delineated in Chapter 7 of the SARP should be incorporated in their entirety into the Certificate of Compliance as a condition of package approval. 


\subsection{References}

[7-1] Washington Savannah River Company, Safety Analysis Report for Packaging, Model 9975, S-SARP-G-00003, Revision 0, Savannah River Packaging Technology, Savannah River National Laboratory (January 2008).

[7-2] Nuclear Regulatory Commission, 10 CFR Part 71, Compatibility with IAEA Transportation Standards (TS-R-1) and Other Transportation Safety Amendments; Final Rule, 69 F.R. 3698, pp. 3698-3814, January 26, 2004, as amended.

[7-3] Regulations for the Safe Transport of Radioactive Material, Safety Requirements, IAEA Safety Standards Series No. TS-R-1, 1996 Edition (As Amended 2003) International Atomic Energy Agency, Vienna, Austria (July 2004).

[7-4] U.S. Nuclear Regulatory Commission, Guide for Preparing Operating Procedures for Shipping Packages, NUREG/CR-4775, July 1988.

[7-5] Occupational Radiation Protection, Code of Federal Regulations, Title 10, Part 835, Washington, DC (November 2006).

[7-6] Institute of Nuclear Materials Management, American National Standard for Radioactive Materials, Leakage Tests on Packages for Shipment, ANSI N14.5-1997, New York.

[7-7] Excepted Packages for Limited Quantities of Class 7 (Radioactive) Materials, Code of Federal Regulations, Title 49, Part 173.421, Washington, DC (October 2007).

[7-8] Empty Class 7 (Radioactive) Materials Packaging, Code of Federal Regulations, Title 49, Part 173.428, Washington DC (October 2007).

[7-9] Standard Format and Content Guide of Part 71 Applications for Approval of Packaging for Radioactive Material, Regulatory Guide 7.9, (proposed Rev. 2), Nuclear Regulatory Commission, Washington, DC (May 1986).

[7-10] U.S. Department of Energy, Safeguards and Security Program, DOE O 470.4A, May 25, 2007. 


\section{ACCEPTANCE TESTS AND MAINTENANCE PROGRAM}

\subsection{Areas of Review}

Chapter 8, Acceptance Tests and Maintenance Program of the Safety Analysis Report for Packaging, Model 9975, Model 9975-96, B(M)F-96, ${ }^{[8-1]}$ was reviewed to verify that the Acceptance Tests meet the requirements of 10 CFR $71,{ }^{[8-2]}$ and that the Maintenance Program is adequate to assure packaging performance during its service life. Commitments specified in the Acceptance Tests and Maintenance Program chapter of the SARP are typically included in the $\mathrm{CoC}$ as conditions of package approval. The review includes an evaluation of the SARP with respect to the requirements specified in the International Atomic Energy Agency (IAEA) Safety Standards Series No. TS-R-1. ${ }^{[8-3]}$

The Acceptance Tests and Maintenance Program review included the following:

\subsubsection{Acceptance Tests}

Acceptance Tests and Maintenance procedures that assure that the Model 9975-96 Packaging will be fabricated, accepted, and maintained in a manner consistent with its evaluation for approval were reviewed. The Acceptance Tests portion of this review included the following:

- Visual Inspections and Measurements

- Weld Examinations

- Component Tests

- Materials Tests

- Structural and Pressure Tests

- Leakage Rate Tests

- Shielding Tests

- Thermal Tests

- Additional Tests

\subsubsection{Maintenance Program}

The Maintenance Program portion of the review included:

- Component Tests

- Material Tests

- Structural and Pressure Tests

- Leakage Rate Tests

- Thermal Tests

- Additional Tests 


\subsubsection{Appendices}

\subsection{Regulatory Requirements}

\subsubsection{Acceptance Tests}

The regulatory requirements of 10 CFR 71 applicable to the Acceptance Tests portion of this review are as follows:

- The applicant shall identify the location, on the outermost receptacle (i.e., on the outside of the package), where the package has been plainly marked with a trefoil radiation symbol that is resistant to the effects of fire and water. [49 CFR 172.310(d)]

- The application must identify the established codes and standards used for the package design, fabrication, assembly, testing, maintenance, and use. In the absence of such codes, the application must describe the basis and rationale used to formulate the quality assurance program. [\$71.31(c)]

- The applicant shall describe the quality assurance program for the design, fabrication, assembly, testing, and use of the proposed package. [\$71.37(a)]

- The applicant shall identify any specific provisions of the quality assurance program that are applicable to the particular package design under consideration, including a description of the leak testing procedures. [\$71.37(b)]

- Before first use, each packaging must be inspected for cracks, pinholes, uncontrolled voids, or other defects that could significantly reduce its effectiveness. [\$71.85(a)]

- Before first use, if the maximum normal operating pressure of a package exceeds $35 \mathrm{kPa}(5 \mathrm{psi})$ gauge, the containment system of each packaging must be tested at an internal pressure at least $50 \%$ higher than maximum normal operating pressure to verify its ability to maintain structural integrity at that pressure. [\$71.85(b)]

- Before first use, each packaging must be conspicuously and durably marked with its model number, serial number, gross weight, and a package identification number. $[\S 71.85(\mathrm{c})]$

- Before first use, the fabrication of each packaging must be verified to be in accordance with the approved design. [\$71.85(c)]

- The applicant must perform any tests deemed appropriate by the certifying authority. $[\S 71.93(\mathrm{~b})]$

\subsubsection{Maintenance Program}

The regulatory requirements of 10 CFR 71 applicable to the Maintenance Program portion of the review are:

- The application must identify the established codes and standards used for the package design, fabrication, assembly, testing, maintenance, and use. In the absence of such codes, the application must describe the basis and rationale used to formulate the quality assurance program. [\$71.31(c)] 
- The applicant shall describe the quality assurance program for the ... testing, maintenance, repair, modification, and use of the proposed package. [\$71.37(a)]

- The packaging must be maintained in unimpaired physical condition except for superficial defects such as marks or dents. [\$71.87(b)]

- The presence of any moderator or neutron absorber, if required, in a fissile material package must be verified prior to each shipment. [\$71.87(g)]

- The applicant must perform any tests deemed appropriate by the certifying authority. $[\S 71.93(\mathrm{~b})]$

- Each type $\mathrm{B}(\mathrm{U})$ or Type $\mathrm{B}(\mathrm{M})$ package design must have on the outside of the outermost receptacle a fire resistance radiation symbol, in accordance with 49 CFR 172.310(d).

\subsection{Review Procedures}

The following procedures are applicable to the review of the Acceptance Tests and Maintenance Program Chapter of the SARP for the Model 9975-96 Packaging. In general, these procedures correspond to the Areas of Review listed in Section 8.1 of this TRR. Where appropriate, however, these requirements are also supplemented by the guidance and/or the requirements specified in Fabrication Criteria for Shipping Containers (NUREG/CR-3854), ${ }^{[8-4]}$ Welding Criteria for Use in the Fabrication of Radioactive Material Shipping Containers (NUREG/CR-3019), ${ }^{[8-5]}$ and the American National Standard for Radioactive Material-Leakage Tests on Packages for Shipment (ANSI N14.5). ${ }^{[8-6]}$

\subsubsection{Acceptance Tests}

Chapter 8 of the SARP indicates that Acceptance Tests are performed prior to the first use of each package. Where applicable, sections of the Quality Assurance program (Chapter 9 of the SARP) and the Operating Procedures (Chapter 7 of the SARP) have also been referenced, as appropriate.

\subsubsection{Visual Inspections}

The applicant has required that the following inspections are complete and operable upon receipt of the packaging:

\subsection{Drum Assembly}

As part of their acceptance criteria, the applicant has specified that the owner shall perform visual inspections (and/or measurements), which include, the drum, the associated Caplugs ${ }^{\circledR}$, the thermal blanket, the air shield, the upper Celotex ${ }^{\mathrm{TM}}$ assembly, the lifting chain, the bearing plates, the drum closure nuts and their associated tack welds, the packaging nameplate and the associated barcode plate, etc. (See Section 8.1.1.1 of the SARP for a complete listing.) The applicant has also specified that the owner shall perform specific acceptance measurements on items such as the lead shield body, and that such measurements be documented.

\subsection{Containment Vessels}

The applicant has required that the owner of new packagings verify that items essential to the containment functions of both the PCV and SCV have been documented in accordance with the requirements specified in Appendix 8.2 of the SARP. 


\subsubsection{Structural and Pressure Tests}

The applicant has specified that the owner will verify that the containment vessels have been pressure-proof tested to at least 1.50 times the design pressure. For the PCV and the SCV, that means corresponding pressure-proof tests of 1,365 ( \pm 10$)$ psig, and 1,235 $( \pm 10)$ psig, respectively.

\subsubsection{Leak Tests}

The applicant has specified that the containment boundaries for both the PCV and SCV shall have been leak-rate tested with helium, in accordance with the evacuated envelope method described in Appendix A.5.4 of ANSI N14.5. The applicant has further specified that the test results must demonstrate that leak rates for both containment boundaries is less than $1 \times 10^{-7} \mathrm{ref} \mathrm{cm} / \mathrm{sec}$, with a test sensitivity of less than $5 \times 10^{-8} \mathrm{ref} \mathrm{cm}^{3} / \mathrm{sec}$, in accordance with the ANSI N14.5 definition of leaktight.

\subsubsection{Component Tests}

The applicant has stated that there are no components or subsystems that require individual testing for acceptance.

\subsubsection{Tests for Shielding Integrity}

The applicant has stated that shielding integrity testing is required per NUREG/CR-3854 for acceptance of the packaging. Alternatively, the applicant has further noted, however, that, after fabrication, the lead shielding is dimensionally inspected and verified to be free of gaps, holes, or pits prior to installation of the stainless steel jacket.

\subsubsection{Thermal Acceptance Tests}

The applicant has stated that no thermal testing is required for acceptance of the packaging.

\subsubsection{Maintenance Program}

Maintenance Program tests are performed to ensure that packaging effectiveness is maintained throughout its service life. Where applicable, sections of the Quality Assurance program (Chapter 9 of the SARP) and the Operating Procedures (Chapter 7 of the SARP) have also been referenced, as appropriate.

\subsubsection{Structural and Pressure Tests}

The applicant has stated that there are no annual structural or pressure test requirements for the Model 9975-96 Package. The applicant has also noted, however, that pressure testing of the containment vessel, as specified in Section 8.1.2 of the SARP, shall be repeated after any structural modifications to, or rebuilding of, the vessel weldments, the cone seal nut, or the cone seal plug.

The applicant has further noted that replacement of the cone-seal gland nut, the leak-test port plug, or the containment vessel's O-rings with like components, does not constitute a structural modification, and does not require pressure testing of the containment vessel. 


\subsubsection{Leak Tests}

The following descriptions, provided by the applicant, are the primary descriptions of the leakage test requirements for the Model 9975-96 Package. All references, throughout the SARP, refer the reader to the following sub-sections for the appropriate tests:

\subsection{Containment Vessel Post-Load Leak-Rate Test}

The applicant has specified that the post-load leakage test requirement for both the PCV and SCV outer O-rings shall be capable of indicating leakage to less than $1 \times 10^{-3} \mathrm{ref} \cdot \mathrm{cm}^{3} / \mathrm{sec}$, using the pressure-drop leak-test method (A.5.1), described in Section 7.6 of ANSI N14.5.

The applicant has specified that the post-load leakage test requirement for both the PCV and SCV leak-test port plugs shall be capable of indicating leakage to less than $1 \times 10^{-3} \mathrm{ref} \mathrm{cm}^{3} / \mathrm{sec}$, using the pressure-drop leak-test method (A.5.1) or the rate of rise leak-test method (A.5.2), described in Section 7.6 of ANSI N14.5.

\subsection{Maintenance Leak-Rate Test}

The applicant has specified that the annual maintenance leakage test requirements for the Model 9975-96 Packaging are specified in Section 8.1.3 of the SARP. (See Section 8.3.1.3 of this TRR.)

\subsubsection{Subsystem Maintenance}

The applicant has noted that there are no components or subsystems that require individual testing for acceptance, including softwood-based and cane-based Celotex ${ }^{\mathrm{TM}}$.

\subsubsection{Valves, Rupture Discs, and Gaskets on Containment Vessels}

The applicant has noted that there are no valves, rupture discs, or gaskets that are used on the Model 9975-96 Package. The applicant has further noted, however, that elastomeric O-rings are used for sealing. The applicant's discussion on the maintenance aspects for the O-rings follows below.

\subsection{Visual Inspection}

The applicant has specified that a visual inspection of the sealing surfaces and O-rings shall be performed prior to closure for gouges, nicks, cuts, cracks, or scratches that could affect containment performance. The applicant has further specified that, if surface damage is found, the vessel in question will be set aside and not used until it has been reworked or repaired, and its performance has been proven acceptable.

\subsection{O-Ring Replacement}

The applicant has specified that new O-rings shall be installed on the cone-seal plug prior to the annual leak lest, or when a visual inspection, or the post-load leak-rate test indicates that replacement is needed. Specifications for the O-Ring replacement are noted in Section 8.2.4.3 of the SARP, and specifications for the O-Ring packaging are provided.

\subsubsection{Shielding}

The applicant has stated that there are no annual maintenance requirements for the shielding features of the Model 9975-96 Package. 


\subsubsection{Thermal}

The applicant has stated that there are no annual maintenance requirements for the passive thermal features of the Model 9975-96 Packaging.

\subsubsection{Miscellaneous}

The applicant has stated that this section is not applicable.

\subsubsection{Appendices}

There are two Appendices included as part of the SARP:

- Appendix 8.1, Visual Inspection Criteria for Acceptance of Newly Fabricated 9975 Packagings. The requirements, specified in Appendix 8.1, include virtually all the acceptance criteria specified on the Drawings in Appendix 1.1 of the SARP.

- Appendix 8.2, Independent Verification Items for Acceptance on Newly Fabricated 9975 Packagings. The requirements specified in Appendix 8.2 provide the cross-linkage between the Acceptance criteria specified in the SARP, the Drawings in Appendix 1.1 of the SARP, and the Quality Assurance requirements specified in the SARP.

\subsection{Evaluation Findings}

\subsubsection{Findings}

The Staff has reviewed the Acceptance Tests and Maintenance Program information, presented in the SARP for the Model 9975-96 Package, for completeness, and for compliance with the regulatory requirements. For both, the information provided by the applicant was provided in the format prescribed directly by NRC Regulatory Guide 7.9. ${ }^{[8-7]}$ Supplemental information on inspections and maintenance, and on records and reporting requirements, has also been provided, in the appropriate level of detail, in Chapters 7 and 9 of the SARP, respectively.

Based on the Staff's review of the statements and representations in the application, the Staff concludes that the Acceptance Tests for the Model 9975-96 Package meet the requirements of 10 CFR 71, and that the Maintenance Program is adequate to assure packaging performance during its service life. The Staff also concludes that the information provided for the Acceptance Tests and Maintenance Program is adequate.

This review also confirms that the Acceptance Tests and Maintenance Program information included in the SARP meets the requirements of IAEA Safety Standards, Safety Series No. TS-R-1. ${ }^{[8-3]}$

\subsubsection{Conditions of Approval}

As was noted in the introduction to this section, commitments specified in the Acceptance Tests and Maintenance Program chapter of the SARP are typically included in the CoC as a condition of package approval. The Staff concurs, and concludes that the Acceptance Tests and Maintenance Program Chapter (Chapter 8) of the SARP should be incorporated, in its entirety, into the $\mathrm{CoC}$ as a condition of package approval.

\subsection{References}


8. Acceptance Tests and Maintenance Program Review

[8-1] Washington Savannah River Company, Safety Analysis Report for Packaging, Model 9975, S-SARP-G-00003, Revision 0, Savannah River Packaging Technology, Savannah River National Laboratory (January 2008).

[8-2] Nuclear Regulatory Commission, 10 CFR Part 71, Compatibility with IAEA Transportation Standards (TS-R-1) and Other Transportation Safety Amendments; Final Rule, 69 F.R. 3698, pp. 3698-3814, January 26, 2004, as amended.

[8-3] Regulations for the Safe Transport of Radioactive Material, Safety Requirements, IAEA Safety Standards Series No. TS-R-1, 1996 Edition (As Amended 2003) International Atomic Energy Agency, Vienna, Austria (July 2004).

[8-4] U.S. Nuclear Regulatory Commission, Fabrication Criteria for Shipping Containers, NUREG/CR-3854 (UCRL-53544), March 1985.

[8-5] U.S. Nuclear Regulatory Commission, Recommended Welding Criteria for Use in the Fabrication of Shipping Containers for Radioactive Materials, NUREG/CR-3019 (UCRL-53044), March 1984.

[8-6] Institute of Nuclear Materials Management, American National Standard for Radioactive Materials, Leakage Tests on Packages for Shipment, ANSI N14.5-1997, New York.

[8-7] Standard Format and Content of Part 71 Applications for Approval of Packaging for Radioactive Material, Regulatory Guide 7.9 (Proposed Rev. 2), Nuclear Regulatory Commission, Washington, DC (May 1986). 
8. Acceptance Tests and Maintenance Program Review

This Page Intentionally Blank. 


\section{QUALITY ASSURANCE}

\subsection{Area Reviewed}

This Technical Review Report (TRR) documents the review of Chapter 9, Quality Assurance, of the Safety Analysis Report for Packaging, Model 9975, Model 9975, B(M)F-96. ${ }^{[9-1]}$ The review includes an evaluation of the SARP with respect to the requirements specified in 10 CFR 71, ${ }^{[9-2]}$ and in International Atomic Energy Agency (IAEA) Safety Standards Series No. TS-R-1. ${ }^{[9-3]}$

The Quality Assurance review included the following:

\subsubsection{Description of Applicant's QA Program}

- Scope

- Program Documentation and Approval

- Summary of 18 Quality Criteria

- Cross-Referencing Matrix

\subsubsection{Package-Specific QA Requirements}

- Graded Approach for Structures, Systems, and Components Important to Safety

- Package-Specific Quality Criteria and Package Activities

\subsection{Regulatory Requirements}

The regulatory requirements of 10 CFR 71 applicable to the Quality Assurance Review of the Model 9975 Packaging are as follows:

- The application must describe the QA program for the design, fabrication, assembly, testing, maintenance, repair, modification, and use of the package. [\$71.31(a)(3), §71.37]

- The application must identify established codes and standards proposed for the package design, fabrication, assembly, testing, maintenance, and use. In the absence of any codes and standards, the application must describe the basis and rationale used to formulate the package QA program. [§71.31(c)]

- Package activities must be in compliance with the QA requirements of Subpart H (§71.101-§71.137). A graded approach is acceptable. [\$71.101(b)]

- Sufficient written records must be maintained to furnish evidence of the quality of the packaging. These records include results of the determinations required by $\S 71.85$; design, fabrication, and assembly records; results of reviews, inspections, tests, and audits; results of maintenance, modification, and repair activities; and other information identified in $\S 71.91(d)$. Records must be retained for three years after the life of the packaging. [\$71.91(b)]

- Records identified in $\S 71.91$ (a) must be retained for three years after shipment of radioactive material. [\$71.91(a)] 
- Records must be available for inspection. Records are valid only if stamped, initialed, or signed and dated by authorized personnel or otherwise authenticated. [\$71.91(c)]

- Any significant reduction in the effectiveness of a packaging during use must be reported to the certifying authority. $[\$ 71.95(\mathrm{a})(1)]$

- Details of any defects with safety significance in a package after first use, with the means employed to repair the defects and prevent their reoccurrence, must be reported. $[\S 71.95(\mathrm{a})(2),[\S 71.95(\mathrm{c})(4)]$

- Instances in which a shipment does not comply with the conditions of approval in the Certificate of Compliance $(\mathrm{CoC})$ must be reported to the certifying authority. $[\S 71.95(\mathrm{a})(3)]$

\subsection{Review Procedures}

The following subsections describe the review methods for the Areas of Review applicable to the Quality Assurance Chapter of the SARP. These procedures correspond to the Elements Reviewed, listed above in Section 9.1.

\subsubsection{Description of Applicant's QA Program}

\subsubsection{Scope}

Chapter 9 of the SARP states that the QA program complies with 10 CFR 71, Subpart H, and is applied to package-related activities, including procurement activities consistent with the applicable regulatory requirements. The introductory text to Chapter 9, Preface, describes the QA requirements for the design, procurement, fabrication, handling, shipping, storage, cleaning, assembly, inspection, testing, operation, maintenance, repair, and modification of the Model 9975-96 Packaging that comply with 10 CFR 71, Subpart H, and that are important to safety. Section 9.1 of the SARP describes the applicant's organization, including the QA organizations and their responsibilities relative to implementation of the QA program. The applicant purchases Model 9975-96 Packaging materials, equipment, and services from suppliers that have been evaluated and approved to meet the applicable elements of American Society of Mechanical Engineers (ASME) NQA-1-2004 (NQA-1). ${ }^{[9-4]}$

\subsubsection{Program Documentation and Approval}

As required by $\S 71.31(\mathrm{a})(3)$ and $\S 71.37$, Section 9.2.1 of the SARP identifies that the Washington Savannah River Company (WSRC) Quality Assurance Management Plan, ${ }^{[9-5]}$ documents the QA program that complies with 10 CFR 71, Subpart H, as well as 10 CFR 830, Subpart A, ${ }^{[9-6]}$ DOE O 414.1.C, ${ }^{[9-7]}$ DOE O 460.1B, ${ }^{[9-8]}$ and NQA-1. (The WSRC Quality Assurance Manual (WSRC 1Q Manual), ${ }^{[9-9]}$ identifies the procedures for implementing the WSRC QA Management Plan. Additional information on the hierarchy and relationship of requirements documents, the WSRC QA Management Plan, and implementing procedures is provided in Figure 9.2 of the SARP. The current revision and date of the applicable WSRC QA documents are provided in the references section in Chapter 9 of the SARP.

\subsubsection{Summary of 18 Quality Assurance Requirements from 10 CFR 71, Subpart H}

The twenty WSRC 1Q Manual sections (that include the quality implementing procedures) implementing each of the 18 QA requirements of 10 CFR 71, Subpart H are listed and 
summarized in Table 9.1 of the SARP. Chapter 9 describes the provisions in the WSRC 1Q Manual sections, as they apply to the scope of the applicant's responsibilities, identified in Section 9.3.1.1, above.

\subsubsection{Cross-Referencing Matrix}

Table 9.1 of the SARP provides a cross-referencing matrix that links each of the 18 QA requirements of 10 CFR 71 Subpart H to the corresponding WSRC 1Q Manual sections. A direct correlation exists between the 18 QA requirements of Subpart $\mathrm{H}$ and the sections of WSRC 1Q Manual. The WSRC 1Q Manual contains two additional sections; Section 19, Quality Improvement, and Section 20, Software $Q A$.

\subsubsection{Package-Specific QA Requirements}

\subsubsection{Graded Approach for Structures, Systems, and Components Important to Safety}

Per $\$ 71.101(\mathrm{~b})$, Section 9.2 .3 of the SARP describes the graded application of the WSRC Quality Assurance Manual to package structures, systems, and components (SSCs) that are important to safety. Safety-related "Q" packaging components are categorized as A, B, or C, with Category A items having the largest impact on safety. Table 9.2 of the SARP correlates the WSRC Safety Designations for "Q" and "non-Q" (not related to safety) for the Model 9975 Packaging to the safety designations in the NRC's Regulatory Guide 7.10. ${ }^{[9-10]}$

Packaging SSCs and their Q categories, functions, and nomenclature (e.g., name and part number) are provided in Table 9.3 of the SARP.

Table 9.4 of the SARP identifies the graded level of QA controls that apply to Q categories A, B, and $\mathrm{C}$, consistent with the requirements in $\S 71.101(\mathrm{~b})$ and the guidance in Reg. Guide 7.10.

\subsubsection{Package-Specific Quality Criteria and Package Activities}

Per $\$ 71.31(\mathrm{a})(3)$ and $\S 71.37$, the SARP describes the QA controls in each section of the WSRC 1Q QA Manual listed in Table 9.1, and describes how these controls are applied to Model 9975 Package activities related to the design, procurement, fabrication, handling, shipping, storage, cleaning, assembly, use, inspection, acceptance testing, maintenance, repair, and modification of the Model 9975 Packaging. The graded approach, described in Section 9.3.2.1 above, is used to selectively apply the QA controls to package SSCs based on their importance to safety.

As required by $\S 71.31(\mathrm{a})(3)$ and $\S 71.37$, Table 9.5 of the SARP details the materials, design, fabrication, testing, examination, QA program and records requirements for the Packaging Containment Vessels that conform to Section III, Division 1, Subsection NB, of the ASME Boiler and Pressure Vessel Code (B\&PV). ${ }^{[9-11]}$ Table 9.6 of the SARP details the materials, design, fabrication, examination, QA program and records requirements for the Drum Bolted Flange Closure that conform to Section III, Division 1, Subsection NF, of the ASME B\&PV Code. ${ }^{[9-12]}$

Section 9.6 of the SARP identifies documents that are controlled to ensure correct documents are used, and that records requirements are met. Controlled documents include operating procedures (SARP Chapter 7), procurement documents (SARP Section 9.4), and the inspection (SARP 
Section 9.10), testing, and maintenance documents (SARP Chapter 8 and Section 9.11 of the SARP).

Section 9.15 defines the controls for documenting, resolving, and preventing the recurrence of package-related nonconformances. Section 9.15 also includes provisions for obtaining WSRC Design Authority and Design Agency approval of nonconformance dispositions, and reporting package defects that significantly reduce safety performance of the package to the DOE Certifying Authority in accordance with $§ 71.95$.

Section 9.17 summarizes the provisions for ensuring sufficient written records are maintained to furnish evidence of the quality of the Model 9975 Packaging. The records and their retention requirements, identified in Section 9.17 and Table 9.7 of the SARP, are consistent with $\S 71.85$, $\S 71.91(\mathrm{~b})$, and $\S 71.91(\mathrm{~d})$.

Section 9.19 of the SARP includes a list of references used in Chapter 9.

\subsubsection{Appendices}

There are no Appendices associated with Chapter 9 of the SARP.

\subsection{Evaluation Findings}

\subsubsection{Findings}

The term "Shipper/Receiver" should be replaced with "WSRC User. The Staff recommends that the appropriate changes be made as part of a subsequent revision to the SARP.

Based on review of the statements and representations in the SARP, the Staff concludes that the applicant's QA program has been adequately described and meets the QA requirements of 10 CFR 71 and IAEA Safety Standards Series No. TS-R-1. Package-specific QA requirements are adequate to assure that the package is designed, fabricated, assembled, tested, used, maintained, modified, and repaired in a manner consistent with its evaluation.

It is recommended that the process for installation of the outer stainless steel jacket onto the lead shield include verification or controls to insure the Q-dimension for minimum thickness of the lead shield is preserved.

\subsubsection{Conditions of Approval}

Any organization involved in the design, procurement, fabrication, handling, shipping, storage, cleaning, assembly, operation, inspection, testing, maintenance, repair, modification, and use of the Model 9975 Packaging shall maintain and follow an appropriate QA program that is compliant with the requirements specified in 10 CFR 71, Subpart H. For non-WSRC users, this shall include compliance with the package-specific QA requirements specified in Chapter 9 of the SARP.

\subsection{References}

[9-1] Washington Savannah River Company, Safety Analysis Report for Packaging, Model 9975, S-SARP-G-00003, Revision 0, Savannah River Packaging Technology, Savannah River National Laboratory (January 2008). 
[9-2] Nuclear Regulatory Commission, 10 CFR Part 71, Compatibility with IAEA Transportation Standards (TS-R-1) and Other Transportation Safety Amendments; Final Rule, 69 F.R. 3698, pp. 3698-3814, January 26, 2004, as amended.

[9-3] Regulations for the Safe Transport of Radioactive Material, Safety Requirements, IAEA Safety Standards Series No. TS-R-1, 1996 Edition (As Amended 2003) International Atomic Energy Agency, Vienna, Austria (July 2004).

[9-4] American Society of Mechanical Engineers, Quality Assurance Program Requirements for Nuclear Facilities, ASME NQA-1-2004, ASME, New York, NY (December 2004).

[9-5] Quality Assurance Management Plan, WSRC-RP-92-225, Revision 13, Washington Savannah River Company, Aiken, SC (August 2004).

[9-6] Department of Energy, 10 CFR Part 830, Nuclear Safety Management, 66 F.R. 1818, pp. 1818-1827, January 10, 2001, as amended. See, in particular, Subpart A, Quality Assurance Requirements, pp. 1820-1821, as amended.

[9-7] Quality Assurance, DOE O 414.1C, U.S. Department of Energy, Washington, DC (June 2005).

[9-8] Packaging and Transportation Safety, DOE O 460.1B, U.S. Department of Energy, Washington, DC (April 2003).

[9-9] Quality Assurance Manual, WSRC-1Q, Washington Savannah River Company, Aiken SC (October 2005).

[9-10] Establishing Quality Assurance Programs for Packaging Used in the Transport of Radioactive Material, Regulatory Guide 7.10, Rev. 2, U.S. Nuclear Regulatory Commission, Washington, DC (March 2005).

[9-11] Rules for Construction of Nuclear Facility Components, Boiler and Pressure Vessel Code, Section III, Division 1, Subsections NB, Class I Components, American Society of Mechanical Engineers (2004).

[9-12] Rules for Construction of Nuclear Facility Components, Boiler and Pressure Vessel Code, Section III, Division 1, Subsection NF, Supports, American Society of Mechanical Engineers (2004). 
This Page Intentionally Blank.

- 99 - 